\title{
Project Plan for the Background Soil Characterization Project on the Oak Ridge Reservation, Oak Ridge, Tennessee
}

\section{Environmental Restoration Division \\ P.O. Box 2003}

Oak Ridge, Tennessee 37831-7256

Date Issued-August 1992

Prepared by

Environmental Sciences Division

Oak Ridge National Laboratory

ESD Publication 3818

Prepared for

U.S. Department of Energy

Office of Environmental Restoration and Waste Management

under budget and reporting code EW 20

MARTIN MARIETTA ENERGY SYSTEMS, INC.

managing the

Oak Ridge K-25 Site

Oak Ridge Y-12 Plant

Oak Ridge National Laboratory under contract DE-AC05-84OR21400
Paducah Gaseous Diffusion Plant Portsmouth Gaseous Diffusion Plant under contract DE-AC05-760R00001

for the

U.S. DEPARTMENT OF ENERGY 


\section{Contributors}
T. L. Hatmaker
S. Y. Lee
L. A. Hook
D. A. Lietzke
B. L. Jackson
C. W. McGinn
C. W. Kimbrough
R. L. Schmoyer
D. C. Landguth
J. Switek

D. R. Watkins

\section{Contributors Affiliations}

L. A. Hook, B. L. Jackson, S. Y. Lee, and J. Switek are members of the Environmental Sciences Division; D. C. Landguth and C. W. McGinn are members of the Health and Safety Research Division; R. L. Schmoyer is a member of the Engineering Physics and Mathematics Division, all part of the Oak Ridge National Laboratory. T. L. Hatmaker and C. W. Kimbrough are members of the Analytical Projects Office, and D. R. Watkins is Coordinator of the Technical Oversight and Review Committee of the Environmental Restoration Division. All of the aforementioned organizations are managed by Martin Marietta Energy Systems, Inc. D. A. Lietzke is a consultant. 


\section{PROJECT PLAN}

\section{Background Soil Characterization Project}

Approved by: Sanid J. Bell

D. T. Bell, Manager

Technical Oversight

Program Integration and Administration

Environmental Restoration Division

M'artin Marietta Energy Systems, Inc.

Approved by:

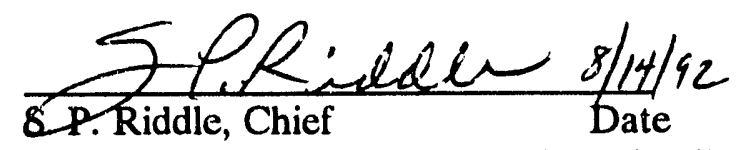

Decontamination and Decommissioning Branch

DOE Oak Ridge Field Office

Approved by: $\frac{a \cdot 2 r . \text { Saulsbury }_{\text {A. W. Saulsbury }} 8 / 5 / 92}{\text { ORNL Industrial Hygiene }}$

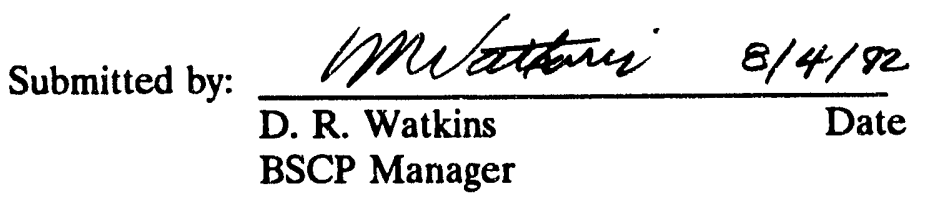




\section{QUALITY ASSURANCE PROJECT PLAN}

\section{Background Soil Characterization Project}

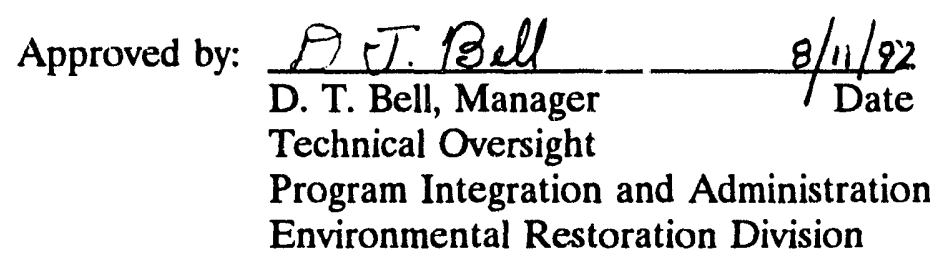

$\frac{7 n 1+0 e^{2}}{\text { T. M. Koepp }} \underset{\text { Environmental Restoration QA Specialist }}{\text { Date }}$

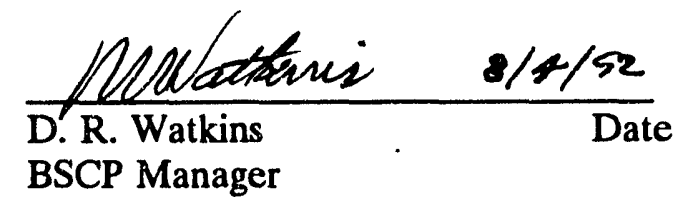




\section{CONTENTS}

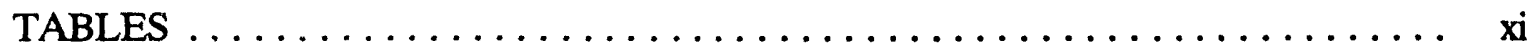

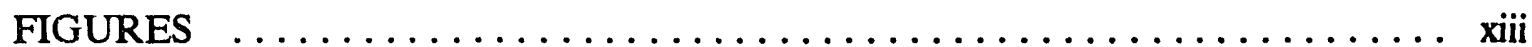

EXECUTIVE SUMMARY $\ldots \ldots \ldots \ldots \ldots \ldots \ldots \ldots \ldots \ldots \ldots \ldots \ldots \ldots$

1. INTRODUCTION $\ldots \ldots \ldots \ldots \ldots \ldots \ldots \ldots \ldots \ldots \ldots \ldots \ldots \ldots \ldots, 1$

1.1 REGULATORY BACKGROUND ...................... 1

1.2 SCOPE OF THE BACKGROUND SOIL CHARACTERIZATION

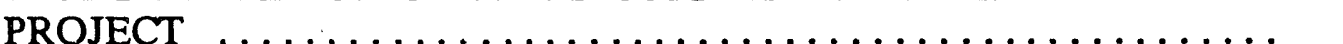

2. OBJECTIVES AND PROJECT ORGANIZATION $\ldots \ldots \ldots \ldots \ldots \ldots, 3$

2.1 OBJECTIVES AND APPROACH $\ldots \ldots \ldots \ldots \ldots \ldots \ldots \ldots \ldots, 3$

2.2 ORGANIZATION OF THE BACKGROUND SOIL

CHARACTERIZATION PROJECT PLAN $\ldots \ldots \ldots \ldots \ldots \ldots \ldots \ldots, 3$

3. HISTORY AND CURRENT CONDITIONS $\ldots \ldots \ldots \ldots \ldots \ldots \ldots \ldots, 5$

3.1 HISTORY OF THE OAK RIDGE FACILITIES $\ldots \ldots \ldots \ldots \ldots \ldots \ldots, 5$

3.2 GENERAL DESCRIPTION OF THE PLANT FACILITIES . . . . . . . 5

3.2.1 Oak Ridge National Laboratory $\ldots \ldots \ldots \ldots \ldots \ldots \ldots \ldots \ldots, 5$

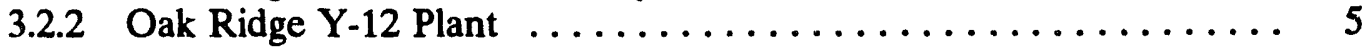

3.2.3 Oak Ridge K-25 Site $\ldots \ldots \ldots \ldots \ldots \ldots \ldots \ldots \ldots \ldots \ldots, 6$

3.3 CONTAMINANT RELEASES BEYOND THE OAK

RIDGE RESERVATION $\ldots \ldots \ldots \ldots \ldots \ldots \ldots \ldots \ldots \ldots \ldots \ldots, 6$

4. ENVIRONMENTAL SETTING $\ldots \ldots \ldots \ldots \ldots \ldots \ldots \ldots \ldots \ldots \ldots$

4.1 GEOGRAPHY OF THE OAK RIDGE RESERVATION $\ldots \ldots \ldots \ldots \ldots, 7$

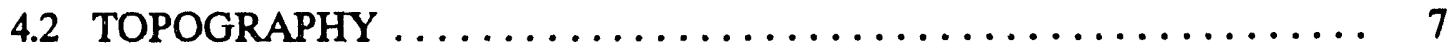

4.3 GEOLOGY $\ldots \ldots \ldots \ldots \ldots \ldots \ldots \ldots \ldots \ldots \ldots \ldots \ldots \ldots \ldots \ldots \ldots \ldots \ldots, 12$

4.4 SOILS $\ldots \ldots \ldots \ldots \ldots \ldots \ldots \ldots \ldots \ldots \ldots \ldots \ldots \ldots \ldots \ldots \ldots \ldots \ldots \ldots, 14$

4.5 HYDROLOGY $\ldots \ldots \ldots \ldots \ldots \ldots \ldots \ldots \ldots \ldots \ldots \ldots \ldots \ldots \ldots \ldots \ldots \ldots, 14$

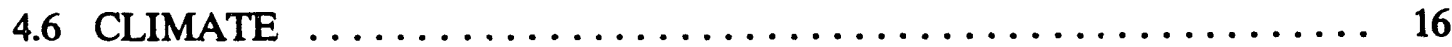

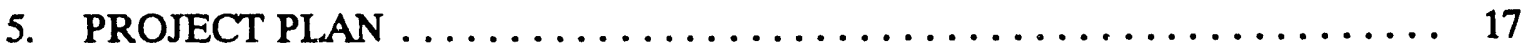

5.1 PROJECT ORGANIZATION AND MANAGEMENT $\ldots \ldots \ldots \ldots \ldots, 17$

5.1.1 Project Organization and Responsibilities $\ldots \ldots \ldots \ldots \ldots \ldots \ldots, 17$

5.1 .2 Project Schedule $\ldots \ldots \ldots \ldots \ldots \ldots \ldots \ldots \ldots \ldots \ldots \ldots, 21$

5.2 SITE SELECTION PLAN $\ldots \ldots \ldots \ldots \ldots \ldots \ldots \ldots \ldots \ldots, 23$

5.2 .1 Introduction and Scope $\ldots \ldots \ldots \ldots \ldots \ldots \ldots \ldots \ldots \ldots \ldots \ldots \ldots \ldots \ldots, 23$

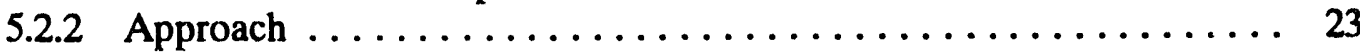

5.3 SOIL SAMPLING AND ANALYSIS PLAN $\ldots \ldots \ldots \ldots \ldots \ldots \ldots \ldots \ldots \ldots \ldots \ldots$

5.3.1 Introduction and Scope $\ldots \ldots \ldots \ldots \ldots \ldots \ldots \ldots \ldots \ldots \ldots \ldots \ldots \ldots \ldots, 25$

5.3.2 Sample Collection $\ldots \ldots \ldots \ldots \ldots \ldots \ldots \ldots \ldots \ldots \ldots \ldots, 25$

5.3.3 Sample Analysis $\ldots \ldots \ldots \ldots \ldots \ldots \ldots \ldots \ldots \ldots \ldots \ldots, 31$ 
5.4 SAMPLE TRACKING AND RECORDS MANAGEMENT $\ldots \ldots \ldots \ldots . . \ldots 2$

5.4 .1 Logbooks .......................... 30

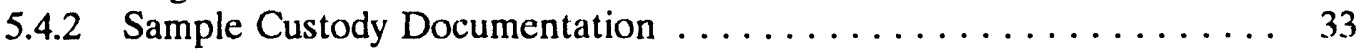

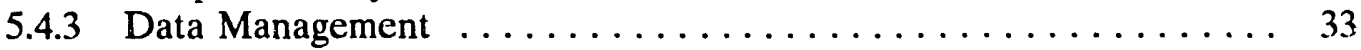

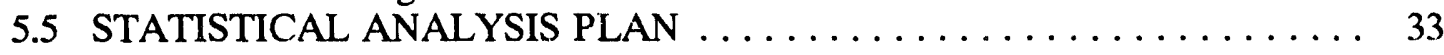

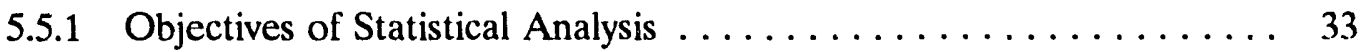

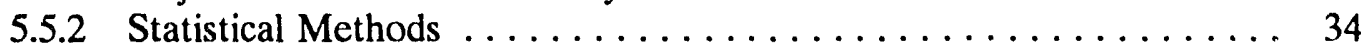

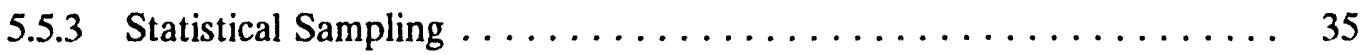

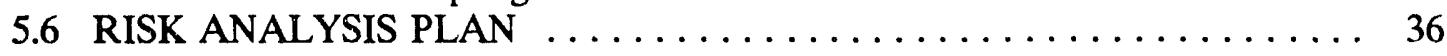

5.6.1 Determining Potential Contaminants of Concern $\ldots \ldots \ldots \ldots . \ldots 37$

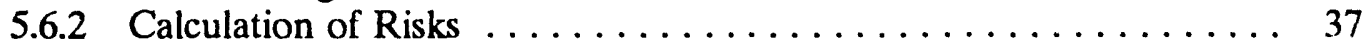

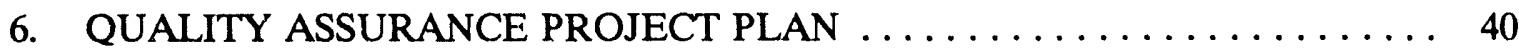

6.1 INTRODUCTION (including Approvals Statement) $\ldots \ldots \ldots \ldots \ldots \ldots .40$

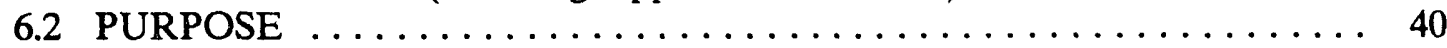

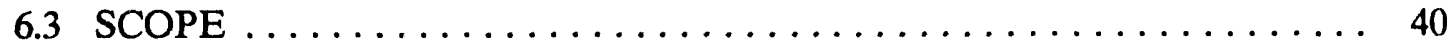

6.4 PROJECT DESCRIPTION AND TRAINING $\ldots \ldots \ldots \ldots \ldots \ldots \ldots \ldots 44$

6.5 PROJECT ORGANIZATION AND QA RESPONSIBILITIES . . . . . . 44

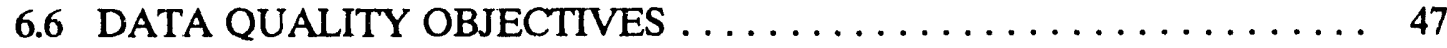

6.6.1 Quality Assurance Objectives For Field Measurement Data . . . . . . 49

6.6.2 Quality Assurance Objectives for Laboratory Measurement Data . . 57

6.6.3 Data Reduction, Validation and Reporting ............ 63

6.7 INTERNAL QUALITY CONTROL CHECKS . . . . . . . . . . . 85

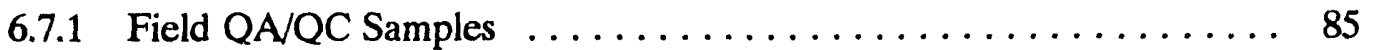

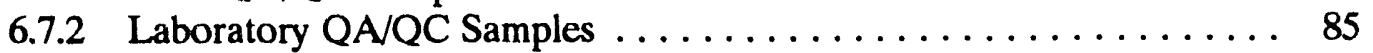

6.8 PERFORMANCE AND SYSTEM AUDITS $\ldots \ldots \ldots \ldots \ldots \ldots \ldots \ldots . \ldots 1$

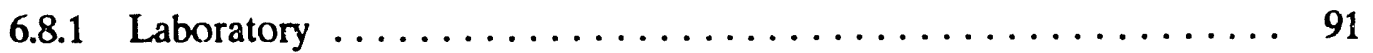

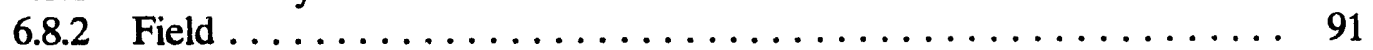

6.9 PREVENTIVE MAINTENANCE $\ldots \ldots \ldots \ldots \ldots \ldots \ldots \ldots \ldots \ldots . \ldots \ldots$

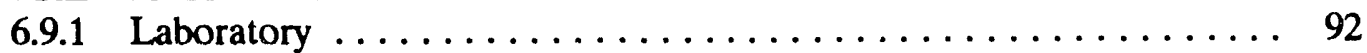

6.9.2 Field . . . . . . . . . . . . . . . . . . . . . 93

6.10 PROCEDURES TO ASSESS DATA PRECISION, ACCURACY

AND COMPLETENESS $\ldots \ldots \ldots \ldots \ldots \ldots \ldots \ldots \ldots \ldots \ldots$

6.11 NONCONFORMANCES AND CORRECTIVE ACTIONS . . . . . . 94

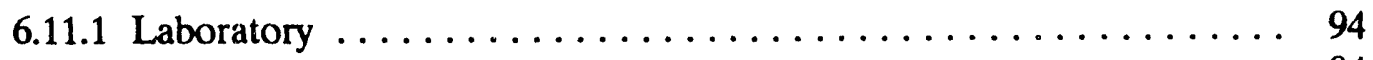

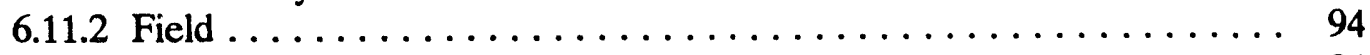

6.12 QUALITY ASSURANCE REPORTS TO MANAGEMENT . . . . . . . . 94

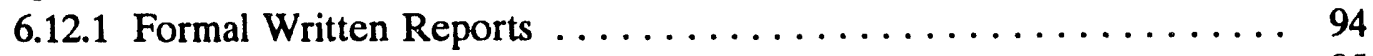

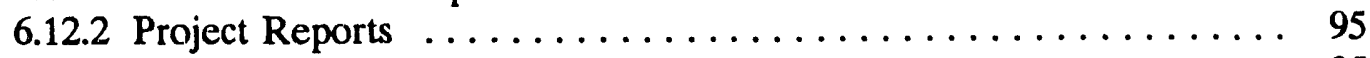

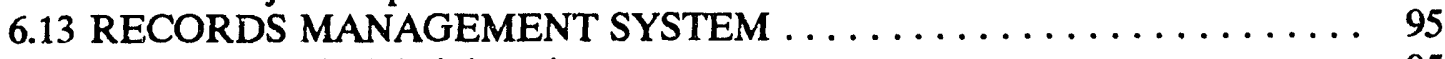

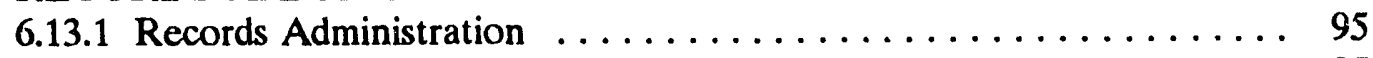

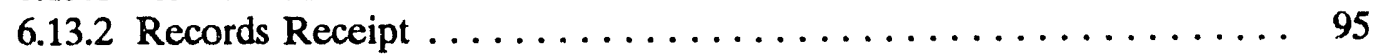

6.13 .3 Storage, Preservation, and Safekeeping $\ldots \ldots \ldots \ldots \ldots \ldots \ldots \ldots$

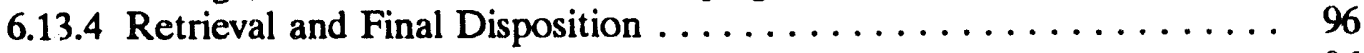

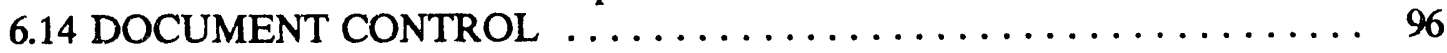

6.15 PROCUREMENT DOCUMENT CONTROL .............. 96

6.16 PURCHASED ITEMS AND SERVICES CONTROL . . . . . . . . . 97

7. DATA MANAGEMENT PLAN $\ldots \ldots \ldots \ldots \ldots \ldots \ldots \ldots \ldots \ldots \ldots \ldots \ldots$

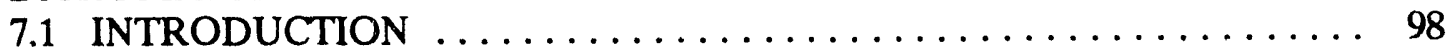

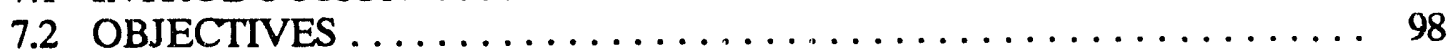

viii 
7.3 DATA MANAGEMENT $\ldots \ldots \ldots \ldots \ldots \ldots \ldots \ldots \ldots \ldots \ldots \ldots$

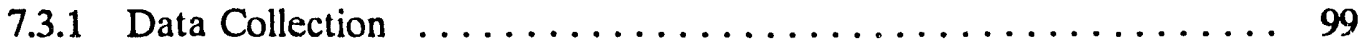

7.3.2 Data Entry ............................. 101

7.3.3 Data Encoding ............................. 101

7.3.4 Data Traceability ... . . . . . . . . . . . . . . . . . . . . 101

7.3.5 Quality Assurance/Quality Control ... . . . . . . . . . . . . . . 102

7.3.6 Facilities .............................. 102

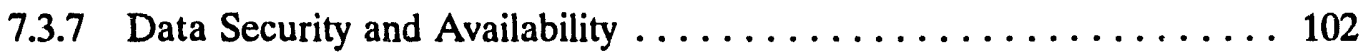

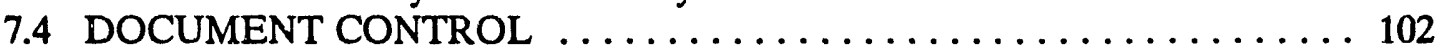

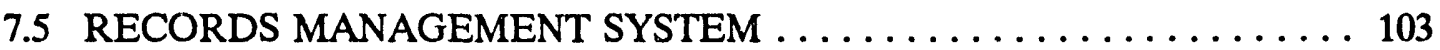

7.5.1 Records Control Process ...................... 103

7.5.2 Document Archive and Index .................. 103

7.5 .3 Document Accessibility . . . . . . . . . . . . . . . . 104

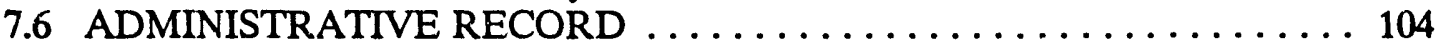

8. HEALTH AND SAFETY PLAN $\ldots \ldots \ldots \ldots \ldots \ldots \ldots \ldots \ldots \ldots \ldots \ldots \ldots$

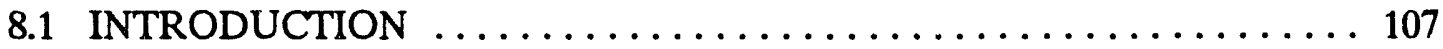

8.1.1 Purpose ........................... 107

8.1.2 Applicability ........................... 107

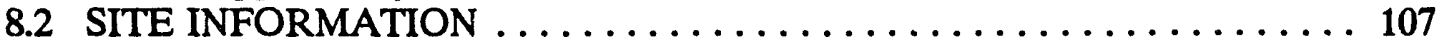

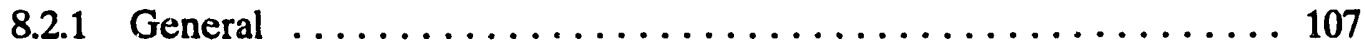

8.2 .2 Physical Hazards . . . . . . . . . . . . . . . . . . 108

8.3 SITE TASK HAZARD ANALYSIS $\ldots \ldots \ldots \ldots \ldots \ldots \ldots \ldots \ldots \ldots$

8.3.1 Site Requirements .......................... 109

8.3.2 Suspected Contaminants ...................... 110

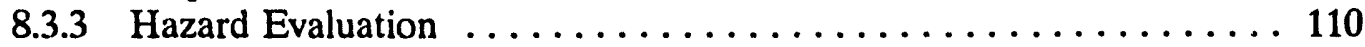

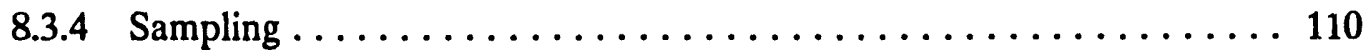

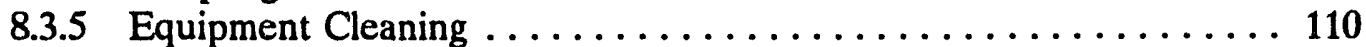

8.4 SPECIAL HAZARDS $\ldots \ldots \ldots \ldots \ldots \ldots \ldots \ldots \ldots \ldots \ldots \ldots \ldots \ldots$

8.4.1 Heat Stress . . . . . . . . . . . . . . . . . . . . 111

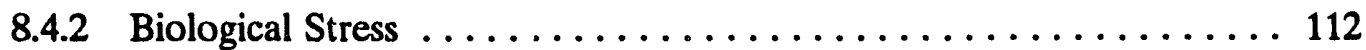

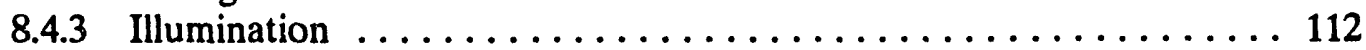

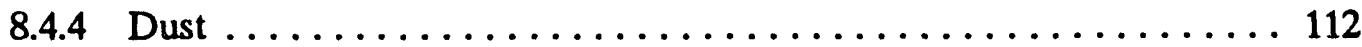

8.4 .5 Ergonomics .......................... 112

8.4.6 Physical Sampling Location Hazards ... . . . . . . . . . 113

8.5 PROJECT ORGANIZATION AND RESPONSIBILI ${ }_{2}$ IES $\ldots \ldots \ldots \ldots \ldots 113$

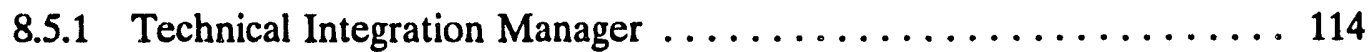

8.5 .2 Project Manager .......................... 114

8.5.3 Technical Coordinator ...................... 114

8.5.4 Site Health Safety Officer/Project Personnel . . . . . . . . . . . 115

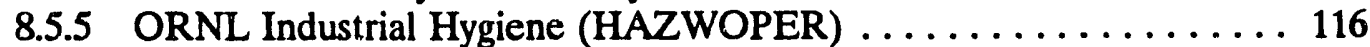

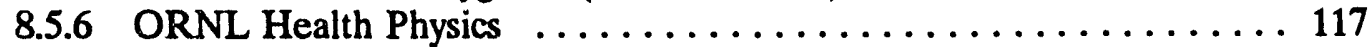

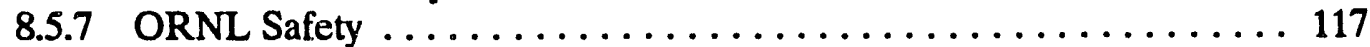

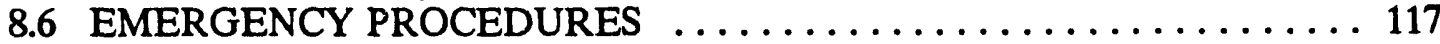

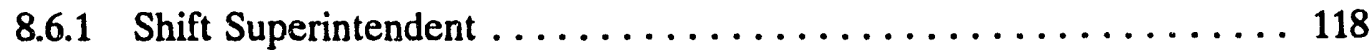

8.6.2 Reporting an Emergency ..................... 119

8.7 SITE MONITORING $\ldots \ldots \ldots \ldots \ldots \ldots \ldots \ldots \ldots \ldots \ldots \ldots \ldots$

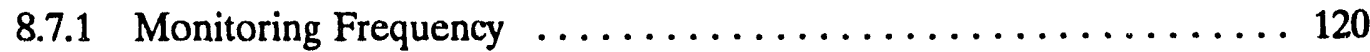

8.7.2 Instrument Calibration/Response Checks $\ldots \ldots \ldots \ldots \ldots \ldots \ldots$

8.7.3 Monitoring Equipment Action Limits ............... 120

8.8 SITE CONTROL MEASURES-SAMPLING AREA . . . . . . . . 121

8.9 HEALTH AND SAFETY TRAINING REQUIREMENTS . . . . . . . . 122 


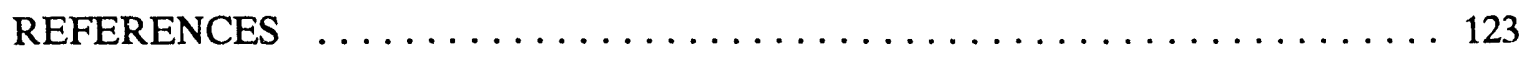

APPENDIX A-REFERENCE SOIL PROFILE DESCRIPTIONS $\ldots \ldots \ldots \ldots 127$

APPENDIX B—SAMPLING AND ANALYSIS PLAN SUPPLEMENT . . . . . 141

APPENDIX C-CHAIN-OF-CUSTODY FORMS FOR SOIL SAMPLES $\ldots \ldots \ldots 149$

APPENDIX D-STATISTICAL ASPECTS OF DQOS $\ldots \ldots \ldots \ldots \ldots \ldots$ 


\section{TABLES}

$5.1 \quad$ On-site resident exposure scenario $\ldots \ldots \ldots \ldots \ldots \ldots \ldots \ldots \ldots \ldots$

6.1 Modular profile and cross-reference of EPA

QAMS-005/80 and NQA-1 elements .................. 41

$6.2 \quad$ Functional responsibility chart for the BSCP $\ldots \ldots \ldots \ldots \ldots \ldots \ldots \ldots$

6.3 QA/QC levels to which BSCP measurement tasks have been assigned $\ldots \ldots .50$

6.4 Recommended sample containers, sample preservation, sample size, and sample holding time requirements for analytical samples $\ldots \ldots \ldots \ldots 53$

6.5 Analyte list for volatile organics by EPA-8240 using the target compound list ........................ 59

6.6 Analyte list for organochlorine pesticides/PCBs by EPA CLP SOW (3/90) $\ldots 60$

$6.7 \quad$ Analyte list for herbicides by EPA-8150 $\ldots \ldots \ldots \ldots \ldots \ldots \ldots \ldots \ldots \ldots$

6.8 Analyte list for polyaromatic hydrocarbons by EPA-8310 $\ldots \ldots \ldots \ldots \ldots$

6.9 Analyte list for atomic absorption of metals $\ldots \ldots \ldots \ldots \ldots \ldots \ldots$

6.10 Analyte list for inductively coupled plasma metals $\ldots \ldots \ldots \ldots \ldots \ldots \ldots$

6.11 Analyte list for inductively coupled plasma/mass spectrometry metals . . . . 66

6.12 Analyte list for inorganic parameters $\ldots \ldots \ldots \ldots \ldots \ldots \ldots \ldots \ldots \ldots \ldots$

6.13 Analyte list for radionuclides $\ldots \ldots \ldots \ldots \ldots \ldots \ldots \ldots \ldots \ldots \ldots \ldots$

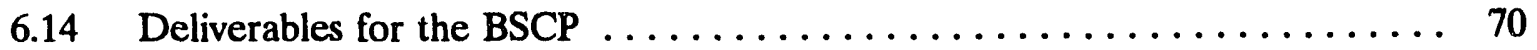

6.15 Analyte concentration equivalent (milligram per liter)

6.16 BSCP-1992 Schedule of surveillance activities $\ldots \ldots \ldots \ldots \ldots \ldots \ldots \ldots$ 
7.1 Records to be included in the BSCP DMA and the originating office.

8.1 Protective equipment for on-site activities $\ldots \ldots \ldots \ldots \ldots \ldots$

8.2 Safe working distances from electrical transmission lines for drill rigs $\ldots \ldots \ldots \ldots \ldots \ldots \ldots \ldots \ldots \ldots \ldots \ldots \ldots \ldots \ldots \ldots$

$8.3 \quad$ Key BSCP personnel $\ldots \ldots \ldots \ldots \ldots \ldots \ldots \ldots \ldots \ldots \ldots \ldots \ldots \ldots$ 


\section{FIGURES}

4.1 Regional map showing location of the Oak Ridge Reservation $\ldots \ldots \ldots \ldots$

4.2 General site map of the Oak Ridge Reservation $\ldots \ldots \ldots \ldots \ldots \ldots \ldots \ldots$. 9

4.3 Location of communities near the Oak Ridge Reservation $\ldots \ldots \ldots \ldots \ldots \ldots$

4.4 Schematic of ridge-valley province near Oak Ridge Reservation $\ldots \ldots \ldots \ldots \ldots 11$

4.5 Distribution of geologic units on the Oak Ridge Reservation $\ldots \ldots \ldots \ldots \ldots$

4.6 Location map of streams and rivers at the Oak Ridge Reservation . . . . . . 15

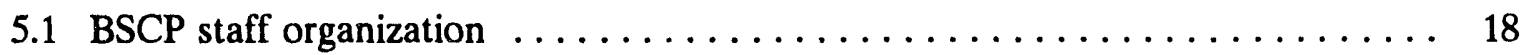

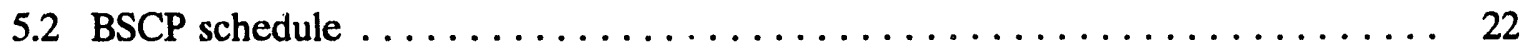

5.3 Location of candidate geology formations near the Oak Ridge Reservation . . . . 24

5.4 Distribution of candidate soil series selected for background soil characterization project in the Oak Ridge Reservation . . . . . . . . . 26

5.5 Approximate location of off-site background soil sampling areas in Roane County and Anderson County $\ldots \ldots \ldots \ldots \ldots \ldots \ldots \ldots \ldots \ldots$

5.6 Selected soil sampling sites in Roane County $\ldots \ldots \ldots \ldots \ldots \ldots \ldots$

5.7 Selected soil sampling site in Anderson County . . . . . . . . . . . . 29

6.1 Field change request/variance form $\ldots \ldots \ldots \ldots \ldots \ldots \ldots \ldots \ldots$

7.1 Responsibility matrix and process flow of BSCP samples, data, and documents .......................... 100 


\section{EXECUTTVE SUMMARY}

The Background Soil Characterization Project (BSCP) will provide background concentration levels of selected metals, organic compounds, and radionuclides in soils from uncontaminated on-site areas at the Oak Ridge Reservation (ORR), and off-site in the western part of Roane County and the eastern part of Anderson County. The BSCP will establish a database, recommend how to use the data for contaminated site assessment, and provide estimates of the potential human health and environmental risks associated with the background level concentrations of potentially hazardous constituents.

ORR background soil characterization data will be used for two purposes. The first application will be in differentiating between naturally occurring constituents and site-related contamination. This is a very important step in a risk assessment because if sufficient background data are not available, no constituent known to be a contaminant can be eliminated from the assessment even if the sampled concentration is measured at a minimum level. The second use of the background data will be in calculating baseline risks against which site-specific contamination (i.e., waste area groups) risks can be compared. 


\section{INTRODUCTION}

\subsection{REGULATORY BACKGROUND}

The U.S. Department of Energy (DOE) Oak Ridge Reservation (ORR) has maintained Oak Ridge National Laboratory (ORNL), the Oak Ridge K-25 Site, and the Oak Ridge Y-12 Plant for more than 40 years. In compliance with Sect. 3004(u) of the Hazardous and Solid Waste Amendments of 1984 (HSWA) to the Resource Conservation and Recovery Act of 1976 (RCRA), numerous individual operational and waste management units located within bourdaries of these facilities are being investigated to determine tive nature and extent of hazardous releases to the environment and, where appropriate, to initiate corrective actions. The ORR was added to National Priorities List (NPL) in November 1989. A Federal Facility Agreement (FFA) [under Sect. 120 of the Comprehensive Environmental Response, Compensation and I iability Act of 1980 (CERCLA) as amended by the Superfund Amendments and Reauthorization Act of 1986 (SARA) and Sect. 6001 of RCRA] between DOE, the U.S. Environmental Protection Agency (EPA) Region IV, and the Tennessee Department of Environment and Conservation (TDEC) was negotiated, signed, and became effective on January 1, 1992. These parties intend to coordinate DOE's CERCLA/RCRA response obligations with the corrective measures required and conducted by DOE under its current HSWA permit, and they expect that the response actions under FFA, together with the corrective measures under the permit, will achieve comprehensive remediation of releases and threatened releases of hazardous substances, hazardous wastes, pollutants, or contaminants at or from the ORR.

The RCRA Facility Investigation Guide (EPA 1987a) and DOE Order 5400.1 (effective November 9, 1989) address the necessity of establishing background values for chemical and radiological constituents in conjunction with the Remedial Investigation and Feasibility Studies (RI/FS) process. This was discussed at the DOE Technical Working Group Meeting of September 26, 1991, at which Martin Marietta Energy Systems proposed and it was agreed to establish a background soil characterization database for the ORR Environmental Restoration Program. To establish the presence and distribution of chemical and radiological constituents associated with a potentially contaminated site, a determination of the presence or absence of those contaminants in the natural environment is required. The term "background soil" is here defined as a natural soil that is not contaminated by constituents generated by operations at the DOE Oak Ridge facilities. Therefore, background soil contains only constituents originating from parent material, global fallout, and related non-DOE human activities. The concentration levels of the constituents in background soils are referred to as "background values" or "background concentration levels."

\subsection{SCOPE OF THE BACKGROUND SOIL CHARACTERIZATION PROJECT}

The Background Soil Characterization Project (BSCP) will provide background concentration levels of selected metals, organic compounds, and radionuclides in soils from uncontaminated areas in the ORR, the western part of Roane County, and the eastern part of Anderson County. Details are presented in Sect. 5.2.1. 
The BSCP will address variability of concentration levels in terms of (1) soil taxonomical types (series) occurring on different geologic formations, (2) soil sampling depths within a specific soil profile, and (3) on-site and off-site areal variations in soils developed in the same geologic formations. The BSCP will establish a database for unrestricted use, with recommendations on how to use the data for ORR contaminated site assessment, and provide estimates of any potential human health and environmental risks associated with the background level concentrations of the potentially hazardous constituents.

ORR background soil characterization data will be used for two purposes. The first application will be in differentiating between naturally occurring constituents and site-related contamination. This is a very important step in a risk assessment because if sufficient background data are not available, no constituent known to be a contaminant can be eliminated from the assessment even if the sampled concentration is measured at a minimum level. The second use of the background data will be in calculating baseline risks against which site-specific contamination risks can be compared.

In coordination with requirements of DOE-OR, the project has been accelerated to provide validated field results as quickly as possible to other environmental monitoring and remedial actions programs associated with the Oak Ridge Reservation. As a result, the project is nov, organized into an accelerated Phase I to provide data progressively through mid CY $19 \% 2$ followed by Phase II. In Phase I, soils from two on-site parent geologies, the Nolichucky Shale and the Dismal Gap Formation in the Conasauga Group, which are characteristic of imminent ORR field projects, will be sampled and analyzed; one of the $\triangleleft$, the Dismal Gap, will be sampled off-site also. The remaining soil series (in the Chickamauga and Knox groups) required to provide comprehensive data on the ORR as a whole will be obtained in Phase II. 


\section{OBJECTIVES AND PROJECT ORGANIZATION}

\subsection{OBJECTTVES AND APPROACH}

The primary objectives of the BSCP are to:

- determine the background concentration levels of selected metals, organics, and radionuclides in natural soils;

- quantify risks to human health and the environment based on exposure to background constituents for later comparison with the risks associated with contaminated sites; and

- make available the background concentration data to CERCLA projects investigating the ORR facilities after statistical treatment of the analytical results.

The following technical approach will be taken to achieve these objectives:

- Identification and selection of the most important geologic formations underrlying potentially contaminated sites at the ORR.

- Identification and selection of a dominant residuum soil corresponding to each selected formation.

- Statistically random selection of uncontaminated soil sampling sites in the ORR, the western part of Roane County, and the eastern part of Anderson County.

- Soil sampling from three different soil horizons and screening by gamma spectroscopy.

- Chemical and radiological analyses by designated contract laboratories.

- Data processing and validation.

- Statistical analysis.

- Risk analysis.

- Data transfer to the Oak Ridge Environmental Information System (OREIS) database.

The BSCP will be coordinated with environmental monitoring and remedial action programs now being conducted at the three Oak Ridge facilities in compliance with the provisions of RCRA, CERCLA, NEPA, and State of Tennessee environmental protection regulations.

\section{ORGANIZATION OF THE BACKGROUND SOL CHARACTERIZATION PROJECT PLAN}

The BSCP Plan is organized as follows: Sects. 1 through 4 include an introduction and summaries of historical, geographical, and environmental data for the ORR. Much of the material presented in these summaries was excerpted from the Oak Ridge Reservation Site Development and Facilities Utilization Plan (MMES 1989a) and the Clinch River RCRA Facility Investigation Plan (MMES 1989b).

Section 5 includes the detailed BSCP Project Plan. The plan consists of organization and management, the site selection plan, the soil sampling and analysis plan, the sample tracking and record management plan, the statistical analysis plan, and the risk analysis plan. The general approach and methodology to be taken in sample analysis are presented in these 
sections. Sections 6,7 , and 8 present the quality assurance/quality control plan, the data management plan, and the health and safety plan, respectively. Supporting data, information, and exhibits are presented in the appendices to the project plan document. 


\section{HIST:JRY AND CURRENT CONDITIONS}

\subsection{HISTORY OF THE OAK RIDGE FACIIITIES}

The three major facilities (K-25 Site, ORNL, and Y-12 Plant) were built in the early 1940s for one purpose: large-scale production of fissionable material to build the world's first nuclear weapons. Although built as temporary facilities, they continue to be used today and have grown into major research and development (R\&D) and production facilities. This growth began in 1947 when the Atomic Energy Commission (a predecessor of DOE) was established to take charge of the country's nuclear program and to administer the development of nuclear energy for beneficial peacetime applications. Since that time, ORNL has expanded into a major R\&D facility, and the Y-12 Plant has experienced continued evolution in function and mission as a production facility for weapons parts and as support for other DOE facilities. The K-25 Site continued its mission of producing fuel for nuclear reactors by the gaseous diffusion method until the plant was placed on ready standby in 1985 .

Today, the buildings at these three facilities represent a considerable investment-almost $\$ 1.7$ billion (FY 1986 dollars), not including equipment. In addition, other programs and facilities have been established on the ORR to complement the activities of the three major facilities and to provide supplemental resources and information. Such facilities include the Office of Scientific and Technical Information (OSTI), Oak Ridge Associated Universities (ORAU), and the American Museum of Science and Energy.

\subsection{GENERAL DESCRIPTION OF THE PLANT FACILITIES}

\section{Oak Ridge National Laboratory}

ORNL, located toward the west end of Bethel Valley, is a large, multipurpose laboratory for basic and applied research in energy technology development. ORNL's facilities include nuclear reactors, chemical pilot plants, research laboratories, radioisotope production laboratories, and support facilities (MMES 1990). The Oak Ridge National Environmental Research Park, which encompasses much of the nonplant area of the ORR, is managed by ORNL.

\section{2 .2 Oak Ridge Y-12 Plant}

The Oak Ridge Y-12 Plant, which is located in the eastern end of Bear Creek Valley and immediately adjacent to the City of Oak Ridge, has five major responsibilities: (1) to fabricate nuclear weapons components, (2) to process source and special nuclear materials, (3) to provide support to the weapons design laboratories, (4) to provide support to other DOE installations, and (5) to provide support to other government agencies. Activities associated with these functions include production of lithium compounds and fabrication of uranium and other materials into finished parts and assemblies. Fabrication operations include vacuum casting, arc melting, powder compaction, rolling, forming, heat treating, machining, inspection, and testing. 


\subsubsection{Oak Ridge K-25 Site}

Until the summer of 1985 , the primary mission of the K-25 Site was enriciument of uranium hexafluoride $\left(\mathrm{UF}_{6}\right)$ for eventual use as a fuel in nuclear reactors. The gaseous diffusion process was used to accomplish the isotopic enrichment. In August 1985, the gaseous diffusion process at the K-25 Site was placed in a ready-standby mode because of a declining demand for enriched uranium. In December 1987, the decision was made to permanently shut down the gaseous diffusion process, and the plant was placed in permanent shutdown status.

K-25 Site personnel were also involved in developing and demonstrating more energy-efficient and cost-effective methods for uranium enrichment. Two such methods under development at the K-25 Site were the gas-centrifuge process and the atomic vapor laser isotopic separation (AVLIS) system. In 1985 the gas centrifuge process was shut down, and in 1986 the AVLIS work at the K-25 Site was significantly reduced.

Although much of the K-25 Site is now shut down, some waste continues to be generated and wastes now in storage will require disposal. Waste management activities at the K.25 Site are increasing. Low-level radioactive wastes from the other DOE sites at Oak Ridge are now being placed in interim storage facilities in K-25 building vaults until a final disposition strategy is identified. Also, wastes contaminated with polychlorinated biphenyls (PCBs) began arriving from other Oak Ridge sites in 1987 for incineration in the new K-1435 Toxic Substance Control Act (TSCA) incinerator. Other remaining missions at the K-25 Site include advanced enrichment technology $R \& D$, various analytical laboratory programs, engineering and computer support, and various waste treatment proc development.

\subsection{CONTAMINANT RELEASES BEYOND THE OAK RIDGE RESERVATION}

ORNL, the K-25 Site, and the Y-12 Plant are all located on the ORR. Production, research, and waste disposal operations at these three facilities have resulted in releases of hazardous and radioactive wastes which can potentially impact the surrounding environment. Potential contamination pathways include surface and subsurface soils, surface water, groundwater, air and biological/ecological pathways. Treated waste water from ORNL, the K-25 Site, and the Y-12 Plant enters local streams (primarily, White Oak Creek from ORNL, East Fork Poplar Creek and Bear Creek from the Y-12 Plant, and Poplar Creek from the K-25 Site) which drain into the Clinch River and then into the Tennessee River and Watts Bar Reservoir.

The groundwater, surface water, and atmospheric pathways are potentially active in the transport of contaminants from ORR sites. Groundwater is frequently the major transport pathway for contamination from the site of disposal and is capable of transporting contamination to surface water, surface soil, and subsurface soil. The surface water pathway, in addition to carrying contaminants in solution, may transport contaminated sediment. There is a significant potential for volatile contaminants to escape from surface water to the atmosphere. The atmospheric pathway should be considered in the evaluation of contaminant transport from the sites, although the extent to which this pathway contributes to contaminant migration has not been determined. Additionally, contamination bound to surface and subsurface soil may be released to transport media in the future. Discussion of environmental pathways and potential receptors is more appropriately reserved for site specific RI studies and reports. 


\section{ENVIRONMENTAL SETTING}

\subsection{GEOGRAPHY OF THE OAK RIDGE RESERVATION}

The ORR is located in East Tennessee in portions of Roane and Anderson counties. The ORR consists of approximately 14,260 ha $(35,236$ acres) of federally owned lands and is bounded on the north and east by the populated portion of the City of Oak Ridge and on the south and west by the Clinch River (Figs. 4.1 and 4.2). Except for the City of Oak Ridge (population 28,000 according to the 1980 U.S. Census, the latest available), the land within $8 \mathrm{~km}$ of the ORR is predominantly rural and is used largely for residences, small farms, and pastureland (MMES 1986).

The approximate location and population (1980 census data) of other towns near the ORR are Oliver Springs (pop. 3600), $11 \mathrm{~km}$ to the northwest; Clinton (pop. 5300), $16 \mathrm{~km}$ to the northeast; Lenoir City (pop. 5400), $11 \mathrm{~km}$ to the southeast; Kingston (pop. 4400), $11 \mathrm{~km}$ to the southwest; and Harriman (pop. 8300), $13 \mathrm{~km}$ to the west. Fig. 4.3 shows the locations of these towns in relation to the ORR. Knoxville is the nearest major metropolitan center and has a population of about 183,000 (Petrich et al. 1984; Baumgardner and Chance 1984).

\subsection{TOPOGRAPHY}

The ORR lies in a region characterized by elongated ridges and broad to narrow valleys that trend in a northeast-southwest direction (Fig. 4.4). Physiographically, this region is part of the Valley and Ridge Province and extends on a larger scale southwesterly from New York and Canada to central Alabama. The ridges were formed by folding and faulting of compressed sedimentary materials. Over time, weathering and erosion removed more of the less-resistant strata, forming valleys, and leaving ridges composed of sandstone or cherty materials.

Each of the three major plant facilities is located in a separate but adjacent valley. Southernmost is ORNL in Bethel Valley between Haw Ridge and Chestnut Ridge (with ancillary facilities in Melton Valley to the south of Haw Ridge). To the northeast is the Y-12 Plant in Bear Creek Valley between Chestnut Ridge and Pine Ridge. Northernmost is the K25 Site, which is located in Big Valley between Pine Ridge and Black Oak Ridge as is the urban portion of the City of Oak Ridge.

The lowest elevation of about $230 \mathrm{~m}(750 \mathrm{ft})$ above mean sea level on the ORR occurs near the Clinch River; the highest elevation of about $385 \mathrm{~m}(1260 \mathrm{ft})$ above mean sea level on the ORR is along Pine Ridge. 


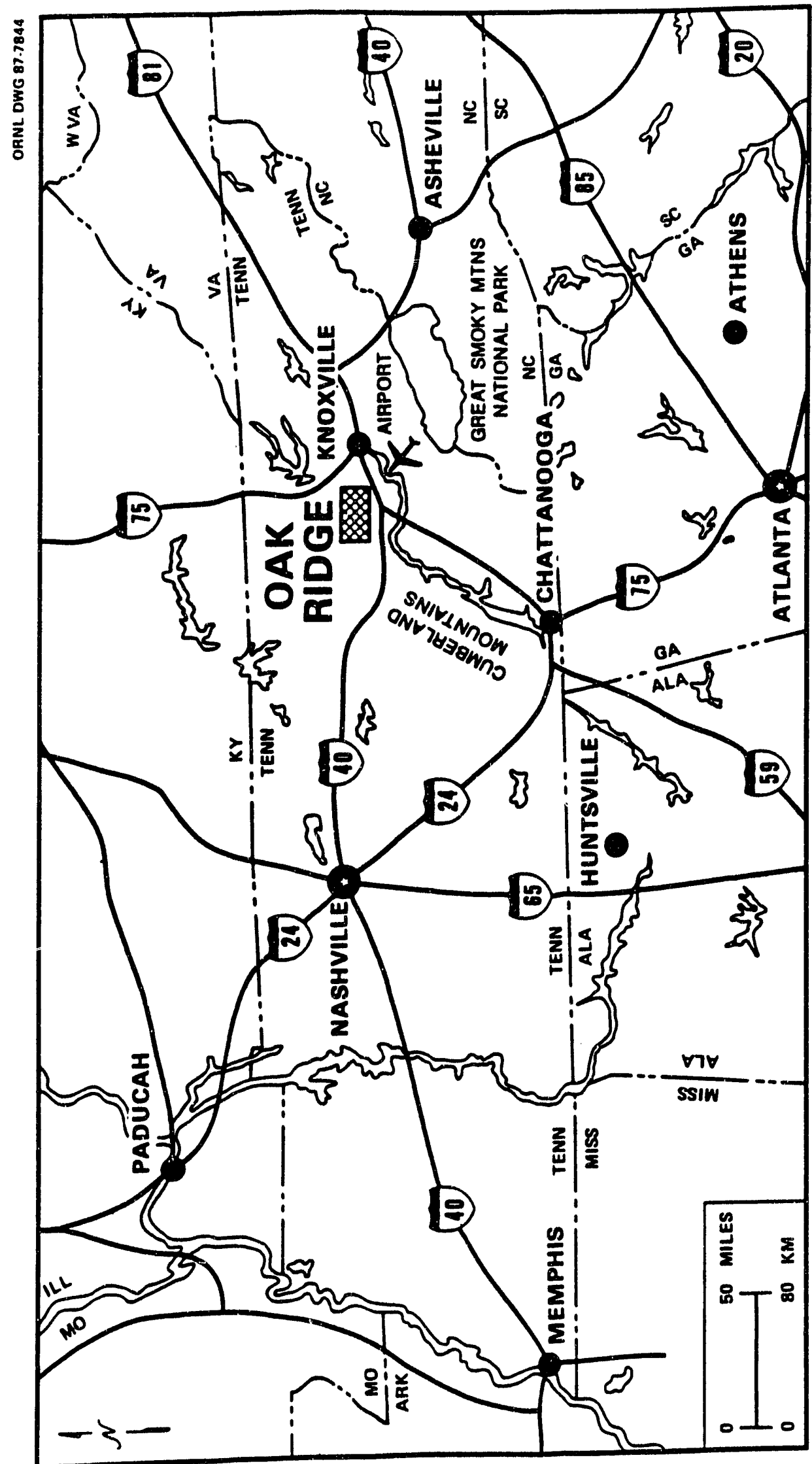

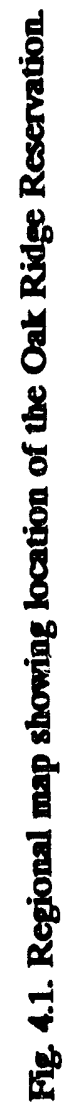



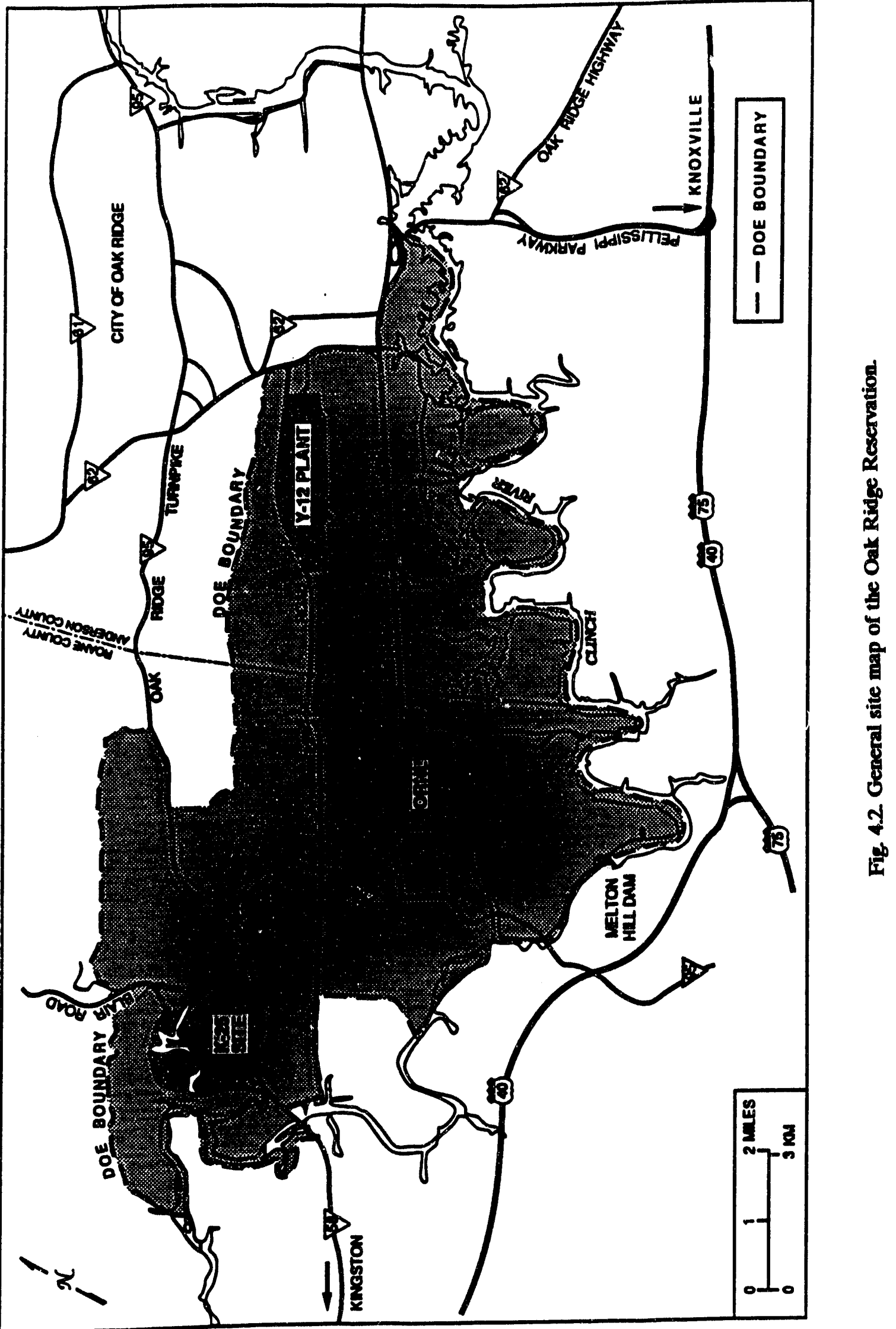


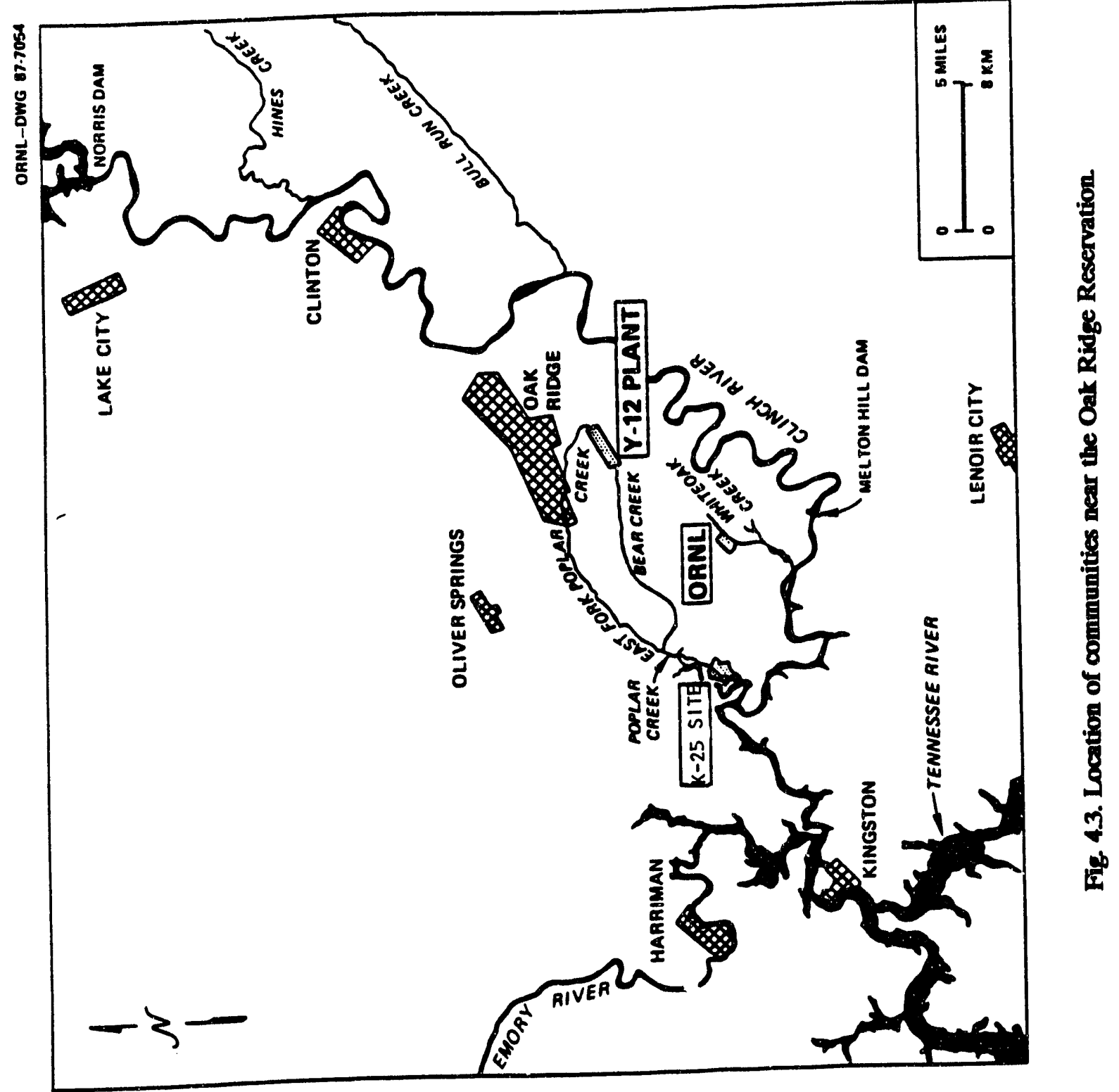




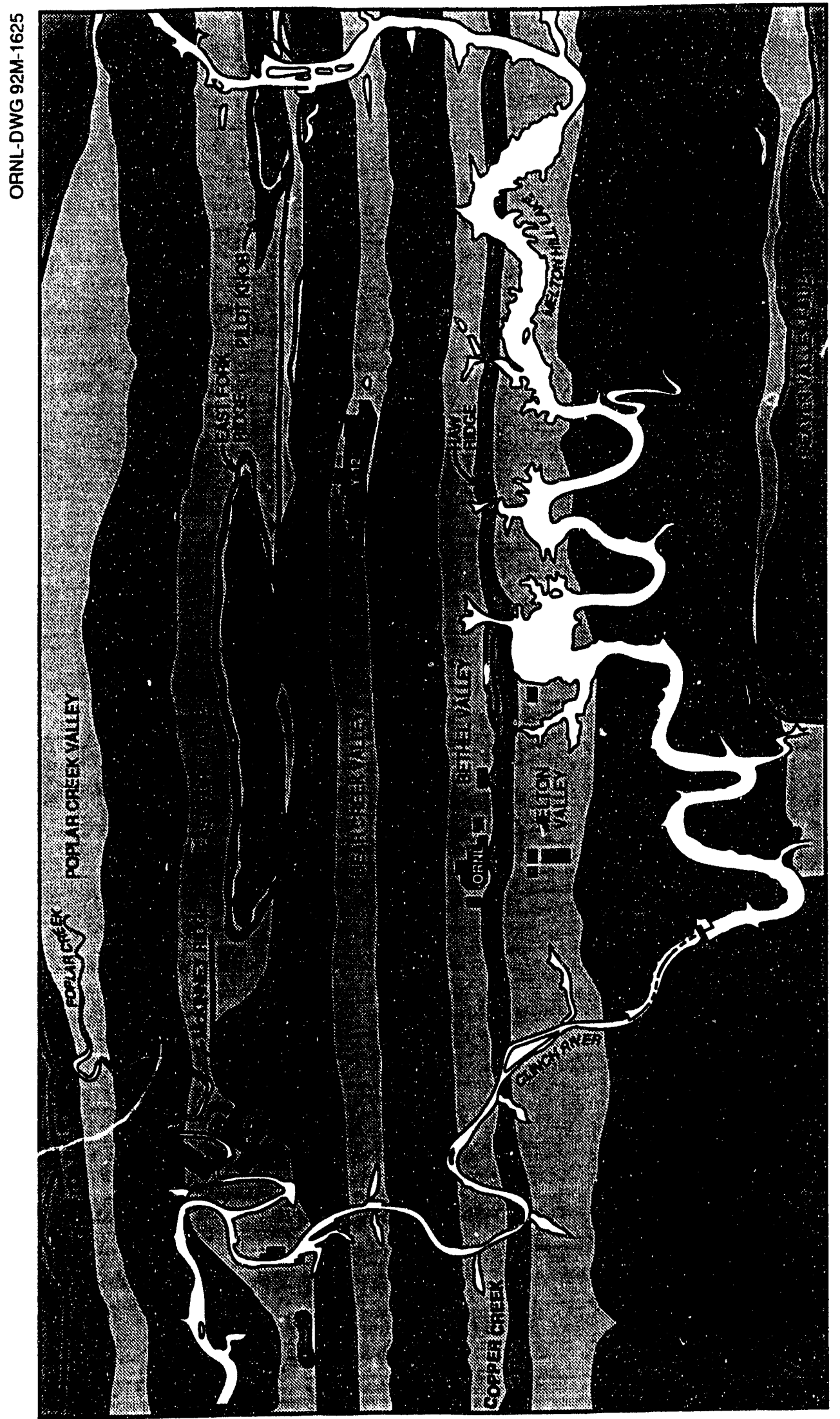

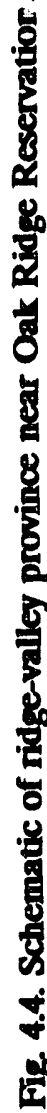




\subsection{GEOLOGY}

Geologic units within the ORR are shown in Fig. 4.5. The principal rock groups (Rome, Conasauga, Knox, and Chickamauga) contain the formations that underlie the ORR plants and waste handling facilities. All the groups are affected by folding, thrusting, and faulting to varying degrees as a result of past tectonic activity. Rock units generally strike northeast-southwest and dip to the southeast except where local faults and folds disrupt normal bedding patterns.

The Rome Formation is a heterogeneous mixture dominated by sandstone, siltstone, and shale, with lesser amounts of dolomite and limestone, that is in many places more than $213 \mathrm{~m}$ $(700 \mathrm{ft})$ thick. The Rome mainly occurs just above major thrust faults and hence is commonly intensely folded and fractured. Rock types of the Rome Formation v.eather differently, but ordinarily soils developed on Rome sandstones and siltstones are generally only a shallow mantle full of rock chips. The carbonatc rocks of the Rome Formation weather more deeply, and locally form bodies of yellowish to reddish, generally silty clay within a red-brown soil layer.

The Conasauga Group consists of light-green, olive-green, and dull-purple shales, mudstones, and limestones. The shales and mudstones of this gro up generally weather to thin acid soils full of shale chips. Where limestones are present within the group, the developed soils are generally deeper and have higher clay content. The thickness of the Conasauga is variable because section is of it can he very highly deformed. The best estimate on true thickness for the Conasauga Group is that it is greater than $610 \mathrm{~m}(2000 \mathrm{ft})$.

The Knox Group is composed primarily of massive, siliceous dolostone. The general lithology varies from massive, dark-gray, crystalline, very cherty dolomite at the base to generally less massively bedded, lighter gray, densely-to-finely crystalline, less-cherty dolomite at the top. Residuum developed on the Knox Group is generally thick and uniform cherty, silty clay. The formations of the Knox Group are generally highly affected by groundwater dissolution, making the Knox Group the most hydrogeologically unpredictable formations within the ORR. Caves, solution cavities, springs, and sinkholes are commonly well developed karst features of the Knox Group.

The Chickamauga Group contains varied lithclogies but is primarily limestone. Complex structural relationships between Chickamauga formations occur in parts of the ORR. The surfaces of valleys underlain by the group are irregular, with the more silty and cherty layers underlying low ridges and hills. Solution cavities, springs, and sinkholes do exist, but they are not as large or as obviously developed as those occurring in the Knox Group.

The geologic structure of the ORR is complex because of extensive regional faulting and deformation. Three regional thrust faults occur in the area (the Kingston, Whiteoak Mountain, and Copper Creek faults). These faults strike northeast-southwest and dip to the southeast, controlling the orientation of the geologic units. Minor seismic activity has been recorded in the region, but no known surface rupturing has been reported associated with any of the faults within the ORR. 


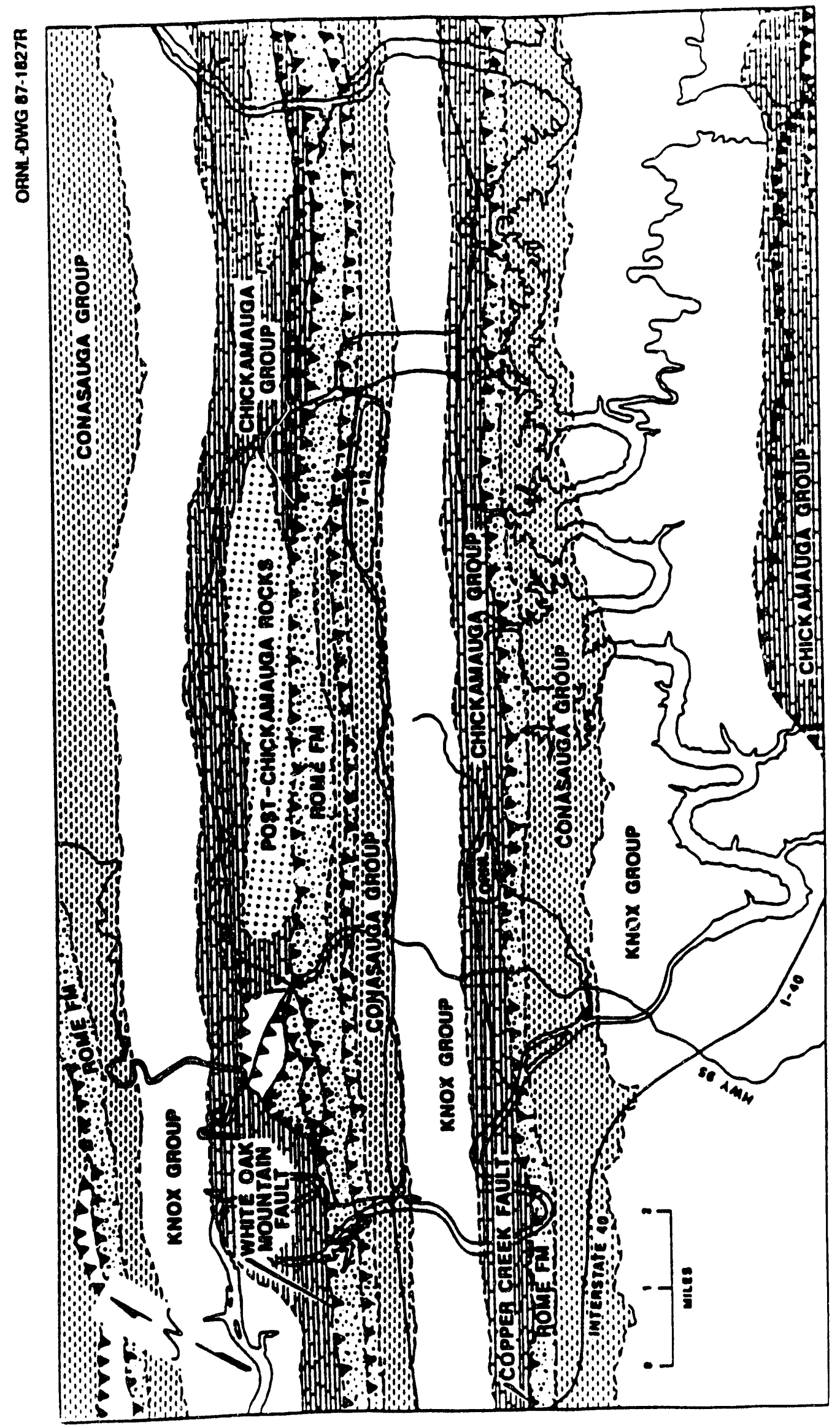

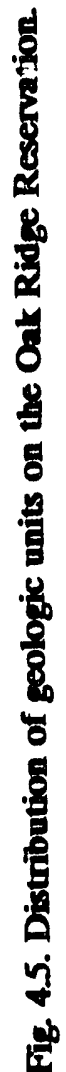




\subsection{SCHS}

The various soil groups of the ORR fall into two categories: soil groups developed from the weathered residuum of the geologic groups (Rome, Conasauga, Knox, Chickamauga, and Rockwood-Sequatchie-Reedsville formations) and transported soil groups developed by colluvial and alluvial processes. If properly managed, all ORR soils have fair-to-good potential for forestry production and wildlife habitat.

Most Rome soils are on steep slopes and are prone to erosion if vegetation is removed and the surface is left exposed. The dip of the geologic strata is very steep and approximately parallel to the slope gradient on south-facing slopes. Consequently, whenever the lower slope is cut, the soil mass above tends to become unstable. Massive earthflows or mudflows are common on these steep-dip slopes. On north-facing slopes, the dip is into the slope and north-facing slopes tend to be more stable if cut.

Knox soils occupy the largest portion of the ORR and can be deeper than $2 \mathrm{~m}(6 \mathrm{ft})$, but it is common to find pinnacles and ledges of dolomite whenever an excavation is made. Knox soils on less-sloping hillsides have good potential for a variety of uses, including building sites.

Soils derived from the Conasauga Group generally have low permeability, and the clays in the residuum are good absorbers of radionuclides.

Most shallow-to-rock Chickamauga soils have few properties conducive to intensive land use. Soils that are deeper to rock have fair-to-good potential for forest production.

Soils in the colluvium and alluvium soil groups have good potential for forestry and wildlife management. Most of these soils, except for very wet areas, were extensively used by farmers and intensively farmed prior to the establishment of the ORR and subsequently were most severely eroded. Numerous shallow-to-deep gullies and ravines are still visible. Some are still actually eroding or have migrating knick points. Similar soils are used for agriculture in areas outside the ORR.

\subsection{HYDROLOGY}

The hydrologic system within the ORR is of major importance to the functioning of natural ecosystem processes as well as to the mobility and fate of contaminants. The hydrologic regime on the ORR, both surface water and groundwater, is controlled regionally by the Clinch River.

Surface water hydrology on the ORR is characterized by a network of small streams that are tributary to the Clinch River (Fig. 4.6). Water levels in the Clinch River are regulated by the Tennessee Valley Authority (TVA), and fluctuations on the river have an impact on the tributary streams and creeks draining the ORR, as well as groundwater levels. The three major facilities each affect a different subbasin of the Clinch River. Drainage from the K-25 Site enters Poplar Creek, drainage from ORNL has its greatest impact on Whitc Oak Creek, and drainage from the Y-12 Plant enters both Bear Creek and East Fork Poplar Creek. 
15

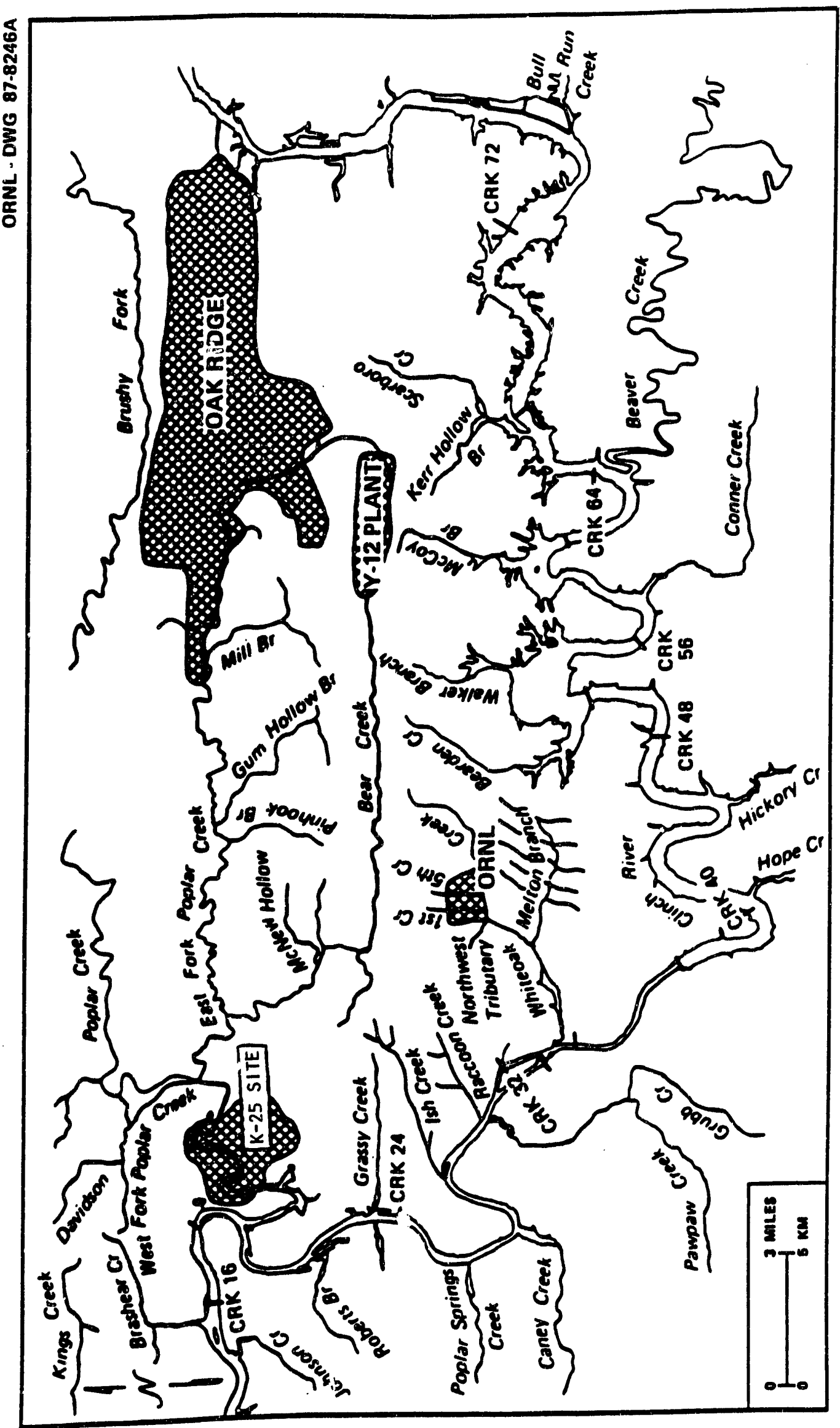


Groundwater is generally in an unconfined (water table) condition on the ORR, but locally perched water tables and confined conditions (i.e., upward gradients) can occur. The variations in the amount of groundwater storage are reflected by fluctuating water table elevations. The depth to water is generally greatest in October to December and least in January to March. In Bethel Valley, depth to water varies between 0.3 and $11.0 \mathrm{~m}$ ( 1 and 36 $\mathrm{ft}$ ), while in Melton Valley the range is generally 0.3 to $19.8 \mathrm{~m}$ (1 to $65 \mathrm{ft}$ ).

\subsection{CLIMATE}

The Oak Ridge area has a temperate climate with warm, humid summers and cool winters. The Smoky and Unaka mountains to the east and the Cumberland Plateau to the west have a protective and moderating influence on the region's climate. As a result, the climate is milder typically than the more continental climate found just to the west on the Cumberland Plateau or on the eastern side of the Smoky Mountains. The prevailing winds in the Oak Ridge area follow the general topography of the surrounding ridges: daytime, up-valley winds come from the southwest and night-time, down-valley winds come from the northeast. The Cumberland Plateau to the west and the Smoky Mountains to the southeast divert severe storms and tornados and high-velocity windstorms are rare. The mountains similarly divert hot, southerly winds which develop along the south Atlantic Coast. Slow-moving high pressure cells suppress rain in the fall, can remain nearly stationary for days, and provide for mild weather. Year-round mean temperatures are about $15^{\circ} \mathrm{C}\left(58^{\circ} \mathrm{F}\right)$, with a January mean of about $3.5^{\circ} \mathrm{C}\left(38^{\circ} \mathrm{F}\right)$ and a July mean of about $25^{\circ} \mathrm{C}\left(77^{\circ} \mathrm{F}\right)$.

Precipitation in this area of the Tennessee Valley is seasonally distributed (McMaster 1967). Peaks in precipitation usually occur in late winter to early spring and in mid to late summer. Winter storms are generally of low intensity and long duration; brief, heavy rains associated with thunderstorms are common in the summer. The annual minimum in precipitation usually occurs in the fall. The mean annual rainfall in the Oak Ridge area is about $136 \mathrm{~cm}$.

Loss of water to the atmosphere by evapotranspiration is about $76 \mathrm{~cm}$ annually in the Oak Ridge area, or about $55 \%$ of the total annual precipitation. Evapotranspiration is at a maximum from July to September during the peak vegetation growing season. Runoff is greatest in the winter when evapotranspiration is low and precipitation is high. Precipitation not lost as evapotranspiration or as quick surface and shallow-subsurface runoff to streams percolates downward through the soil and eventually recharges the groundwater system. 


\section{PROJECT PLAN}

\subsection{PROJECT ORGANIZATION AND MANAGEMENT}

The management of the Background Soil Characterization Project (BSCP) is under the DOE and Martin Marietta Energy Systems management structure for the Environmental Restoration (ER) Program at Oak Ridge.

\subsubsection{Project Organization and Responsibilities}

The BSCP staff organization is summarized in Fig. 5.1. Functional responsibilities for project activities are listed here. Specific responsibilities herein are in addition to other specific duties called for in Sect. 6.5 of the QAPP and Sect. 8.4 of the Health and Safety Plan.

Program Manager: The program manager is the principal contact between the ER programs of DOE and Energy Systems.

Project Manager: The project manager is the principal project contact between the BSCP coordinators and the Energy Systems ER Program. He has overall responsibility for technical, financial, and scheduling matters. Specific duties of the BSCP project manager follow.

- Ensure excellence in meeting the goals and objectives of the BSCP in a timely and costefiective manner.

- Provide project planning, coordination, and supervision.

- Assign duties to the project staff and orient the staff to the needs and requirements of the project.

- Allocate resources to facilitate achievement of project objectives and requirements.

- Provide budget and schedule control and coordinate preparation of the Project Plan.

- Obtain DOE approval for the proposed variances to any of the support plans, if required.

- Coordinate Corrective Actions and Nonconformance Reports.

- Review subcontract work and approve subcontract invoices.

- Establish and maintain project files and the records management system.

- Ensure that field records and raw data submitted by BSCP investigators are safeguarded in secure files.

- Ensure that project reports and submissions are reviewed for technical accuracy and completeness.

- Ensure that project milestones and deliverables are achieved and submitted according to the project schedule. 


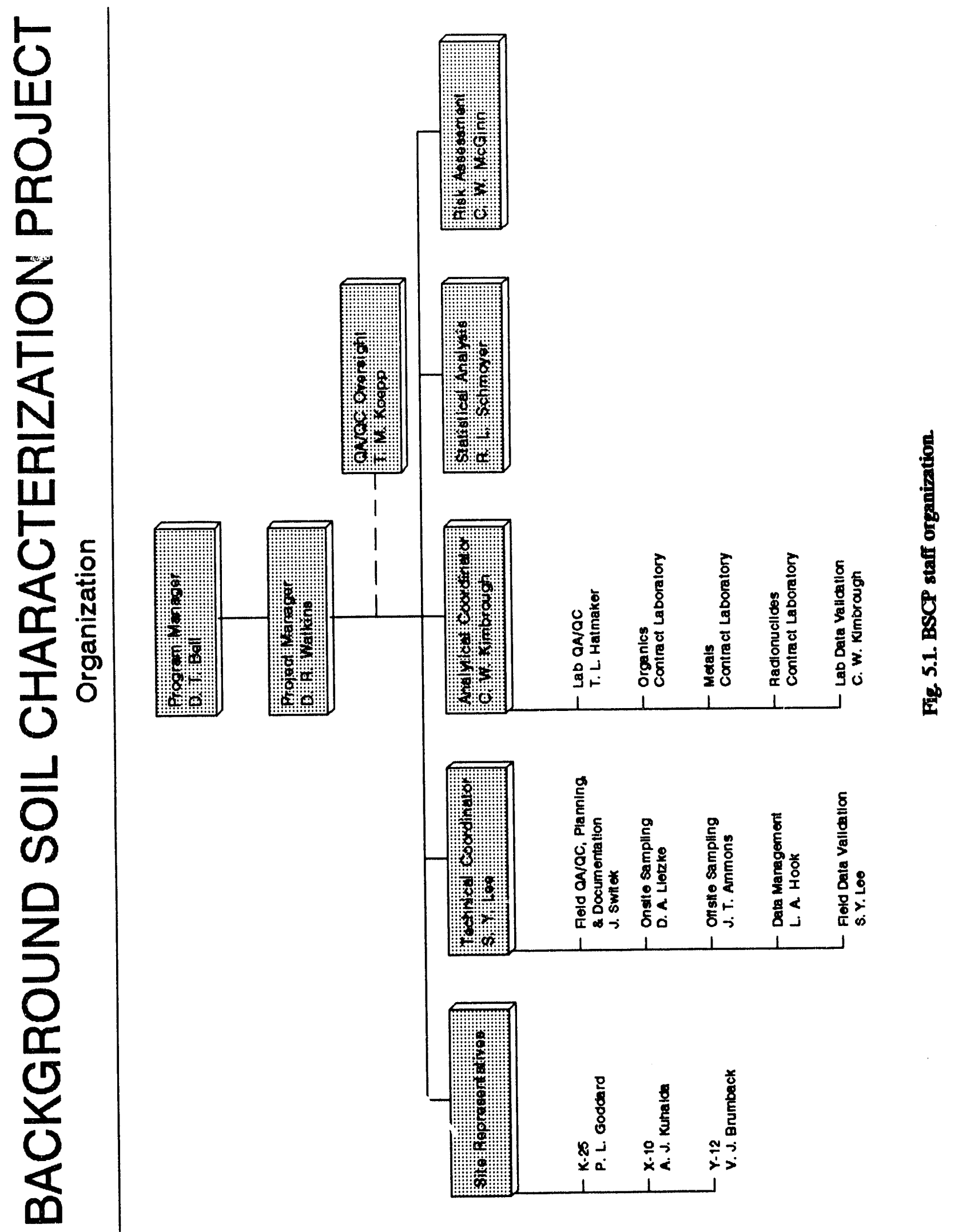


Site Representatives: The site representatives are responsible for integrating availabie information and identifying information needed to meet the requirement of their site ER programs. Responsibilities of the site representatives include the following:

- Assist the project manager in achieving the goals and objectives of the BSCP investigation.

- Provide existing information of their site RI/FS activities for the establishment of BSCP project scope.

- Ensure that the data needs of the three-plant ER programs are being met by the BSCP.

- Provide input on the requirements for consistency of data and reports with that collected in the three-plant programs.

- Provide liaison for individual site investigators at the plants with the BSCP coordinators.

- Provide input and review for the BSCP Project Plan.

Technical Coordinator: The technical coordinator is responsible for coordinating efforts of work planning, site selection, soil sampling, and characterization. The technical coordinator has responsibility for facilitating interactions among the analytical coordinator, statistical analysis coordinator, and risk analysis coordinator. Specific responsibilities of the technical coordinator include the following:

- Assist the project manager in achieving the goals and objectives of the BSCP.

- Oversee all technical aspects of the project and provide assistance to other task coordinators, if required.

- Provide input for the BSCP Project Plan and any project progress reports.

- Supervise and review site selection, soil sampling, data management, and subcontractor activities as appropriate.

- Maintain records in accordance with the Data Management Plan.

- Provide final validation of field and analytical laboratory data, review of data for completeness, documentation, procedures, and consistency with sound physical-chemical principles.

- After validation, coordinate all data verification activities and establish required procedures.

- Resolve any technical questions concerning the data and interpretations.

- Implement appropriate staff training and ensure that all project staff comply with project QA/QC, health and safety, data management requirements, and project-generated waste management requirements, if needed.

Analytical Coordinator: The analytical coordinator is responsible for identifying analytical requirements, determining viable analytical methods to be used, identifying data recording and documentation requirements, selecting contract analytical service laboratories, selecting target organics, metals, radionuclides for analysis, specifying analytical methods and detection limits, and coordinating with other tasks. Specific responsibilities of the analytical coordinator include the following:

- Assist the project manager in achieving the goals and objectives of the BSCP.

- Provide assistance to other task coordinators, as required.

- Provide input for the BSCP Project Plan and any project progress reports. 
- Select target organic, metal, and radionuclide lists for analysis in consultation with on-site team members, and coordinate extraction and analytical methods and analytical service laboratories for the BSCP.

- Select and pre-qualify analytical services laboratories.

- Establish QA/QC procedures with laboratory contractors and establish analytical laboratory data validation procedures.

- Resolve any technical questions concerning the data.

- Maintain records and Level IV (or D) data packages in accordance with the Data Management Plan.

- Provide validation of analytical laboratory data, review of data packages for completeness, documentation, procedures, and consistency with known physical-chemical principles.

Statistical Analysis Coordinator: The statistical analysis (SA) coordinator will provide appropriate statistical design (test design) for sample collection to ensure an adequate representation of the background soils for the BSCP. The SA coordinator will assist in determining data collection requirements for statistical analysis, assist in preparation of project plan, and provide statistical analysis of data when collected. The SA coordinator will provide a summary of statistical findings in drafi form and in the final reports. The SA coordinator will interact with the site selection team to achieve statistically valid sampling sites and with the risk assessment coordinator to guide data collection towards reducing uncertainty in risk analysis.

Risk Assessment Coordinator: The risk assessment (RA) coordinator has responsibility for quantifying any risks to human health and the environment resulting from background levels of organics, metals, and radionuclides in the soils. The RA coordinator will interact with the analytical coordinator for listing target elements and compounds for analysis and establishing analytical detection limits of the listed elements and compounds. The RA coordinator will also assist in determining analytical requirements for risk assessment screening in the project plan, and screen analytes according to health-based criteria to determine if background or health-based criteria should be the determining factor in remedial investigations. The RA coordinator will provide input and review for the BSCP Project Plan and a summary of findings for the draft and final project reports.

Laboratory QAVC Coordinator. The laboratory QA/QC coordinator is responsible for outlining the analytical QAVQC procedures related to BSCP analytical and chain of custody requirements. Responsibilities of the laboratory QA/QC coordinator include the following:

- Prepare the portions of the QAPP plan dealing with the analysis of BSCP samples by internal and contract laboratories.

- Verify that the methods specified are appropriate for obtaining data of known quality, integrity, and validity.

- Conduct surveillances of analytical procedures to ensure that procedures adhere to BSCP requirements.

- Ensure that all laboratory data are properly validated and verified in accordance with BSCP QA requirements.

- Review laboratory data to ensure that analytical methods and protocols have been followed.

- Report quality related issues to project and program management and maintain "Stop Work" authority. 
- Prepare corrective action documentation, nonconformance reports, and ensure that variance activities are initiated, completed and documented appropriately.

Field QAVC Coordinator: The field QAVQC coordinator is responsible for developing field QA/QC procedures related to BSCP sampling, analysis, and chain-of-custody requirements. Responsibilities of the field QAVQC coordinator include the following:

- Prepare the field sampling portions of the QA Project Plan.

- Verify that methods specified are appropriate for obtaining data of known quality, integrity, and validity.

- Conduct field surveillances of sampling methods to ensure that procedures adhere to chain-of-custody requirements.

- Review field QAVQC sample results to ensure that field measurement and sampling protocols have been followed.

- Report quality related issues to project and program management and maintain "Stop Work" authority.

- Prepare Corrective Action documentation, Nonconformance Reports, and ensure that variance activities are initiated, completed, and documented appropriately.

\subsubsection{Project Schedule}

The project schedule, organized by major project phases and elements, is provided in Fig. 5.2. This schedule is designed in accordance with the specific requirements of the FFA negotiated between DOE, EPA Region IV, and TDEC.

Major project events and milestones for submissions to DOE and the regulators are shown here.

\section{Milestone/Event}

BSCP Draft Project Plan

BSCP Final Project Plan

Project Status Review

Preliminary Phase I Data

Report/Annual Report

Project Status Review

Preliminary Phase II Data Report

Risk Assessment Review

Draft Final Report

Final Report

\section{Completion/Deliverable Date}

12/31/91

5/29/92

$8 / 25 / 92$

9/30/92

$2 / 10 / 93$

$4 / 30 / 93$

$6 / 15 / 93$

7/30/93

10/29/93 


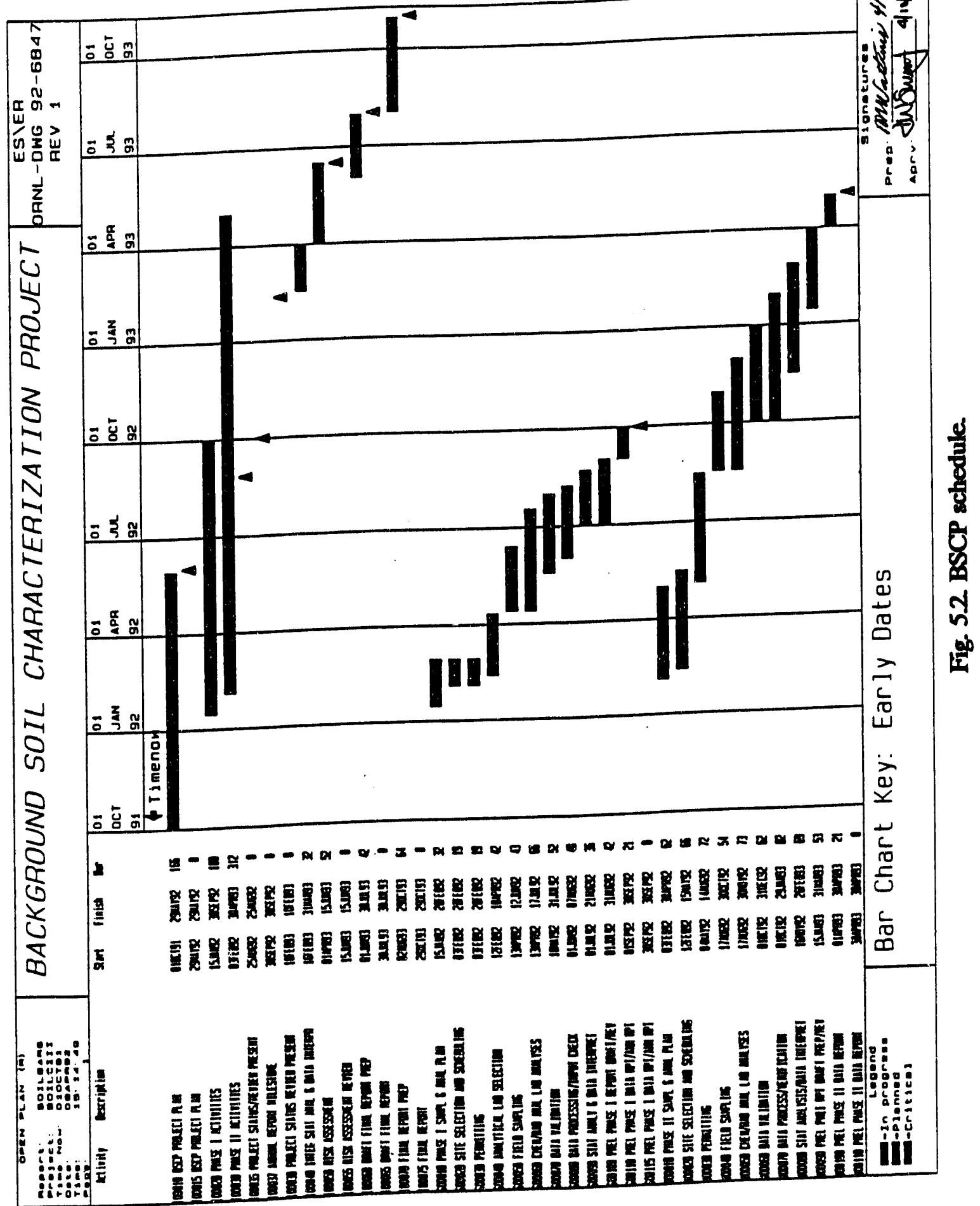




\subsection{SITE SELECTION PLAN}

\subsubsection{Introduction and Scope}

The Site Selection Plan supports the Soil Sampling and Analysis Plan of the BSCP. Planning for the initial site surveys will require obtaining and reviewing site land use records (MMES 1989a), soil maps and classifications (Lietzke et al. 1988), and geologic maps (Lemiszki 1992; Hardeman 1966). This assessment will then be used to establish approximate boundaries of candidate areas for background soil sampling.

Two approaches are available for the selection of background soil sampling sites. One is to use remote sites outside the ORR, while the other option is to use sites on the ORR outside the K-25, ORNL, and Y-12 security fences. Both options have advantages and disadvantages, but the selection of sites within the ORR perimeter is favored for the following reasons: (1) the similarities of pedogenic, geomorphic, and hydrologic characteristics between soils within and outside of the facilities, and (2) the availability of land use records and other information for the best background soil sampling site selections. A possible drawback would be contamination through atmospheric deposition of contaminants on soils resulting from ORR facility activities. To check this possibility and establish unequivocally that gross contamination is not present at selected sampling sites, the Site Selection Plan designates two off-site areas, one in western Roane County and the other in eastern Anderson County. Both areas are about 20 miles away from the ORR, but they have the same soil series developed from the same geologic formations as found on the ORR. Subsequent analyses are expected to confirm that such distances are sufficient.

\subsection{Approach}

The complexity of the geological and hydrological setting of the ORR and surrounding areas requires that care be taken in establishing locations for the background soil sampling sites. Therefore, the location and number of reference soils have been determined by considering soil classification, parent material, bedrock formation, geomorphology, hydrology, and land use history of the sites. The following describes the approaches to be taken in a stepwise manner after consultation with site RI/FS investigators and statisticians to avoid contaminated areas and to collect representative fractions of the soil with the minimum number of samples and effort.

- On-site soil distribution and remedial investigation data were obtained for identifying the geologic groups that were most heavily impacted by past DOE activities.

- Formations selected are the Witten Formation (or Ridley Limestone) and Benbolt Formation (or Rockdell Formation) of the Chickamauga Group, the Chepultepec Dolomite and Copper Ridge Dolomite of the Knox Group, and the Nolichucky Shale and Dismal Gap Formation of the Conasauga Group (Fig. 5.3).

- A dominant soil series, formed from residuum, was selected among all the soil series identified as occurring on each geologic formation selected. They are (1) Typic Hapludults-fine, mixed, thermic, for the Witten Formation (or Ridley Limestone); (2) Typic Hapludults-clayey, mixed, thermic for the Benbolt (or Rockdale Formation); (3) Typic Paleudults-clayey, mixed, thermic for the Chepultepec Dolomite; (4) Typic Paleudults-clayey, kaolinitic, thermic for the Copper Ridge Dolomite; (5) Ruptic-Ultic 


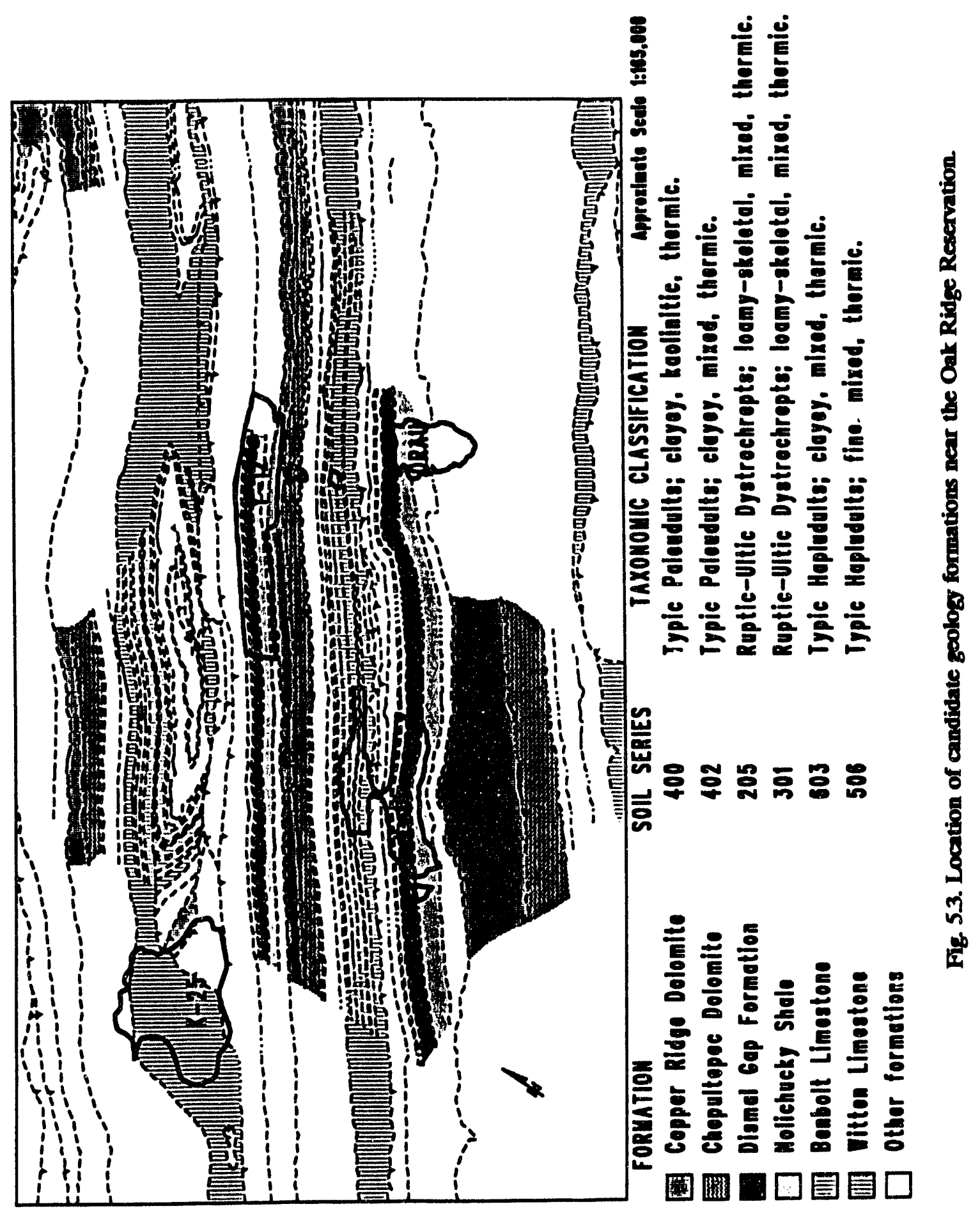


Dystrochrepts-loamy-skeletal, mixed, thermic for the Nolichucky Shale; and (6) RupticUltic Dystrochrepts-loamy-skeletal, mixed, thermic for the Dismal Gap Formation.

- A soil distribution map will be prepared for the six soil series, and about 24 site candidate polygons for each soil series will be selected randomly from the map (Fig. 5.4).

- Candidate areas for off-site (remote site) soil sampling have been selected from the western end of Roane County and the eastern end of Anderson County after reviewing soil survey and geology maps (Fig. 5.5). Detailed maps showing off-site sampling locations are presented in Figs 5.6 and 5.7.

- Two soil series-Typic Paleudults, clayey, kaolinite, thermic for the Copper Ridge Dolomite; and Ruptic-Ultic Dystrochrepts, loamy-skeletal, mixed, thermic for the Dismal Gap Formation-have been selected for remote site sampling.

- After field survey of the 24 candidate sites, 12 sites for each soil series will be selected from the ORR, Roane County, and Anderson County sampling areas on the basis of accessibility for sampling, degree of disturbance, and past and present land use history.

The sites selected for soil sampling shall be on stable land forms with minimum soil erosion and deposition, minimum groundwater discharge, and minimum influence of past and present DOE activities (on site) and farming practices (off site).

\subsection{SOIL SAMPLING AND ANALYSIS PLAN}

\subsubsection{Introduction and Scope}

The objective of the Soil 5 -mpling and Analysis Plan is to present a comprehensive soil sampling procedure and analytical methodology before project start, and to provide the framework or basis for developing the QA/QC Plan. After completion of sampling site selection, background soil sampling will begin. After that the samples collected will be sent to designated analytical laboratories for comprehensive analysis.

Surface soil samples will be subjected first to screening analysis to determine acceptability of each site. Screening for both gamma activity and the presence of VOCs will be conducted. This is discussed further in Sects. 5.3.2 and 5.3.3.

The analytical laboratory analysis plan appears in Sect. 6. This plan discusses sample parameters to be analyzed and the specific analytical Data Quality Objectives (DQOs) associated with each parameter (detection limit, accuracy, precision). Discussion of the accuracy and precision of the methods specified in Sect. 6 can be found in the text of the methods themselves. In addition, the analytical methods and required level of documentation are discussed. Details are specified in individual laboratory statements of work.

\subsubsection{Sample Collection}

The objective of this section is to give general guidance for the collection of soil samples during field operations. Guidance for preparing soil sampling protocols, including statistical sampling methodology, is included in the EPA publication "Preparation of Soil Sampling Protocol, Techniques and Strategies" (EPA 1983). Standard procedures are also followed for collection of samples (Kimbrough et al. 1988) and "Engineering Support Branch Standard Operation Procedures and Quality Assurance Manual" (EPA 1991d). In this section, a general approach for the collection of soil samples is presented, and detailed requirements are presented in the soil sampling procedure. 


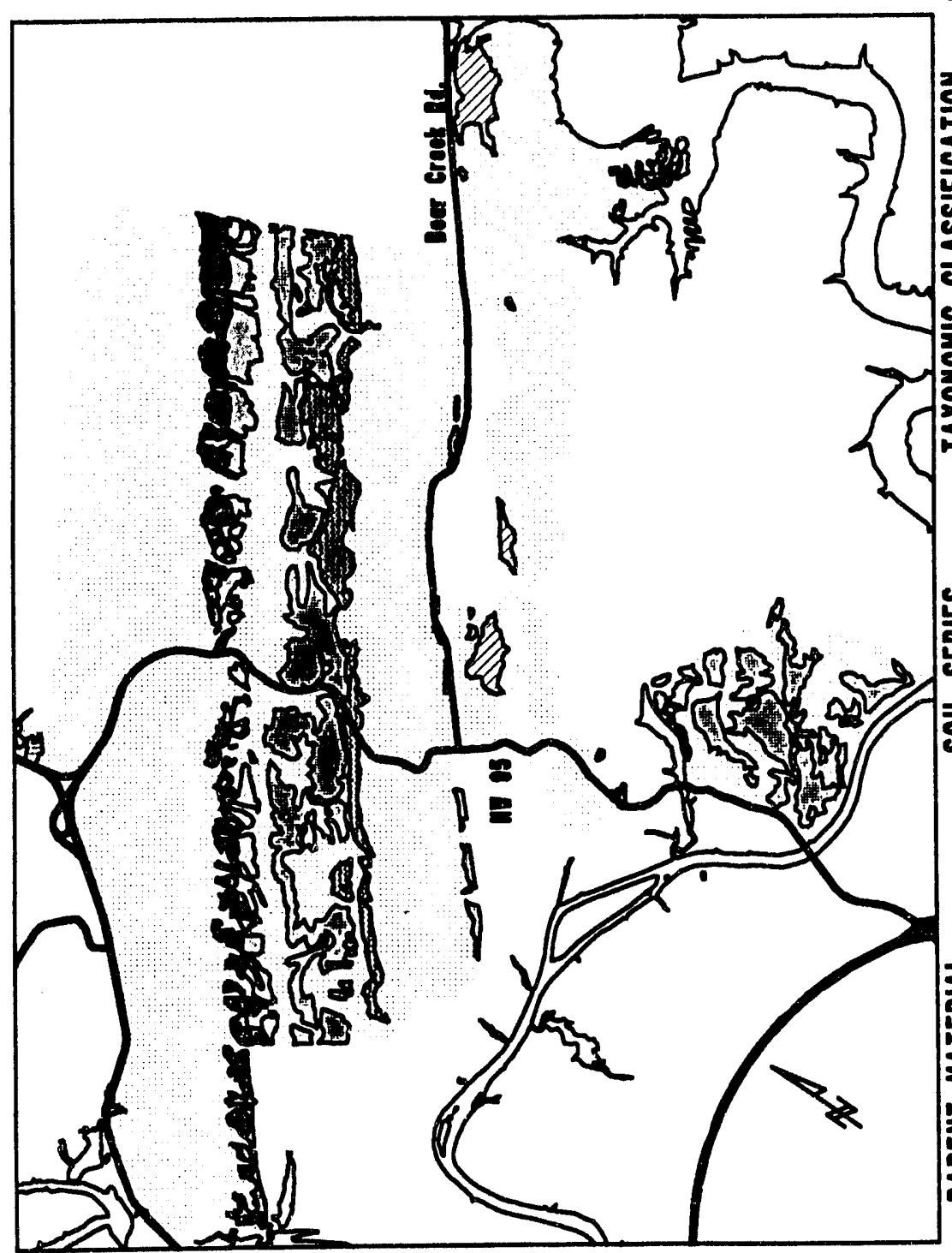

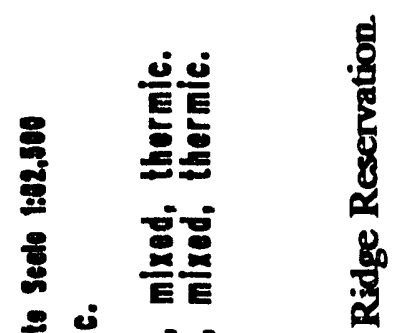

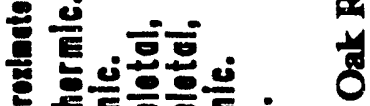

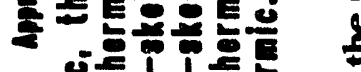

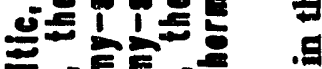

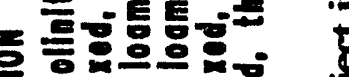

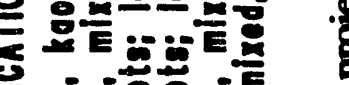

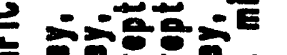

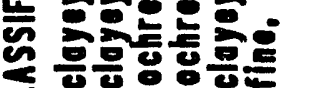

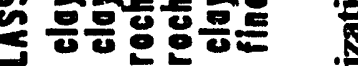

c

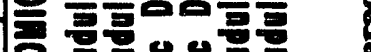

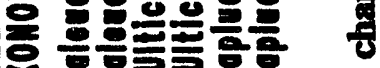

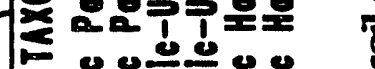

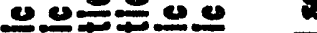

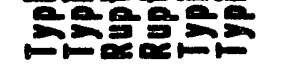

4

施 우우궁요

용

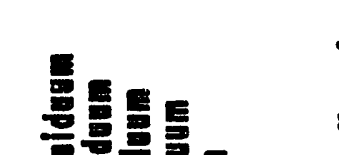

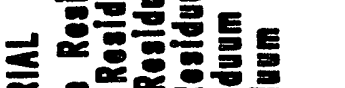

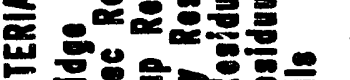

등 형궁으응

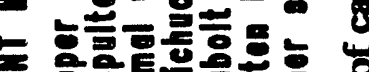

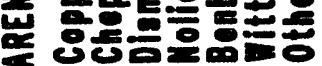

固团国目四口 


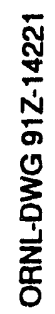

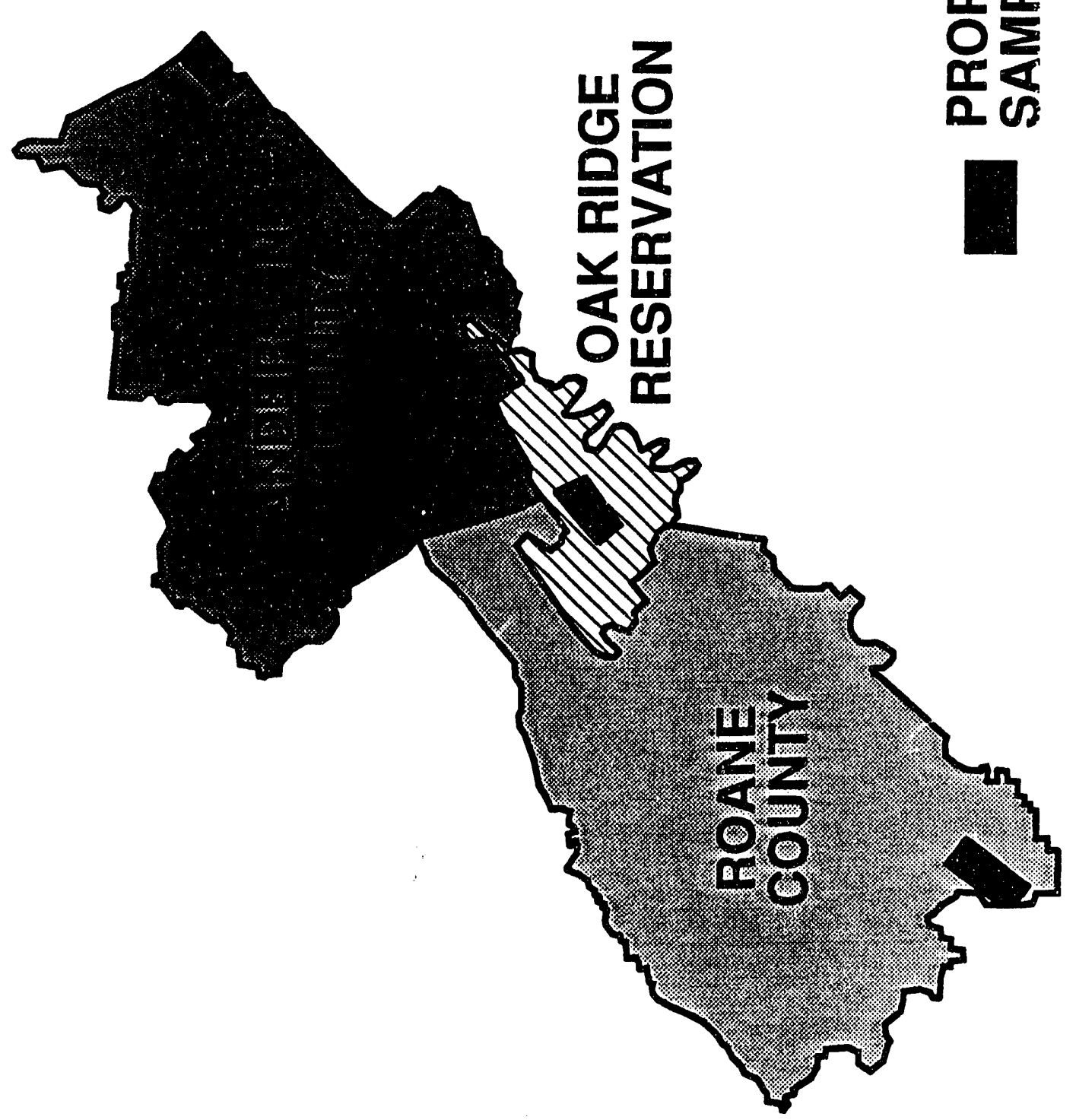

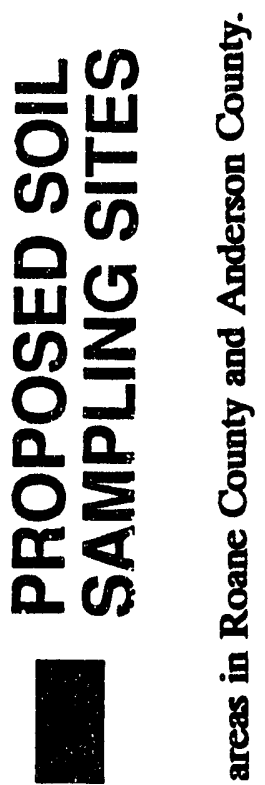

昌

틀

몽

푬.

量 

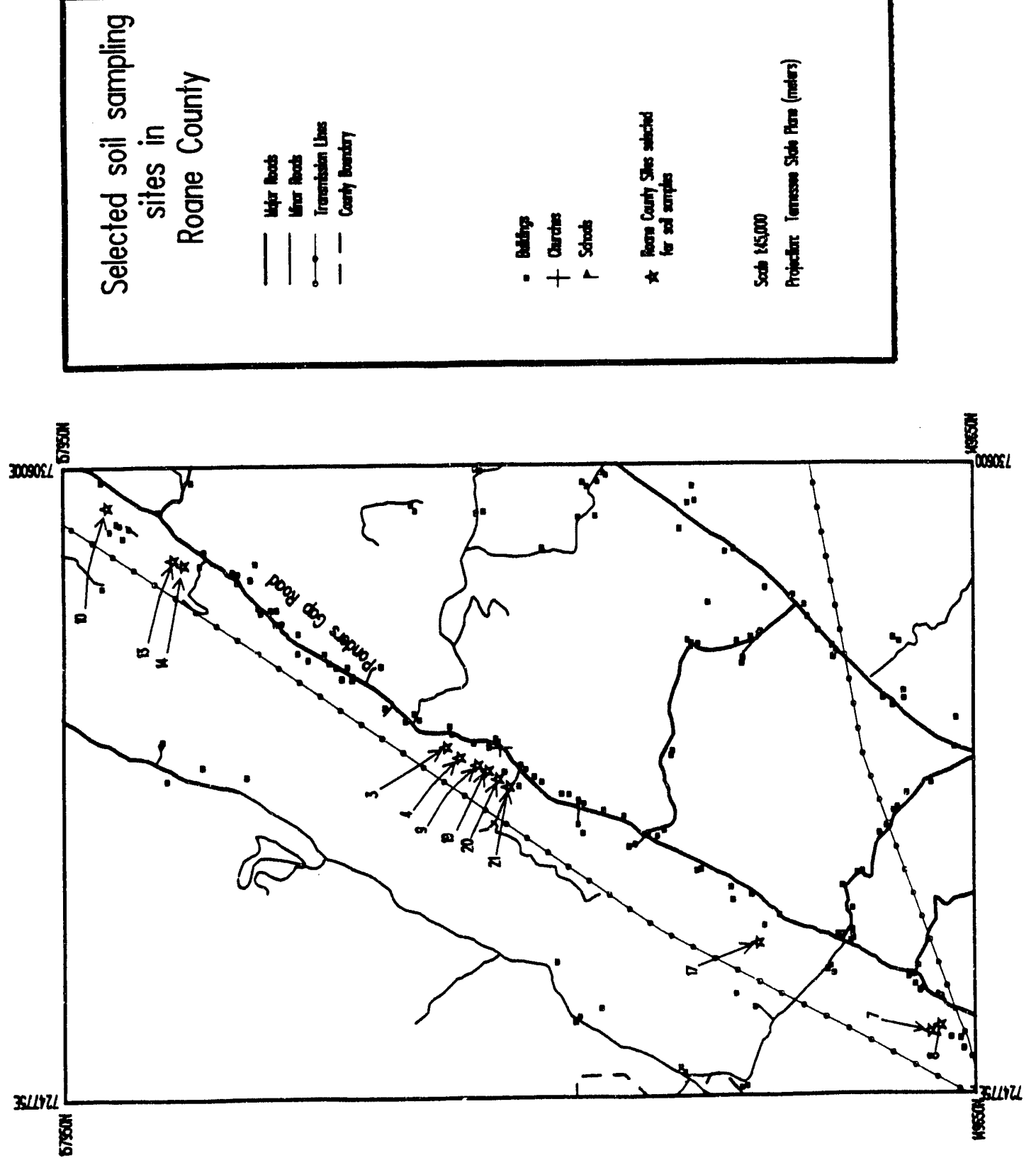


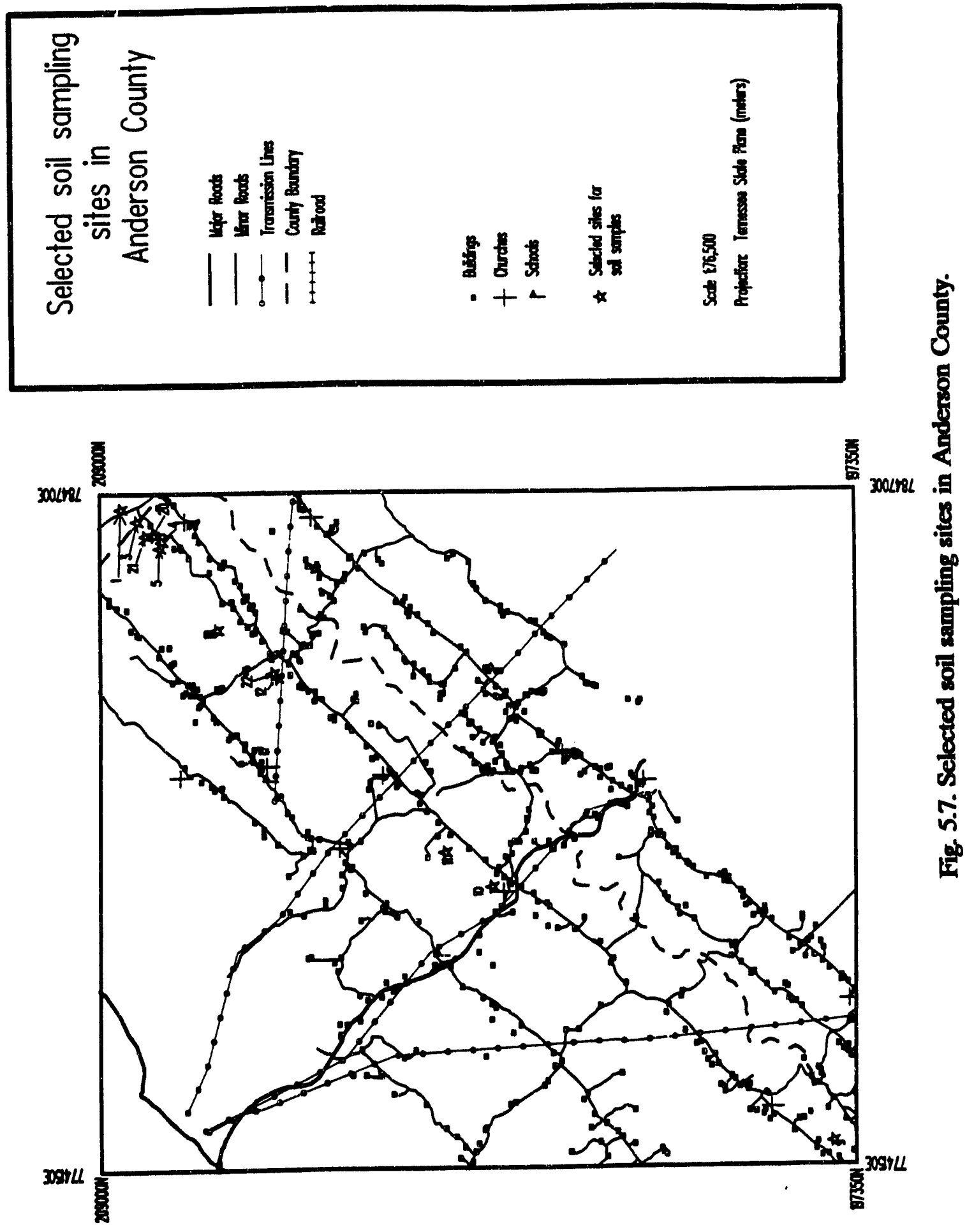


- Equipment: The following equipment is available for field soil sampling: stainless steel spoons, stainless steel scoops, stainless steel hand augers, stainless steel shovels, Shelby tubes, portable power stainless steel augers (Little Beaver), and associated equipment.

- Confirmation of Soil Series: Taxonomical soil property confirmation of the selected site shall be made before soil sampling by comparing key soil properties with the reference soil profile descriptions (Appendix A).

- Preparation of Sampling Site Description: Site identification number, location, geomorphic position, slope and aspect, parent material, vegetation, and date are recorded in the field notebook.

- Surface Soil (A horizon) Sampling: Prior to sampling, leaves, grass, and surface debris are removed from the site to be sampled using a clean stainless steel spoon or shovel. Surface soil (entire depth of the $A$ horizon) samples are then collected using a precleaned, stainless steel scoop or spoon.

- Shallow Subsurface Soil (Bt borizon) Sampling: Shallow subsurface soil samples are collected by digging a hole with a stainless steel shovel, then removing all of the loose soil and collecting a sample at the desired depth (entire thickness of Bt1 horizon) using a stainless steel spoon, a stainless steel hand auger, or a Shelby tube. The shallow subsurface soil samples could also be collected by using a portable power auger (Little Beaver) with a stainless steel hollow stem auger as described below, or if a drill rig is required an appropriate procedure will be developed.

- Deeper Subsurface Soil (B or C horizon) Sampling: For deeper sampling using hand equipment, a stainless steel auger is used to bore a sampling hole until the desired depth is reached. Another clean auger bucket or a Shelby tube is then used to collect the sample from $\mathrm{B}$ or $\mathrm{C}$ horizon depending on the degree of soil development. In cases where difficulties with hand augering are experienced, a Little Beaver portable auger can be used to reach the desired depth. A split spoon sampler attached to a power drilling rig can be used for sampling at greater depths. A hollow stem auger is used to advance the hole to the desired depth. The split spoon is then added to the correct length of drill rod, forced into undisturbed soil through the auger, and retrieved from the hole. The desired amount of sample will then be collected from the undisturbed portion of the soil core.

- Soil Sampling for Gamma-Spectrometry Screening: The objective of soil screening is to validate that the selected site was not affected by ORR facility activities in the past. If the site selected has radioactivity significantly higher than regional natural background levels (due to local fallout, for example), the selected site will be rejected as a sampling site. Average background level of ${ }^{137} \mathrm{Cs}$ for southeastern United States is about $13 \mathrm{pCi} / \mathrm{cm}^{2}$. Soils located on a sediment depositional landform could have higher values under certain conditions. In this project for screen sampling, a stainless steel auger or power-driven bollow stem auger will be used. In this case, a soil core sample will be taken from surface to $30 \mathrm{~cm}$ below the surface. 
- Location Marker Placement: A permanent steel fence post with an identification marker will be placed at each sampling site for location identification. Documentation of site locations by land surveying can be done at a later time if warranted.

- Preparation of Composite Soil Samples: After sample collection and prior to analysis, soil samples not used in screening and VOC analyses will be composited before further analysis according to procedures discussed in Sect. 6.6.1.7.

For noncomposite samples for gamma screening, five 5-cm depth increments will be collected from a 10 - by $10-\mathrm{cm}^{2}$ area down to $30 \mathrm{~cm}$ below surface in plastic containers. All of these samples will be transported to the Environmental Sciences Division (ESD) gamma spectroscopy laboratory for analysis.

\subsubsection{Sample Analysis}

Selection of parameters for analysis and selection of analytical laboratory methodologies were determined based on the following project objectives and assumptions:

- The objective of the study is determination of background concentration levels and ranges for naturally occurring inorganic, organic, and radiological parameters. These data will be utilized for comparison with characterization and compliance data for soils and sediments with significant differences being indicative of contamination.

- The laboratory analytical methods and techniques selected for this study will be those usually required by regulations and/or normally used for characterization and compliance analyses. These methods and procedures are those associated with such laws as: the Clean Water Act, Safe Drinking Water Act, Resource Conservation and Recovery Act, and the Comprehensive Environmental Response, Compensation, and Liability Act.

- Detection limits required for this study are those routinely reached by accepted analytical methods and techniques for soils and sediments. Detection limits are discussed in detail in Sect. 6.11.

- The parameters to be determined are those normally found in soils and sediments of natural origin, which are indicative of contamination when found above natural background. They include heavy metals, organic compounds, and radionuclides which are used in or generated by industrial, agricultural, and research activities associated with the Oak Ridge Reservation. (See Sect. 6.11 for details.)

- However, parameters which do not occur in nature are assumed to have a priori concentrations equivalent to zero background that are below analytical detection limits. Some of these include man-made compounds, such as semi-volatile organics, herbicides, pesticides, and polychlorinated biphenyls (PCBs). Radionuclides are an exception in this category. While nuclear activation and fission do not occur in nature, they may have been added to natural background by natural processes (atmospheric deposition) from sources removed from the Oak Ridge Reservation. 
S? Il samples will be sent to contract analytical laboratories for analysis. Details pertaining to the distribution of samples obtained and the distribution of analyses to be performed and relevant parameters for both Phase I and Phase II are presented in Appendix B. For volatile organic compounds (VOCs) and tritium analyses, about $500 \mathrm{~g}$ of surface (A and $\mathrm{E}$ horizon) uncomposited soil will be collected in two amber glass bottles and sent to one of the on-site analytical laboratories. About $500 \mathrm{~g}$ of surface soil will be collected in amber glass bottles for non-VOC analysis for the chemical parameters in Table 6.4. Composite samples prepared in an Environmental Sciences Division soils laboratory will be sent to the contract laboratory for complete analyses of heavy metals and radionuclides.

Analytical laboratories will be selected from a pool of preapproved laboratories experienced in the routine analysis of characterization and compliance samples. The laboratories are preapproved based on reliability and accuracy, review of their Laboratory Quality Assurance Plan (per requirements of ES/ER/TM-4/R1), ability to run the required methods and deliver required reports, and audits against the laboratory QA plan; cost will be considered only after prequalification is determined.

Multiple techniques will be used for certain analyses when they are either routinely used in the analytical laboratories or have been approved and used in remedial investigations. For example, two techniques will be used to analyze metals: atomic absorption spectroscopy (AAS), inductively coupled plasma spectroscopy (ICP), and Inductively Coupled Plasma/Mass Spectrometry (ICP/MS). The Neutron Activation Analysis (NAA) technique may also be considered later for additional metals analyses.

Parameters indicative of contamination include heavy metals, polynuclcar aromatic hydrocarbons (PAHs), Vui, pesticides, SVOCs, radionuclides, and uranium and its isotopes. The relative importance of indigenous versus locally transported contaminants, i.e., uranium and its isotopes, as well as heavy metals, will be discussed in the project report after data are

available. Surface samples will be analyzed for pesticides and herbicides as a determinant of possible previous use of the site by man. Surface soil analyses will be run prior to all other analysis for Vui to determine possible previous waste disposal at the site or the presence of groundwater contaminant plumes under the site. A site will be rejected if any Vui appear above analytical instrumentation detection limits.

\subsection{SAMPLE TRACKING AND RECORDS MANAGEMENT}

This section describes the records management procedures for field sampling. The objectives of the records management program are to provide organization, protection, retrievability, and accountability of the data and documents generated by field sampling activities and soil analysis. These procedures will also ensure that quality assurance objectives are met, as specified by the QA/QC Plan. Records management activities are described in Sect. 7.4.

\subsubsection{Logbooks}

Bound, registered logbooks with numbered pages will be used to record all information concerning the collection, handling, and current location of samples. Data will be recorded directly in an official logbook or on a sequentially numbered data form. Charts and other 
printed material of suitable size will be glued or otherwise securely fastened in the logbook. Pages that are too large to go in the logbook will be kept in a designated place which will be referenced in the logbook. All logbook entries will be made in indelible ink with a single line drawn through errors. Changes will be initialed and dated by the individual making the correction (Kimbrough et al. 1988). Either the sampling team leader or a responsible designee will be the custodian of the logbook. Each page will be signed by the recorder upon completion of entries of that page and reviewed/signed by the team leader.

\subsection{Sample Custody Documentation}

The Technical Coordinator will establish and maintain the chain-of-custody (COC) control system. The system requires the use of two forms, one for field and the other for laboratory samples. Examples of these forms are shown in Appendix C. A sequentially numbered chain-of-custody form will accompany all samples as they are transferred from one custodian to another and will be signed and dated by the person who relinquishes custody as well as the person who accepts custody. If samples are subdivided or separated into groups for transfer to a different custodian, a separate chain-of-custody form will be prepared for each group. Description of sample COC documentation is presented in Sect. 6.6.1.11.

When samples are sent to another laboratory for analysis, a chain-of-custody form will accompany the samples. These forms will be filled out by the sample custodian, and a copy of the form will be sent to the Analytical Coordinator. The Technical Coordinator will then deliver the samples to the appropriate analytical laboratory and transfer custody to the person in charge. Upon final disposition of the samples, the completed original chain-of-custody form will be returned to the BSCP project manager and then submitted to the Document Management Center.

\subsubsection{Data Management}

Data and information management activities that support the BSCP are discussed in Sect. 7, the Data Management Plan.

\subsection{STATISTICAL ANALYSIS PLAN}

\subsubsection{Objectives of Statistical Analysis}

Data will be analyzed statistically to compute upper and lower tolerance bounds for background constituents for each soil horizon in each of the ten selected areas.

Although the best feasible chemical and radiological analysis procedures will be used, the results for some constituents may likely show only "non-detect" along with a detection limit, in which case we say that the result is left censored. If, for a particular constituent-horizon/target-area combination, all or nearly all of the data are left censored, it may be impossible to compute good tolerance bounds for that constituent. Some approaches to analyzing such results are discussed below, but because of the small sample sizes, the most likely conclusion of the study for such constituents will be that more data or better laboratory procedures are needed to better assess the background distributions. 
Determination of tolerance bounds is one objective of the statistical analysis. Other objectives include

- searching the data for statistical outliers,

- computing summary statistics such as means and variances,

- describing the distributions of the data (e.g., as normal or lognormal),

- resolving components of variance - laboratory from spatial,

- investigating possible approaches to combining data (e.g., across soil horizons or parent geologies) so that tolerance bounds and summary statistics may be less variable, and

- exploring the data for other relationships of possible interest (e.g., between the presence of a metal and $\mathrm{pH}$ or soil type).

\subsubsection{Statistical Methods}

When there are plenty of data (e.g., 20 or more separately analyzed soil samples per horizon and soil type), sample percentiles can be used to compute nonparametric tolerance bounds valid under very general conditions. Unfortunately, the expense of the collection and, especially, the analysis of the samples preclude this approach. Therefore, as a compromise, our tolerance bounds will be premised on the underlying constituent distribution having a particular parametric form (such as normal or lognormal), the choice of which will be based on data characteristics.

Using a standard statistical approach, tolerance bounds can be computed from any (statistically) independent estimates of the distribution's mean and variance. Unless all or nearly all of the observations for a particular constituent are censored, the mean, variance, and other parameters of its distribution can be estimated from censored data, with basically the same approach as for uncensored data. (The method of maximum likelihood generalizes to accommodate the censoring.) The SAS LIFEREG procedure handles censored data for various parametric distributions including the normal and lognormal, and computes percentile estimates and standard errors, from which confidence bounds for percentiles can be constructed. The same approach can be used to make variance components analysis accommodate the censoring.

Other approaches to dealing with censoring include setting censored values to zero, setting them to their detection limits, or "imputing" them by interpolation with a distribution fitted using the uncensored data. All these approaches will be considered in this project, pending examination of the data.

If all or nearly all of the data for a constituent are left censored, there will be few options for the statistical analysis. If there are numerous different detection limits, the maximum likelihood approach would, in theory, still work, but this sort of parametric modelling is not likely to be good in the distribution's extreme left tail. Furthermore, because there will be only four (composited) samples for any particular target area, as discussed in the statistical sampling plan in Sect. 5.5.3, numerous detection limits are not likely. The approach will most likely only be useful if we can justify combining results for several areas or horizons.

If all or nearly all of the data are censored, we can still compute confidence bounds for the probability that an observation exceeds the largest detection limit. These confidence bounds do not require the assumption of an underlying parametric form for the distribution 
and are based typically only on the binomial distribution. Theoretically, such confidence bounds could be used like tolerance bounds. But tolerance bounds which are based on more information are preferable when they can be computed.

The other objectives stated in Sect. 5.1.1 will be addressed using standard statistical procedures. Graphics (e.g., residual plots) will be used to search for outliers. Goodness-of-fit tests will be employed to assess the adequacy of parametric models. Analysis of variance will be used to investigate possible approaches to combining data, and analysis of covariance will be used to explore the data for other relationships of possible interest.

\subsubsection{Statistical Sampling}

The basic structure (6 parent geologies, 4 off-site and 6 on-site areas, and 12 sites or locations per area) of the sampling plan was inferred by considering total costs and the relative costs and errors of field sampling and laboratory analysis. We consider the proposed plan to make the most effective use of available resources. For some of the soil constituents the conclusion of the study may be only that more data are needed to adequately assess the background distribution.

Twelve sampling sites will be selected randomly corresponding to each of the ten target areas (geologic formations). At each site, each of three soil horizons will be sampled. The twelve sites will be randomly partitioned into four sets of three for metal and radionuclide analyses. For each horizon, each of the four sets of three samples (corresponding to three sites) will be composited, and the resulting four composites-of-three will be chemically and radiologically analyzed for background constituents. Compositing is intended to reduce spatial variability, and thus the overall variability, minimizing laboratory analysis requirements. For volatile organic compound analysis, surface soils will not be composited. Therefore, in this case iwelve samples will be analyzed for each target area.

A valid sampling plan should (1) use available resources efficiently and (2) lead to a statistically valid analysis. Therefore, we should sample in a way that prevents the selected sampling locations (12 sites from each of 10 areas) from being either too congested or sparse (missing) over the expanse of each target area. Thus item (1) suggests using a stratified sampling scheme.

But, as discussed in Sect. 5.5.2, because we seek to characterize not just the mean but also the spread of the background distributions, background survey estimates of variances will be just as important as estimates of means. Under a stratified (or other restricted randomization) sampling scheme, it would be difficult or impossible to obtain acceptable variance estimates from the limited composite-sample data.

Furthermore, because of the relatively large target areas and the small number (twelve) of sites, close sites are unlikely even under conditions of simple random sampling. Therefore, (1) and (2) together suggest simple random sampling, and we have chosen that approach. To effect it (or at least a close approximation), we will select a grid on each target area, and sample randomly from the grid nodes. Some of the selected points will have to be discarded because of access difficulty, but twelve feasible locations will be chosen for each area. Sampling from a grid also ensures that no two sampled points can be closer than the grid increment. 
The sampling scheme will be implemented at ESD using the ARCINFO system. A grid will be superimposed on the digital geology region map. The grid increment will be determined (by trial and error if necessary) to ensure that sampled points are far enough apart (increment adequately large) and that there are sufficiently many points in the grid that simple random sampling will be approximated (increment adequately small). We will start with a grid increment of approximately 250 feet.

Coordinate pairs will be sampled at random from the grid (using pseudorandom numbers). For each sampled grid point, the ARCINFO system will determine which, if any, area of interest the sampled point is in. By repeating this procedure, we will build a set of candidate points for each formation. Because not all points will be physically accessible, more that 12 ordered sets of coordinates (e.g., 24 or 30 ) will be generated at first. The points will then be considered in order, and selected or rejected on the basis of accessibility until 12 usable sampling locations are determined.

\subsection{RISK ANALYSIS PLAN}

CERCLA establishes a national program for responding to releases of hazardous substances into the environment. To help meet the mandate of CERCLA (to protect human health and the environment from current and potential threats posed by uncontrolled hazardous substance releases), EPA's Office of Emergency and Remedial Response has developed a human health evaluation process as part of its remedial response program. The purpose of the remedial process is to implement remedies that reduce, control, or eliminate risks to human health and the environment. The remedial investigation and feasibility study (RI/FS) is the methodology that has been established for characterizing the nature and extent of risks posed by uncontrolled hazardous waste sites and for developing and evaluating remedial options. The first stage of the RI/FS is to determine the risks that might exist at a site if no remediation or institutional controls are applied. This step is known as a baseline risk assessment.

A risk assessment is often requested, or required, to demonstrate whether the public health and environment are threatened by the concentrations of toxic or hazardous chemicals on a site. One of the first steps in the risk assessment process is identifying the potential contaminants of concern, which involves a comparison of background data to site data in order to differentiate between site-related contamination and naturally occurring constituents. This step is followed by an assessment of the exposure potential and the identification of exposure pathways. Exposure, in the context of human health risk, is defined as the direct contact of a person with a chemical or physical agent. To quantify exposure, exposure concentrations must be determined and chemical intakes must be calculated for the various exposure pathways that are identified.

The identification of exposure pathways of concern is determined by evaluating all of the components (source, transport medium, exposure point, potential receptors, and routes of exposure) necessary to complete the potential exposure pathway. For an exposure pathway to be considered complete, each of these components must be identified and must be linked to each of the other components. Routes of exposure (ingestion, inhalation, dermal absorption, and external exposure to radiation) and potential receptors are critical in identifying the validity of an exposure pathway. Once a pathway is deemed relevant, exposure 
is estimated quantitatively and the toxicity of the potential contaminants of concern is appraised. Risk is then calculated from the results of the exposure and toxicity assessments.

The ORR background soil characterization data will be used for two purposes in the risk assessment process. The first application will be in differentiating between naturally occurring constituents and site-related contamination. This is a very important step in a risk assessment because if sufficient background data are not available, no contaminant can be eliminated from the assessment even if the sampled concentration is measured at a minimum level. The second use of the background data will be in calculating baseline risks that can be used as a regional standard against which site-specific risks can be compared.

\subsubsection{Determining Potential Contaminants of Concern}

As previously mentioned, one of the first steps in the risk assessment process is identifying the potential contaminants of concern. This step compares background data to site data in order to distinguish between the constituents that are present in naturally occurring concentrations, contaminants present as a result of activities conducted on the site, or in some cases, contaminants that are present because of natural and site-related causes. Often, sites on the ORR have no site-specific background data. In this case, the ORR soil characterization data will be used to make the distinction between naturally occurring and site-related contamination.

\subsubsection{Calculation of Risks}

When the list of potential contaminants of concern has been determined, the health risk is then calculated. Risks are estimated by multiplying the chronic daily intake, CDI (the amount of a substance contacted per unit body weight per unit time, averaged over a long period of time) by health risk factors available from EPA. The results are quantitative estimates of (1) the increased risk of getting cancer from carcinogenic chemicals in the soil and (2) the risk of getting sick from noncarcinogenic chemicals in the soil. As an example, the national average risk of contracting cancer is 0.25 , or $25 \%$. This means that out of an exposed population of $1,000,000$ people, the number expected to develop a cancer of some sort is 250,000 . If it is determined that a particular naturally occurring constituent poses an incremental background risk of $1 \times 10^{-6}$, then that estimated number of individuals increases to 250,001 . If a site-related risk from that same contaminant is then estimated to be $1 \times 10^{-4}$, then 250,100 individuals are expected to contract the disease.

Using the ORR soil background data, risk numbers will be calculated to determine the background risks due to naturally occurring constituents and then used as a criterion to which

site-specific risks can be compared. The background risks will be estimated by assuming a residential scenario, a possibility at the K-25 Site if institutional controls are removed in the future. Assuming background concentration levels in the soil are constant over time, the potential pathways affecting the on-site resident would include direct exposure to soil, as well as exposure to soil contaminants transferred to the air, groundwater, and the food chain. The direct exposure to soil would involve the ingestion, dermal contact, and external routes of intake. For this report, only ingestion of soil and external exposure to radiation (since gamma rays travel beyond their source, and the resident may be exposed to external radiation without actually coming in contact with the soil) will be considered since the intake calculations for 
ingestion and external exposure use the exact soil concentrations determined from the background characterization while the other routes require that modelling be performed to arrive at the estimated concentration of each contaminant available for intake.

Risk Assessment Guidance for Superfund (RAGS) (EPA 1989) provides an outline for estimating the intake of a contaminant for both the ingestion and external exposure routes. Table 5.1 presents the equation for calculating intake along with explanations of the associated variables. The variables used in each exposure equation have been derived from standard intake rates, and skin surface areas. It is assumed the resident is exposed to site contamination $\mathbf{3 5 0}$ days a year, for $\mathbf{3 0}$ years. For the evaluation of the external exposure route, the residents are considered to be average adults with average adult inhalation rates, body surface area, and soil ingestion rates. The calculation of the soil ingestion CDI considers a child's ingestion rate $(200 \mathrm{mg} /$ day $)$ and body weight $(15 \mathrm{~kg})$ for 6 years and an adult's ingestion rate $(100 \mathrm{mg} /$ day) and body weight $(70 \mathrm{~kg})$ for 24 years.

Once these background risks have been determined and deemed appropriate, site-specific comparisons of contaminant-induces risks can be made on a regional basis. This comparison can be made for each lithology and soil horizon characterized in this project. 
Table 5.1. On-site resident exposure scenario

A. Residential ingestion scenario

CS $\times$ CF $\times$ IR $\times$ FI $\times$ EF $\times$ ED

$\mathrm{BW} \times \mathrm{AT}$

Radiation Exposure Intake $(\mathrm{PCi})=\mathrm{CS} \times \mathrm{IR} \times \mathrm{EF} \times \mathrm{ED}$

Variable

$\mathrm{CS}=$ Concentration in soil

$\mathrm{CF}=$ Conversion factor

$\mathbf{I R}=$ Ingestion rate

$\mathbf{F I}=$ Fraction ingested

$\mathrm{EF}=$ Exposure frequency

$\mathrm{ED}=$ Exposure duration

BW $=$ Body weight

$\mathrm{AT}=$ Averaging time
Value used

Chemical-specific

(mg/kg, pCi/kg)

$10^{-6} \mathrm{~kg} / \mathrm{mg}$

$0.0002 \mathrm{~kg} / \mathrm{day}$

$0.0001 \mathrm{~kg} /$ day

1 (unitless)

350 days/year

6 years

24 years

$15 \mathrm{~kg}$

$70 \mathrm{~kg}$

365 days $\times \mathrm{ED}$ 365 days/yr $\times 70$ yr
Explanation/source

Concentration is obtained from site specific data.

Necessary to convert to appropriate units.

Child rate (Sect. 6, RAGS, EPA 1989).

Adult rate (Sect. 6, RAGS, EPA 1989).

Maximum value used; equivalent to $100 \%$.

OSWER Directive 9285.6-03

(EPA 1991a).

Two-part (childhood and adult) residential exposure for a 30-year duration (OSWER Directive, EPA 1991a).

Child (OSWER Directive, EPA 1991a). Adult (Sect. 6, RAGS, EPA 1989).

Averaging time for noncarcinogens. Averaging time for carcinogens.

B. Residential external exposure to radiation scenario

$$
\text { Radiation Exposure Intake }(\mathrm{PCi})=\mathrm{CS} \times \mathrm{SD} \times \mathrm{D} \times \mathrm{EF} \times \mathrm{ED}
$$

\section{$\mathrm{CS}=\stackrel{\text { Variable }}{\text { Concentration in soil }}$}

SD $=$ Soil density

D = Soil depth

$E F=$ Exposure frequency

$\mathrm{ED}=$ Exposure duration
Value used Chemical-specific (pCi/kg)

$1.60 \times 10^{3} \mathrm{~kg} / \mathrm{m}^{3}$

$0.1 \mathrm{~m}$

0.959 (unitless)

30 years

\section{Explanation/source}

Concentration is obtained from site specific data.

Blount County Soil Survey".

Depth of soil contamination.

Equivalent to 350 days per year (1 year/365 days).

Residential exposure for a 30-year duration. 


\section{QUALITY ASSURANCE PROJECT PLAN}

\subsection{INTRODUCTION}

This Quality Assurance Project Plan (QAPP) has been prepared to meet the requirements of QAMS-005/80 (EPA 1980a) and ASME NQA-1 (ASME 1989) and with the Environmental Restoration Division (ERD) Quality Assurance Program Plan (ES/ER/TM4/R1). The format used follows guidance provided in Sect. 6 of QAMS-005/80 but is cross referenced to NQA-1 and ES/ER/TM-4/R1. Most of the QA/QC protocols are addressed as an integral part of the project work plan. A QAPP locator, modular profile and cross reference chart have been inserted (Table 6.1) at the beginning of this section to direct the reader to the appropriate page(s) and section(s) where each of the 16 essential QAPP elements is described. QAPP elements not found in the work plan are presented in this section. The order of presentation follows the sequence established in the QAPP locator. Elements not found in this section are listed to provide continuity and for the convenience of readers.

Procedures needed by the BSCP will be included by reference when directly applicable or will be adapted from existing procedures of other ER Division projects. These project-level procedures are referenced in the modular profile in Table 6.1. Modifications to these procedures will clarify responsibilities within the context of the BSCP. The modified procedures will be controlled as if they were original procedures (see Sect. 6.14).

The approval page for the BSCP QAPP is found on page v.

\subsection{PURPOSE}

The objective of the QAVQC Plan is to develop and ensure implementation of procedures for field sampling, laboratory analyses, chain-of-custody data reporting, and information handling that will provide data of known quality that is technically and legally defensible.

\subsection{SCOPE}

The QAPP for the BSCP has been separated into the requirements used by the field sampling team and those used by the analytical laboratory. This QAPP addresses the field (DQ Level I) and analytical laboratory (DQ Level II and IV) activities of the project which will be supervised and implemented by MMES personnel and their subcontractors. The bulk of laboratory analytical activities will be performed by contract commercial laboratories chosen from a pool of preapproved laboratories. On-site, MMES laboratory facilities will be used for gamma screening, soil sample compositing, and VOC screening analyses. Screening sample analyses will be performed to DQ Level II. Contract laboratories will be used for all metal and radionuclide analyses and other chemical analyses. These analyses will be performed to satisfy DQ Level IV. The contract laboratory will use standard EPA methods, as EPA Method 6010 in EPA (1991e) and AEC (1972) and those in the Contract Laboratory Program (CLP). BSCP QA coordinators, appropriate project personnel and MMES QA organizations will have access to all pertinent laboratory records as part of the laboratory contract (refer to Sects. 6.15 and 6.16). 


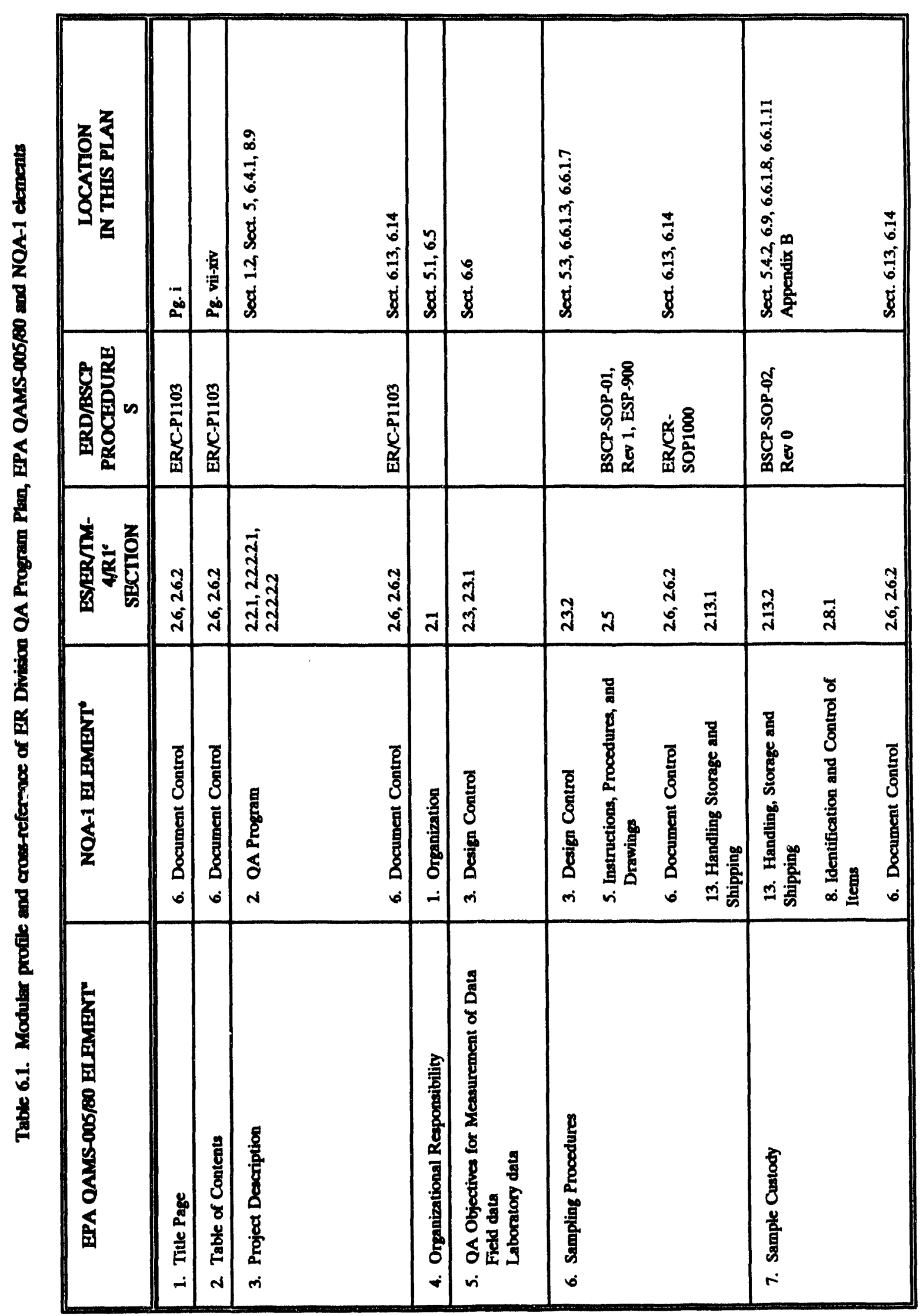




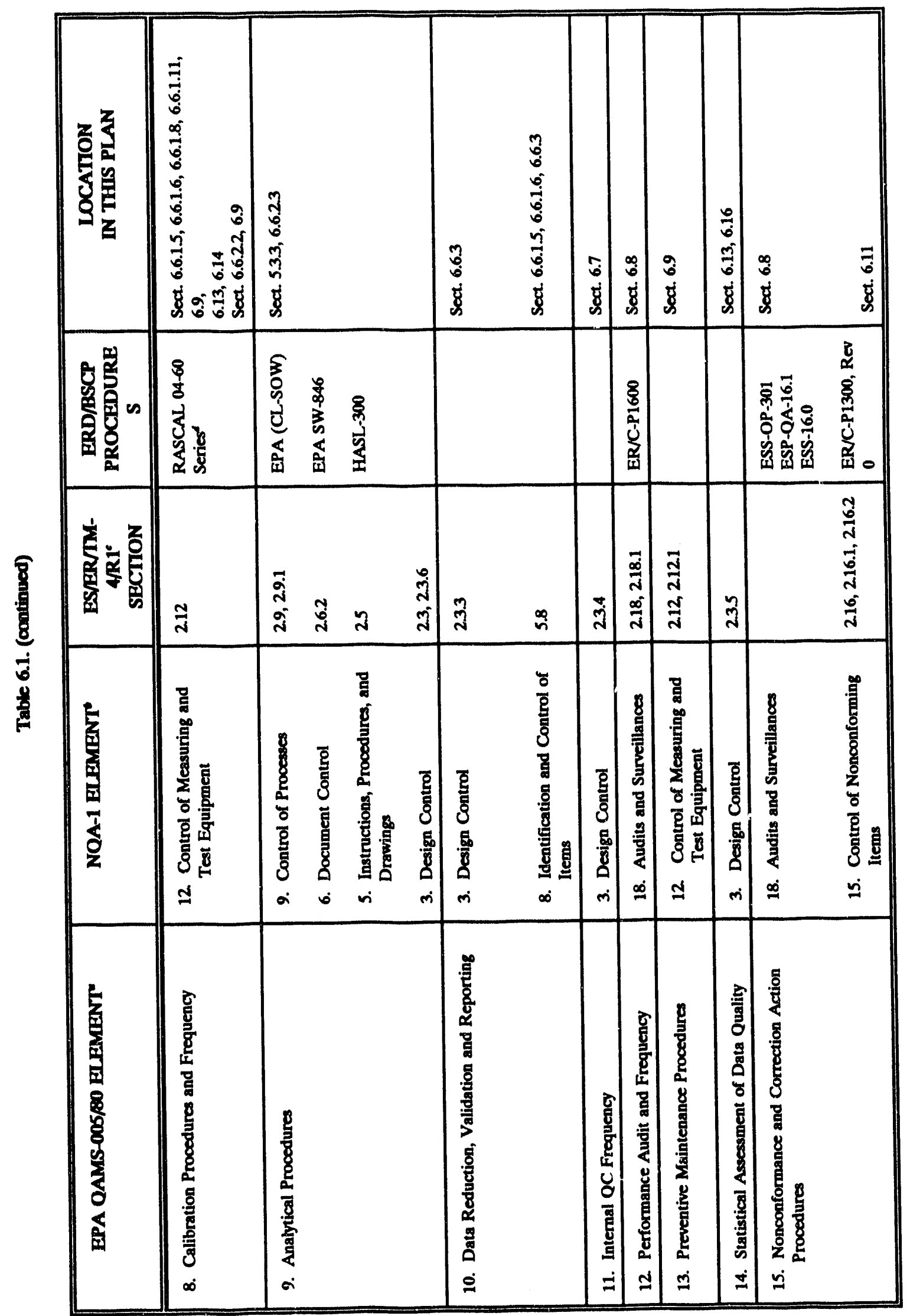




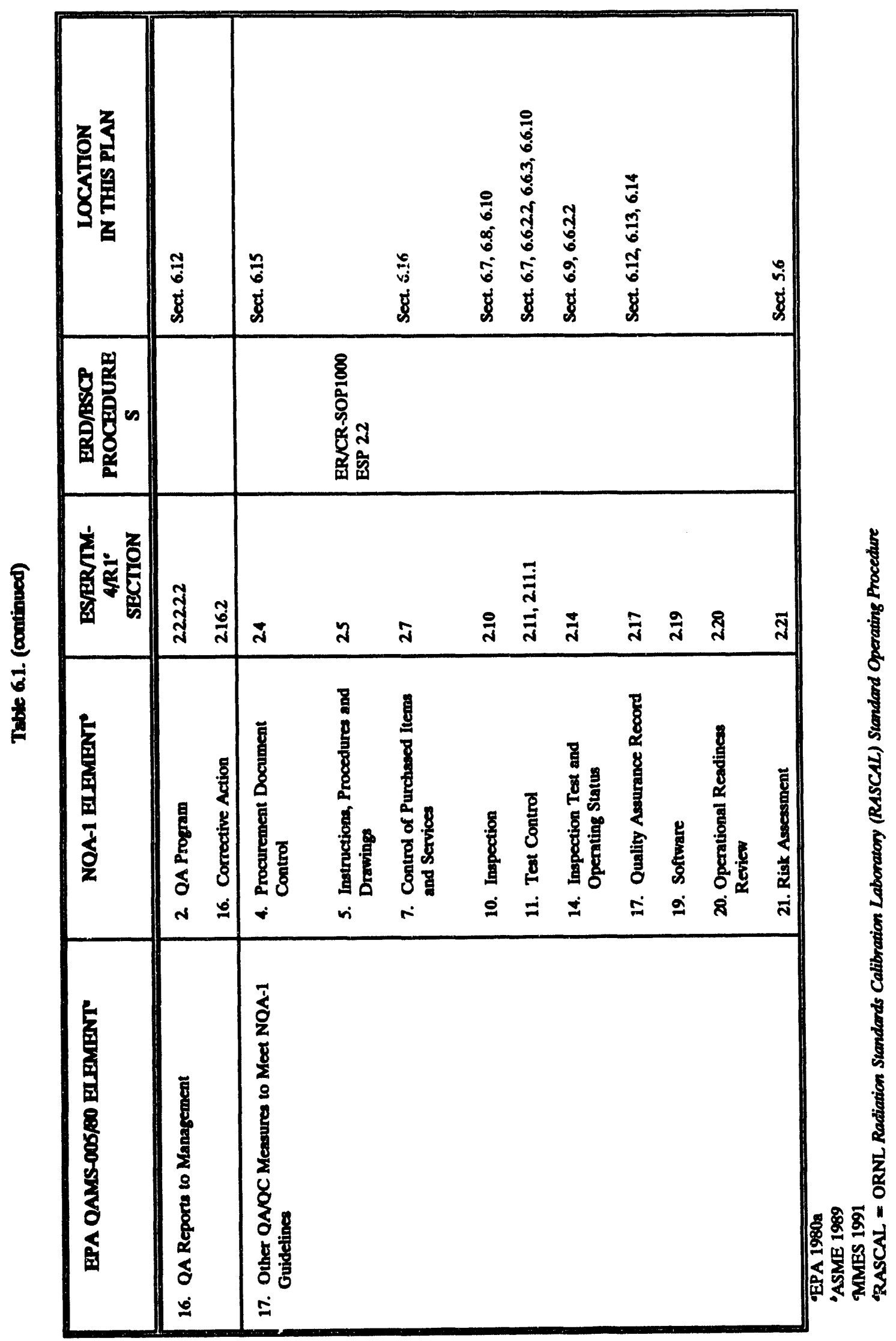




\subsection{PROJECT DESCRIPTION AND TRAINING}

The project is described in detail in Sects. 1.2 and 5. Field sampling personnel for the BSCP will receive project-specific training in all project SOPs, the QAPP, and the Health and Safety Plan in accordance with the Martin Marietta Energy Systems Training Program ESP2.2, 6/5/87. Such training will be documented in accordance with ESP-2.2.

\subsection{PROJECT ORGANIZATION AND QA RESPONSIBIITIIES}

Individuals and organizations identified to conduct the Background Soils Characterization Project (BSCP) and their responsibilities are described in this section. The staff responsible for the successful completion of the BSCP is drawn primarily from Energy Systems organizations from the Oak Ridge Reservation Site. Fig. 5.1 shows the line and project relationships and interfaces (both internal and external). Key positions re ponsible for ensuring the collection of valid measurement data and the routine assessment of measurement systems for precision and accuracy are described below.

Table 6.2 is a Functional Responsibility Chart the purpose of which is to provide a cross reference from specific quality-affecting activities to those project staff positions responsible for their accomplishment.

General responsibilities for ER Division management BSCP management and QA staff are described in the ER Division Quality Assurance Program Plan (ES/ER/TM-4/R1) and are not restated here. Specific responsibilities of the Environmental Restoration Program (ERP) Division and BSCP staff for ensuring accomplishment of the technical and quality objectives of the QAPP are listed below.

\section{Program Manager}

- Reviews and approves the QAPP.

- Ensures that resources required to accomplish the work are available.

- Ensures that the philosophy of Total Quality Management (TQM) is applied to the BSCP.

\section{Project Manager}

- Ensures all project deliverables are completed on schedule or arranges for project extension.

- Ensures the overall success and quality of the project.

- Ensures the development of and approves the QAPP.

- Ensures that the work is done in accordance with the QAPP.

- Initiates a stop work if required.

- Is responsible for application of the philosophy of TQM to all aspects of the BSCP.

- Ensures that corrective actions are implemented in a timely manner. 


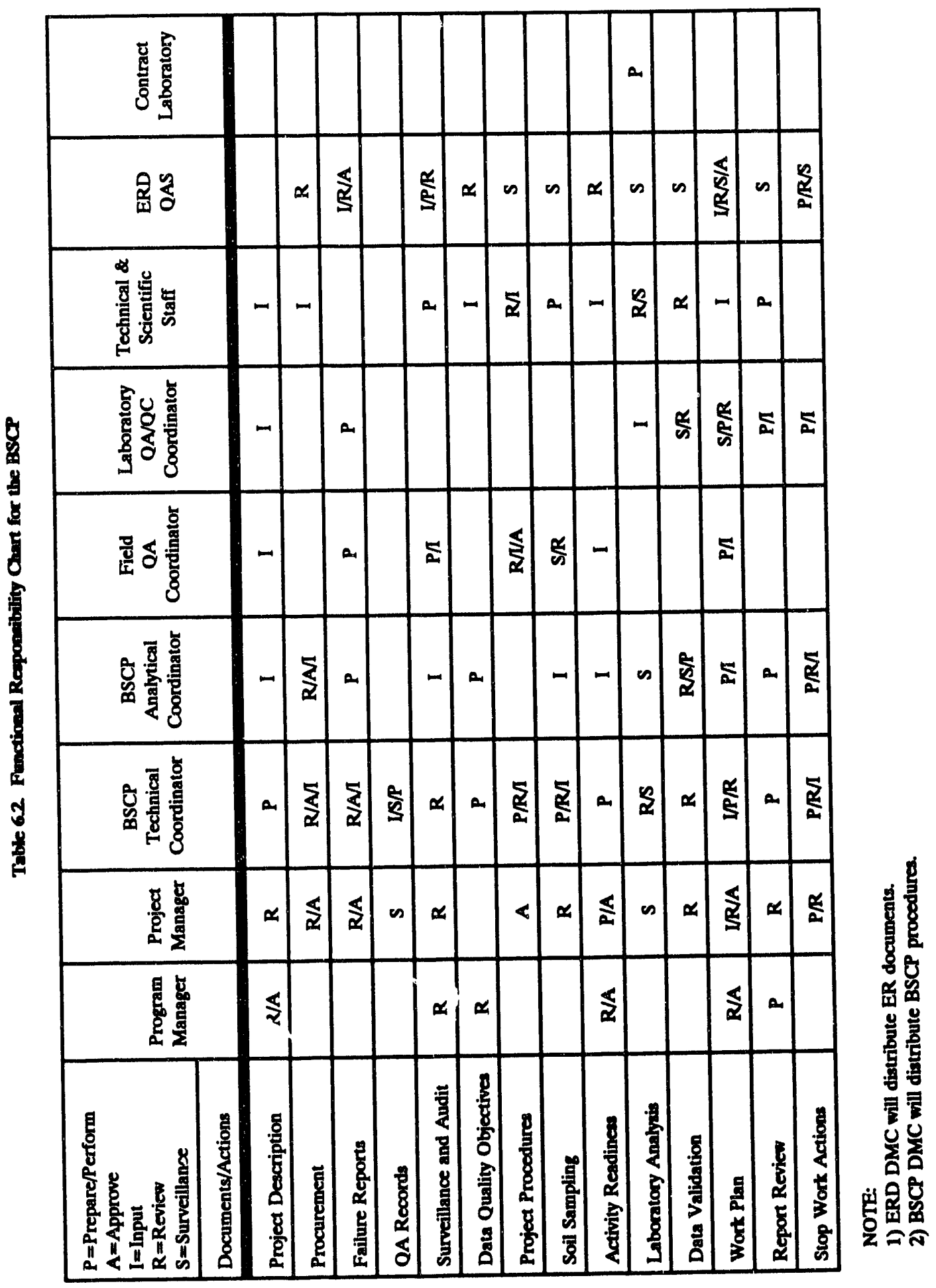


- Ensures that variances, field changes and corrective actions are communicated and discussed with all project staff concerned with data quality.

- Ensures that all general records and project QA records are transferred to the ERDocument Management Center.

\section{BSCP Technical Coordinator}

- Ensures the success and quality of field sampling and statistical analysis activities.

- Ensures coordination between all organizations involved in the data gathering and treatment activities in the project.

- Ensures that all organizations involved in project data activities are aware of their responsibilities and data quality requirements as outlined in the QAPP.

- Assigns project technical activities in accordance with the QAPP.

- Establishes a file for project QA records and ensures their deposition into a records management system.

- Arranges for peer and editorial review of technical reports issued by the project team.

- Ensures project technical reports satisfy the technical requirements of the ERP.

- Ensures that all sampling personnel have adequate technical and health and safety training.

- Initiates a stop work order, if required.

\section{BSCP Analytical Coordinator}

- Ensures quality of laboratory analytical data.

- Ensures proper development of portions of the QAPP dealing with laboratory analytical data.

- Ensures that proper analytical data reporting, validation, and verification are performec' in accordance with the QAPP.

- Ensures that analytical QA records are forwarded to the project DMC.

- Initiates a stop work order, if required.

\section{Analytical QAQC Coordinator}

- Ensures development, maintenance and distribution of the laboratory analytical portion of the QAPP (laboratory QAPP).

- Ensures that the data requirements specified in the laboratory QAPP are known to other project staff.

- Provides liaison and surveillance of the contract analytical laboratory ensuring the data generated satisfy the requirements of the laboratory QAPP.

- Reports any discrepancies and nonconformances in the data generated by the contract laboratory to the Project Manager and Technical Coordinator as soon as possible to allow for quick corrective action discussion and planning.

- Ensures that analytical activities are conducted in accordance with approved analytical SOPs. 


\section{Field QAYC Coordinator}

- Ensures development, maintenance and distribution of procedures for QA activities.

- Ensures that the data requirements specified in the field QAPP activities are provided to trained samplers and other project staff.

- Provides QA liaison and oversight of the sampling crew ensuring the data generated satisfy the requirements of the field activities and laboratory QAPPs.

- Reports any variances and nonconformances in the field activities to the Project Manager and Technical Coordinator as soon as possible to allow for quick corrective action discussion and planning.

- Ensures that field activities are conducted in accordance with project SOPs.

\section{BSCP Technical and Scientific Staff}

- Conduct assigned project activities in accordance with the requirements of the QAPP.

Vendors, Consultants and Subcontractors

- Conduct assigned project activities in accordance with the requirements of the QAPP.

Environmental Restoration and Environmental Sciences Division QA Specialists

- Provide input to development of the QAPP.

- Review and approve the QAPP.

- Conduct verification activities such as audit and surveillance.

- Initiate a stop work order, if required.

\section{ERD QA Manager}

- Reviews all failure reports generated by project activities.

- Reviews the results of all Surveillance and Audits for the BSCP.

- Initiates a stop work order, if required, and approves stop work actions initiated by others.

\subsection{DATA QUALTY OBJECTIVES}

Because this project plan emphasizes ORR background soil characterization, data quality objectives (DQOs) for the BSCP must be EPA DQ Level IV, as required for remedial investigations to be technically comprehensive and defensible. The intended uses of the data derived from this project are very oroad, as described in the Project Objectives (Sect. 1.3). Because this database will be the only comprehensive database for background concentration of organics, metals, nonmetals and radionuclides on the ORR, the data will be used by many on-going and future remediation projects for an extended time period. Therefore, data quality objectives for the BSCP are derived from the intended uses of the data. The intended users and uses of the data are:

1. BSCP statistician will use the analytical data for estimating means, variances, confidence levels, etc. 
2. BSCP risk analyst will use the statistically treated data for estimating the risks associated with the background concentration of the organics, metals, nonmetals, and radionuclides.

3. RI/FS project managers of the ORR facilities will use the statistically treated data and risk analysis results to establish contamination levels relative to background concentrations and risks associated with their operable units/waste area groups.

4. DOE managers and EPA and State Regulators will use the data for establishing clean-up criteria for contaminated sites and evaluating the performance of remedial technologies.

The number of field soil sampling sites, sampling locations, and sample compositing procedure were predetermined on a statistical basis. The analytical data will be used to compute upper and lower tolerance bounds as well as means and standard errors for background constituents. A tolerance bound is a confidence bound for a distribution interval or percentile. Preliminary information about the relative costs and uncertainty of field sampling and laboratory analysis indicates that soil samples should be composited to reduce the variability of survey estimates. The level of compositing was conservatively taken to be three field samples per laboratory sample. And, tolerance bounds will be premised on the underlying constituent distribution having a particular parametric form (such as normal or lognormal), the choice of which will be based on the data itself. A probability analysis of existing soil analysis data indicated that six or seven composited samples would be needed to sample each soil series and horizon with reasonable certainty (Detailed statistical aspects of DQOs are in Appendix D).

A group of risk assessment and soil specialists has identified the potential contaminants of concern (Tables 6.5 through 6.13). Risk assessors will use the background soil concentrations to quantify risks to human health and the environment resulting from natural levels of contaminants. Background risks will be compared with the risks associated with contaminated areas as part of the ongoing and future RI/FS projects on the ORR. To adequately determine background risks, the appropriate data collection and useability criteria have been identified.

Background samples have been defined as critical reference samples for the site-specific RI/FS projects. As such, the analytical data will meet the requirements of EPA's QC level IV as described in subsequent sections. Level IV data are sufficient for risk assessment purposes and all activities associated with the BSCP. To meet the DQO for use in site remedial investigations and feasibility studies, QC Level IV (EPA 1987c) will be applied for the project. EPA-approved methods (Contract Laboratory Program) will be the first choice for chemical analyses if they are available. Commercial laboratories employing these methods will be used for some organics and all metals and radionuclide analyses to be technically and legally defensible, as well as to improve public perception.

Five indicators can be utilized to judge the level of acceptance for DQO level: precision, accuracy, representativeness, completeness, and comparability (PARCC).

Precision: Decision on the desired level of precision was made on the basis of exposure risk for selected elements and compounds. Precision will be measured by the standard deviation and range of the data set (see statistical analysis plan). Replicate quality control samples will 
be submitted from the field to provide a means of determining the precision of the measurement process (see Sect. 6.6.1).

Accuracy: Accuracy is controlled primarily by the laboratory and is reported as bias. Standards, spiked samples, and referee samples are all used to assess and control the accuracy of the results as well as the comparability of the results (see Sect. 6.6.2).

Representativeness: The representativeness of the selected soil samples for analyses will be accomplished by logical site selection and collecting a sufficient number of samples, gamma spectroscopy and VOC screening to reject unrepresentative sites, and minimum sample preparation (see Sect. 6.6.1).

Completeness: The sampling plan of this project is designed to achieve the project objectives with the minimum number of samples needed to yield the desired level of precision for the final results. The probabilities of false positive and false negative answers are specified at the outset. Project coordinators have set a completeness objective at $90 \%$ for both field sampling and laboratory analyses.

Comparability: Standard operating procedures were prepared to ensure that data sets are comparable. To ensure that the samples will be collected from comparable sites and in a comparable manner, a few on-site and off-site locations will be sampled by both on-site and off-site sampling teams in the beginning.

\subsubsection{Quality Assurance Objectives For Field Measurement Data}

The objectives for the BSCP field activities are

1. to select representative sampling sites,

2. to provide representative samples to analytical laboratories, and

3. to prevent cross contamination during sampling and keep sample integrity.

The DQOs of field soil sampling can be met only if the sites sampled are not disturbed by ORR facility activities, off-site farming, nor recreational activities. Any sign of physical disturbance or the presence of man-made organic compounds or radionuclides above global fallout levels will disqualify a site as a candidate.

To meet field data use requirements, field measurement tasks will be assigned the appropriate data quality level. Detailed approaches to meet field DQOs are presented in the following subsections.

\subsubsection{Data quality levels for field data}

Field data quality levels are listed in Table 6.3. Field data (including soil color, texture, depth, approximate location) will consist primarily of descriptive materials and field notes. Descriptive field data will meet the requirements of DQ Level I as defined Data Quality Objectives for Remedial Response Activities (EPA 1987c) because the data will not be quantitative and will be readily available in the field notebook. Samples collected for volatile organic compound and radionuclide analyses for site screening purposes will meet the requirements for Level II. 
Table 6.3. QAVQC levels to which BSCP measurement tasks have been assigned

\begin{tabular}{|c|c|c|}
\hline Parameter & Media & $\begin{array}{c}\mathrm{QC} \\
\text { Level }^{\mathrm{b}}\end{array}$ \\
\hline Soil Description" & Soil & I \\
\hline Volatile Organic Compound, Screening Sample & $\begin{array}{c}\text { Soil } \\
\text { Water Blanks }\end{array}$ & II \\
\hline Radionuclide, Screening Sample & Soil & II \\
\hline Pesticide and Herbicide & $\begin{array}{c}\text { Soil } \\
\text { Water Blanks }\end{array}$ & IV \\
\hline Polynuclear Aromatic Hydrocarbons & $\begin{array}{c}\text { Soil } \\
\text { Water Blanks }\end{array}$ & IV \\
\hline Atomic Absorption, Metals & $\begin{array}{c}\text { Soil } \\
\text { Water Blanks }\end{array}$ & IV \\
\hline $\begin{array}{l}\text { Inductively Coupled Plasma } \\
\text { (ICP), Metals }\end{array}$ & $\begin{array}{c}\text { Soil } \\
\text { Water Blanks }\end{array}$ & IV \\
\hline ICP/Mass Spectrometry, Metals & $\begin{array}{c}\text { Soil } \\
\text { Water Blanks }\end{array}$ & IV \\
\hline Radionuclides & $\begin{array}{c}\text { Soil } \\
\text { Water Blanks }\end{array}$ & IV \\
\hline
\end{tabular}

Field description data are taken in situ for physical characterization of the soil. The number of measurements will depend on the variability of soil properties at each site.

'Anatysis level from Kimbrough et al. (1988), ESP-700, Sect. IV.

\subsubsection{Sample site selection}

The Site Selection Plan is presented in Sect. 5.2. Candidate sampling sites within each geologic formation or group will be selected using statistical methods to minimize sampling bias. Each candidate site will then be field checked by the technical coordinator and the sampling personnel to assure there is no obvious contamination nor indications of present or past activity that would jeopardize the sites' status as a candidate area.

A sample of the A horizon will be collected at each checked site and subjected to field and laboratory screening for manmade radionuclide contaminants using protocols outlined in the Soil Sampling and Analysis Plan (Sect. 5.3) before sample analysis begins. Positive identification of manmade contamination will eliminate the site from further sampling. 


\subsubsection{Field soil sampling procedures}

Soil sampling will be done in accordance with BSCP Procedure BSCP-SOP-01, Rev. 1 (or the most recent version). These soil sampling procedures are being developed and will be maintained and documented in the BSCP-DMC. These procedures are based on recommended techniques taken from appropriate sections of the following documents:

1. A Compendium of Superfund Field Operations Methods, U.S. Environmental Protection Agency, Washington, D. C., EPA/540/P-87/001 (EPA 1987b).

2. Data Quality Objectives for Remedial Response Activities, U.S. Environmental Protection Agency, Washington, D. C., EPA/540/G-87/003 (EPA 1987c).

3. Samplers and Sampling Procedures for Hazardous Waste Streams, U.S. Environmental Protection Agency, Washington, D. C., EPA/600/2-80/018 (EPA 1980c).

4. Engineering Support Branch Standard Operating Procedures and Quality Assurance Manual, U.S. Environmental Protection Agency, Athens, Georgia (EPA 1991d).

5. Soil Investigation and Sampling by Auger Borings, American Society for Testing and Materials, ANSI/ASTM D 1452-80, Philadelphia, Pennsylvania, 1980.

\subsubsection{Prevention of cross contamination}

Cross contamination of samples will be controlled by adherence to established procedures for equipment preparation and decontamination before and after each site is sampled. Separate pieces of equipment will be used to sample individual soil horizons at each site, and all equipment will be cleaned in the soils laboratory (using soap and distilled water) after each work day. Cleaning procedures will be as per ESP-900 (Kimbrough et al. 1988) or a BSCP developed procedure based on ESP-900 should it prove to be inadequate. Cleaning activities will be recorded in the field logbook.

\subsubsection{Sample identification}

Each individual sample will be given a unique number identifier as it is collected in the field. The identifier will be recorded in the field notebook, and the number will be affixed to all sample containers used for that sample. The identifier will appear on the chain of custody documentation accompanying the sample.

\subsubsection{Soil sample numbering system}

The soil sample numbering/identification system will contain the following elements:

Each soil and water/rinsate sample obtained from field operations will be given a unique, sequential number for identification and tracking purposes.

All numbers will be entered appropriately into logbooks and used to reference field notes and verbal descriptions and placed indelibly on all sample bottles/containers. In addition a site location map will be affixed to the logbook showing where samples were taken at the site. 
The sequential numbering system will begin with 1001 for all samples from on-site ORR locations; 2001 for all samples obtained in Anderson County; and 3001 for all samples from Roane County.

Composite samples mixed in the on-site soils laboratory facilities will be given new sequential numbers, beginning with 5001 for on-site ORR locations and 6001 for off-site (Anderson and Roane County) locations.

\subsubsection{Preparation of composite soil samples}

The following procedures will be implemented (BSCP-SOP-01, Rev.1):

Samples from respective $A, B$, and $C$ horizons from three field sites/locations will be composited.

Soil samples will be stored in a refrigerator until all three sites have been sampled.

The three samples for a given horizon will be passed through $4.75 \mathrm{~mm}$ stainless steel sieves in the on-site soils laboratory. An equal amount (about $1 \mathrm{~kg}$ ) of each sieved sample will be composited in a stainless steel container. One-third of each composite sample will be stored in a precleaned glass jar for metals analysis, one-third in a polypropylene bottle for radionuclide analysis, and the remaining one-third will be used for measurement of general soil properties.

The composite samples will be shipped to the designated contract laboratories according to EPA guidelines by the Technical Coordinator. Details are discussed in Sect. 5.4.2.

Holding times for samples to be composited for metals and radionuclide analysis will be less than $15 \%$ of EPA requirements. Holding times are critical only for volatile organic materials (VOCs), which will not be composited in this project.

\subsubsection{Shipping and handling of samples}

Shipping, handling and storage of samples and data resulting from field activities will adhere to custody and safety procedures and will ensure that sample integrity for analytical purposes is maintained. Sample shipping and handling will be done in accordance with ESP 800 (Kimbrough et al. 1988). Sample preservation and choice of container materials will be in accordance with Table 6.4.

\subsubsection{Field variance system}

The sampling procedures outlined in Sect. 5.3.2 allow a certain amount of flexibility to deal with a range of field conditions and the need for variances should be minimal. Variances from established procedures and field changes will be documented using the Field Change Request/Variance Form (Fig. 6.1). Variances are defined as being applicable to field operations on all sites, whereas field changes apply only for specific instances at sites. Most likely, field changes or modifications to standard operating procedures will be necessary to accommodate site conditions. The field samplers will strive to avoid major variances in the procedure if possible. Should variances become necessary, however, the field sampler shall contact the Technical Coordinator to discuss the situation before proceeding. 


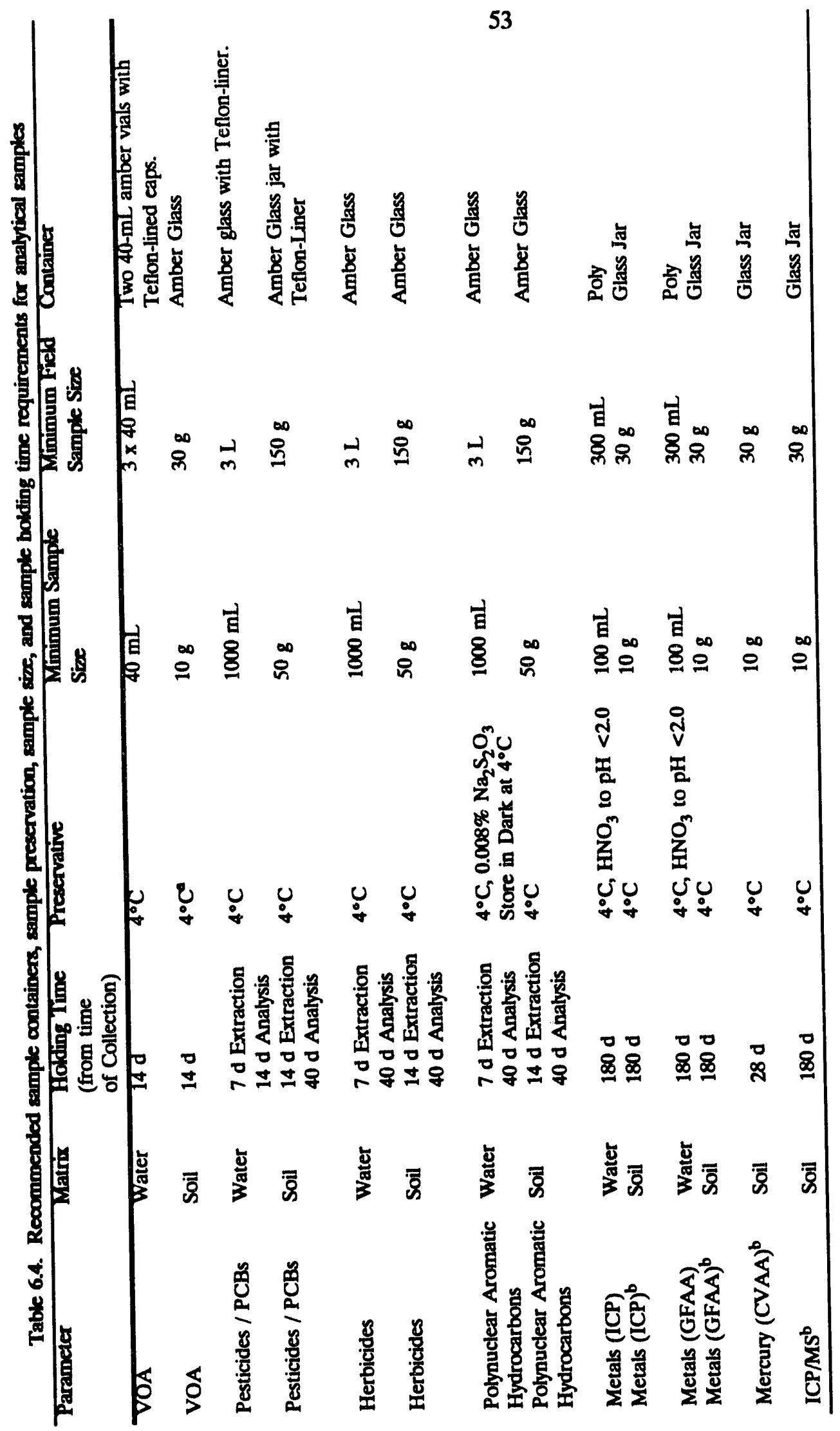




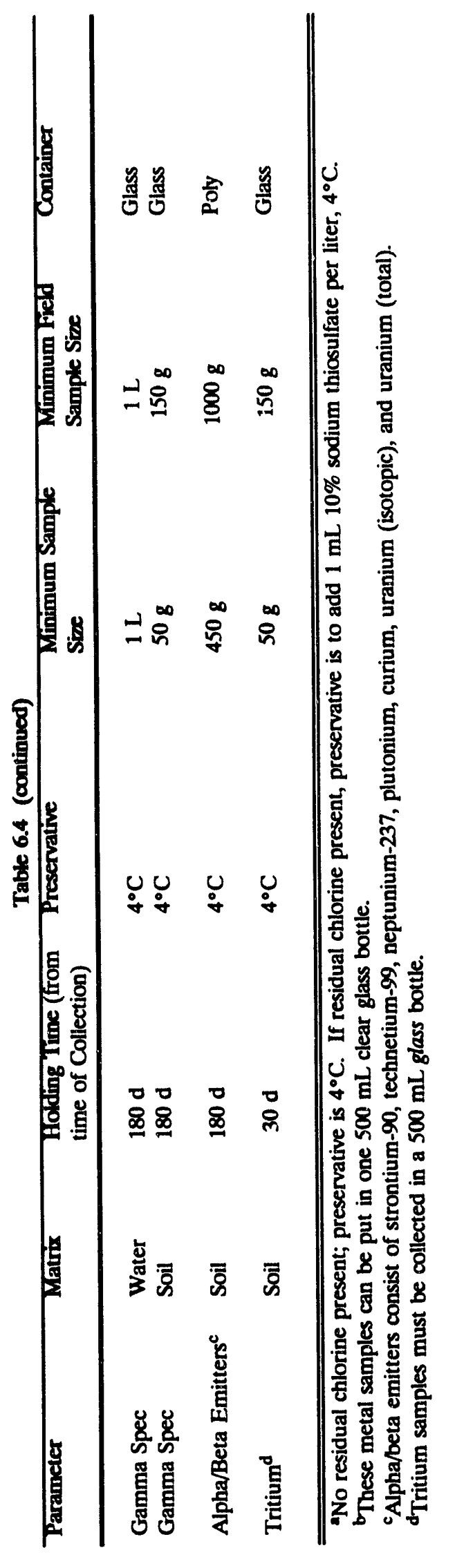




\section{FIELD CHANGE REQUEST/VARIANCE FORM}

Field Change

Change Number:

Variance

Date:

Site:

Affected Method:

Substituted Method:

Impact on Data Quality:

Justification:

Approvals:

Project Manager (Variances Only):

Technical Coordinator:

Date:

Field QA/QC Coordinator:

Date:

Date:

Other Approvals:

Name/Organization:

Date:

Date:

-Approval signatures can be after the fact for field changes but must be in advance for variances.

Fig. 6.1. Field change request/variance form. 
Field changes should be discussed with the Technical Coordinator as soon as possible and noted in the logbook but will not hold up sampling provided the change does not affect the actual collection of the sample. All changes that affect the manner in which the sample is taken or handled will be treated as a variance.

The Technical Coordinator will keep a log of variances/field changes and will hold periodic meetings with the various project coordinators and Project Manager to discuss the implications of the variances/field changes for project data. Results of the discussion will support a decision to resample where the variance/field change occurred.

When it is decided that a variance will become a part of the standard procedures, as a special case procedure for example, the new procedure will be a tached as an addendum to the project plan.

Any variances from the health and safety plan must be approved by the appropriate Health and Safety Officer.

\subsubsection{Field data management}

Field records will be legibly recorded in permanent ink. The records will be complete enough to permit reconstruction of data-gathering activities by a qualified individual (other than the originator). Field notebook entries should be factual, detailed, and objective. The field records will be the basis for later written reports. All entries must be free of terminology that might be ambiguous or inappropriate. The method of data reduction will be identified and recorded. The Technical Coordinator will review the field entries for completeness and accuracy.

Field data sets will contain enough information to clearly identify the sample in the context of the overall project. The data should be traceable to the originating documents. Field data sets will contain a unique sample number, sample location, sampling date and time, names of persons collecting samples, preservation method, and remarks about sample characteristics.

\subsubsection{Sample custody}

Sample custody will be documented from the time the sample is collected in the field until final disposition (archive). The documentation will trace sample possession through all transfers of custody. A sample is considered to be under a person's custody if any of the following conditions are met:

1. the sample is in the person's physical possession,

2. the sample is in line of sight of the person after he/she has taken possession,

3. the sample is secured by that person so any tampering can be detected, or

4. a sample is secured by the person in possession in an area which only authorized personnel can enter.

All sample custody procedures will be in accordance with ESP-500 (Rev. 0), "Manual Chain of Custody Procedures" (Kimbrough et al. 1988). 
6.6.2 Quality Assurance Objectives for Laboratory Measurement Data

The QA objectives for BSCP laboratory measurements are as follows:

- Laboratory data generated will withstand scientific scrutiny and be subject to data validation procedures.

- Data will be gathered using appropriate procedures for chain-of-custody, laboratory analyses, and data reporting.

- Data will be complete and of known precision and accuracy and will be technically and legally defensible.

\subsubsection{Data quality level of analyses}

Data quality levels for BSCP sample analyses are listed in Table 6.3. Analytical laboratory data for site screening samples will meet the requirements of DQ Level II.

Analytical laboratory data will meet the requirements of DQ Level IV. The contract laboratory will use standard EPA methods, as EPA Method 6010 in EPA (1991e) and AEC (1972) and those in the Contract Laboratory Program (CLP). Level IV provides for a wide array of analytes with known accuracy and precision accompanied by rigorous QAVQC protocols and documentation which provides analytical data that is defensible along with complete raw data packages. The corresponding level of analysis pertaining to field data is discussed in Sect. 6.6.

To satisfy DQ Level IV QAVC requirements $10 \%$ of the total number of samples taken will be duplicate samples for QAVC purposes. Three (3) reference soil samples will be submitted for analysis with the data to be compared to published results for those standards. Four (4) distilled water blanks will be submitted to verify the quality of the laboratory distilled water supply used for cleaning the sampling equipment. Twelve (12) equipment rinsate blanks will be submitted to verify the effectiveness of the equipment cleaning procedures. Uncomposited soil samples undergoing analysis for VOCs and tritium will be analyzed in accordance with Level II data protocols and documentation requirements.

Data quality levels for field data are discussed in Sect. 6.6.1.1.

\subsubsection{Calibration procedure and frequency}

For the BSCP measurement instrumentation requiring calibration will be almost exclusively laboratory analytical instrumentation. The exception will be beta-gamma radiation meters used on the ORR for site survey purposes only. Sampling crews will use ORNL survey meters that are calibrated in accordance with appropriate instrument-specific calibration procedures contained in the ORNL Radiation Standards Calibration Laboratory (RASCAL) Standard Operating Procedure Series 04-60. Calibration procedures and frequency for betagamma survey instruments are determined by the ORNL Health Physics Department and are executed by ESD HP representatives who keep calibration records for their instruments. The results of field calibrations of beta-gamma meters will be recorded in the field logbooks by field crew members. 
Laboratory analytical instrumentation will be controlled through a calibration program that is in accordance with the following.

Each instrument or analytical measurement system must be calibrated before use or, in some cases, the calibration checked before use. Records will be maintained by the responsible laboratory. Typically, a calibration procedure begins with requirements given in the analytical method and is expanded to cover instrument-specific needs and laboratory practices. For each method, the laboratory must have the detailed calibration procedure in a Standard Operating Procedure (SOP) and a summary in the laboratory quality assurance plan. For GC/MS analysis, the most current CLP SOW is the method specified, so calibration must follow CLP criteria. Standards used to calibrate an instrument must be NIST-or EPA-traceable, and the laboratory must maintain supporting documentation.

\subsection{Analytical procedures}

The objective of this section is to provide the analytical procedures required for the analysis of soil samples collected for the Background Soil Characterization Project. The choice of analytical procedures has been based on assumptions detailed in Sect. 5.3.3 of this plan. The analytical procedures have been taken from EPA Contract Laboratory Program Statement of Work (CLP-SOW), March 1990 (EPA 1990a,b); EPA (1991e); and AEC (1972).

\section{Onganics}

The analysis of volatile organic compounds (VOCs) will be performed on all noncomposited surface soil samples as a screen to determine whether there was any disposal of wastes at the site or evidence of contaminated groundwater plumes under the site. The volatile organic analyses will be performed according to Level II/B quality control. The analytical method to be used is a gas chromatography/mass spectrometry technique (EPA Method 8240, see Table 6.5).

The analysis of pesticides, polychlorinated biphenyls (PCBs), and herbicides shall be performed on surface soil samples. The laboratory will analyze the samples for both organochlorine pesticides and PCBs [using EPA CLP SOW 3/90 (EPA 1990a)] and herbicides (using EPA Method 8150). The preparation methods for herbicides will employ EPA Methods 3550 (soil) and 3510 (water) as the preparation procedure. (See Tables 6.6 and 6.7 for the analytes and detection limits of these methods).

The analysis of polynuclear aromatic hydrocarbons (PAHs) will be performed on composite samples using EPA Method 8310. Samples will be prepared using EPA Method 3550 (soils) and 3510 (water). (See Table 6.8 for the analytes and detection limits of these methods). 
Table 6.5. Analyte list for volatile organics by EPA-8240 using the target compound list

\begin{tabular}{|c|c|c|}
\hline \multirow{2}{*}{ ANALYTE } & \multicolumn{2}{|c|}{ REQUIRED DETECTION LIMIT } \\
\hline & $\begin{array}{l}\text { Water } \\
(\mu \notin \Omega)\end{array}$ & $\begin{array}{c}\text { Soil } \\
(\mu \mathrm{g} / \mathrm{kg})\end{array}$ \\
\hline Chloromethane & 10 & 10 \\
\hline Bromomethane & 10 & 10 \\
\hline Vinyl Chloride & 10 & 10 \\
\hline Chloroethane & 10 & 10 \\
\hline Methylene Chloride & 5 & 5 \\
\hline Acetone & 100 & 100 \\
\hline Carbon Disulfide & 5 & 5 \\
\hline 1, 1-Dichloroethene & 5 & 5 \\
\hline 1, 1-Dichloroethane & 5 & 5 \\
\hline 1, 2-Dichloroethene (total) & 5 & 5 \\
\hline Chloroform & 5 & 5 \\
\hline 1, 2-Dichloroethane & 5 & 5 \\
\hline 2-Butanone & 100 & 100 \\
\hline 1, 1, 1-Trichloroethane & 5 & 5 \\
\hline Carbon Tetrachloride & 5 & 5 \\
\hline Bromodichloromethane & 5 & 5 \\
\hline 1, 2-Dichloropropane & 5 & 5 \\
\hline cis-1, 3-Dichloropropene & 5 & 5 \\
\hline Trichloroethene & 5 & 5 \\
\hline Dibromochloromethane & 5 & 5 \\
\hline 1, 1, 2-Trichloroethane & 5 & 5 \\
\hline Benzene & 5 & 5 \\
\hline trans-1, 3-Dichloropropene & 5 & 5 \\
\hline Bromoform & 5 & 5 \\
\hline 4-Methyl-2-pentanone & 50 & so \\
\hline 2-Hexanone & 50 & 50 \\
\hline Tetrachloroethene & 5 & 5 \\
\hline Toluene & 5 & 5 \\
\hline 1, 1, 2, 2-Tetrachloroethane & 5 & 5 \\
\hline Chlorobenzene & 5 & 5 \\
\hline Etbylbenzene & 5 & 5 \\
\hline Styrene & 5 & 5 \\
\hline Xylenes (total) & 5 & 5 \\
\hline
\end{tabular}


60

Table 6.6. Analyte list for organochlorine pesticides/PCBs by EPA-CLP SOW (3/90), (EPA 1990a)

\begin{tabular}{|c|c|c|}
\hline Analyte & $\begin{array}{c}\text { Quantitation } \\
\text { Limit } \\
(\mu \mathrm{g} \Omega \mathrm{L}) \\
\end{array}$ & $\begin{array}{c}\text { Quantitation } \\
\text { Limitit }^{1} \\
(\mu \mathrm{g} / \mathbf{k g}) \\
\end{array}$ \\
\hline Aldrin & 0.05 & 1.7 \\
\hline a-BHC & 0.05 & 1.7 \\
\hline b-BHC & 0.05 & 1.7 \\
\hline d-BHC & 0.05 & 1.7 \\
\hline g-BHC (Lindane) & 0.05 & 1.7 \\
\hline 4, 4'-DDD & 0.1 & 3.3 \\
\hline 4, 4'-DDE & 0.1 & 3.3 \\
\hline 4, 4'-DDT & 0.1 & 3.3 \\
\hline Dieldrin & 0.1 & 3.3 \\
\hline Endosulfan I & 0.05 & 1.7 \\
\hline Endosulfan II & 0.1 & 3.3 \\
\hline Endosulfan sulfate & 0.1 & 3.3 \\
\hline Endrin & 0.1 & 3.3 \\
\hline Endrin aldehyde & 0.1 & 3.3 \\
\hline Heptachlor & 0.05 & 1.7 \\
\hline Heptachlor epoxide & 0.05 & 1.7 \\
\hline Methoxychlor & 0.05 & 17.0 \\
\hline Toxaphene & 5.0 & 170.0 \\
\hline Endrin Ketone & 0.1 & 3.3 \\
\hline Alpha-chlordane & 0.05 & 1.7 \\
\hline Gamma-chlordane & 0.05 & 1.7 \\
\hline Aroclor-1016 & 1.0 & 33.0 \\
\hline Aroclor-1221 & 1.0 & 33.0 \\
\hline Aroclor-1232 & 2.0 & 67.0 \\
\hline Aroclor-1242 & 1.0 & 33.0 \\
\hline Aroclor-1248 & 1.0 & 33.0 \\
\hline Aroclor-1254 & 1.0 & 33.0 \\
\hline Aroclor -1260 & 1.0 & 33.0 \\
\hline
\end{tabular}

The detection limit is on a wet-weight basis. 
61

Table 6.7. Analyte list for herbicides by EPA-8150

\begin{tabular}{||l|c|c|}
\hline \multicolumn{1}{|c|}{ Analyte } & $\begin{array}{c}\text { Estimated } \\
\text { Detection } \\
\text { Limit } \\
(\mu \mathrm{g} / \mathrm{L})\end{array}$ & $\begin{array}{c}\text { Estimated } \\
\text { Detection } \\
\text { Limit }^{1} \\
(\mu \mathrm{g} / \mathrm{kg})\end{array}$ \\
\hline \hline $2,4-\mathrm{D}$ & 12 & 804 \\
\hline $2,4-\mathrm{DB}$ & 9.1 & 610 \\
\hline $2,4,5-\mathrm{T}$ & 2.0 & 134 \\
\hline $2,4,5-\mathrm{TP}$ (Silvex) & 1.7 & 114 \\
\hline Dalapon & 58 & 3886 \\
\hline Dicamba & 2.7 & 181 \\
\hline Dichloroprop & 6.5 & 435.5 \\
\hline Dinoseb & 0.7 & 46.9 \\
\hline MCPA & 2490 & 167,000 \\
\hline MCPP & 1920 & 129,000 \\
\hline
\end{tabular}

'The detection limit is on a wet-weight basis. 
Table 6.8. Analyte list for polyaromatic hydrocarbons by EPA-8310

\begin{tabular}{||l|c|c|}
\hline \multicolumn{1}{|c|}{ Analyte } & $\begin{array}{c}\text { Estimated Detection } \\
\text { Limit }(\mu \mathrm{g} / \mathrm{L})\end{array}$ & $\begin{array}{c}\text { Estimated Detection } \\
\text { Limit }(\mu \mathrm{g} / \mathrm{kg})^{1}\end{array}$ \\
\hline Acenaphthene & 1.8 & 1206 \\
\hline Acenaphtylene & 2.3 & 1541 \\
\hline Anthracene & 0.66 & 442.2 \\
\hline Benzo(a)anthracene & 0.013 & 8.71 \\
\hline Benzo(a)pyrene & 0.023 & 15.41 \\
\hline Benzo(b)fluoranthene & 0.018 & 12.06 \\
\hline Benzo(k)fluoranthene & 0.017 & 11.39 \\
\hline Benzo(ghi)perylene & 0.076 & 50.92 \\
\hline Chrysene & 0.15 & 100.5 \\
\hline Dibenzo(a,h)anthracene & 0.030 & 20.1 \\
\hline Fluoranthene & 0.21 & 140.7 \\
\hline Fluorene & 0.21 & 140.7 \\
\hline Indeno(1,2,3-cd)pyrene & 0.043 & 28.81 \\
\hline Naphthalene & 1.8 & 1206 \\
\hline Phenanthrene & 0.64 & 428.8 \\
\hline Pyrene & 0.64 & 180.9 \\
\hline
\end{tabular}

'The detection limit is determined on a wet-weight basis. 


\section{Inonganics}

Five analytical techniques will be used to analyze metals for this project. We will be using Cold Vapor Atomic Absorption (CVAA), Flame Atomic Absorption (FAA), Graphite Furnace Atomic Absorption (GFAA), Inductively Coupled Plasma (ICP), and Inductively Coupled Plasma/Mass Spectrometry (ICP/MS). Tables 6.9-6.12 provide the analytical methods and detection limits for the analytes of interest. The preparation methods for lithium, silicon, and strontium, analyzed by ICP, need to be provided by the laboratory for approval prior to receipt of samples.

In addition to the above, the following anions will be analyzed in soil: nitrate, sulfate, and cyanide. These will be performed according to the methods listed in Table 6.12. The detection limits for these methods shall be provided by the laboratory for approval prior to receipt of samples.

\section{Radionuclides}

The radionuclides to be analyzed for this project are listed in Table 6.13. This table provides the suggested method and detection limit for each radionuclide. For the radionuclides that do not have methods, the laboratory shall provide methods for approval (the total dissolution of alpha and beta emitter is required). The contracted laboratory will be required to provide the methods and detection limits for each analyte prior to receipt of samples. Gamma screening will be done at the ESD gamma spectroscopy laboratory of ORNL.

\subsubsection{Sample turnaround time}

Sample turnaround time will be mandated by appropriate clauses in the contract with the laboratories performing the analyses. Such mandate will be driven by shelf life and sample holding times for the various analyses as listed in Table 6.4 in order to obtain meaningful data from the samples. The mandate will also take into account the project schedule as outlined in Sect. 5.1.2 in order to keep the schedule for project deliverables on time.

\subsubsection{Data Reduction, Validation and Reporting}

\subsubsection{Field data reduction and reporting}

Field data generated by the BSCP will be primarily descriptive in nature and will be in the form of handwritten notes recorded in the field notebooks. Such data will not be subjected to any kind of mathematical reduction techniques. These field data will be validated per DQ Level I as specified in Sect. 6.6. The nature and format of the descriptions generated will be obvious but the person entering the data will flag the description of each new sample in the margin with the comment "Begin sample ___ description." If new data or comments are generated for that sample later, the margin comment will read "Additional data for sample material is recorded.

(Page _ _. The page number will be in reference to the page where the original

The field notebooks will be reviewed weekly and signed off by the BSCP Technical Coordinator. Verification and validation of the field data (soil description and classification) 
will result from interactions between the Technical Coordinator and the field staff during technical report preparation. A standard soil taxonomy (U.S.D.A. 1975) will be used as a validation criterion for the field data. Technical reports will be reviewed by the ER Manager, BSCP Manager, and the ESD/ER editorial staffs and will be subject to peer review for technical content before publication. Scheduling of the delivery of the technical reports resulting from BSCP data is given in Sect. 5.1.2.

All project records and data will be maintained to support report generation, risk assessment, and any further administrative or legal actions (Sect. 7).

Table 6.9. Analyte list for atomic absorption metals

\begin{tabular}{|c|c|c|c|}
\hline Analyte & $\begin{array}{c}\text { EPA } \\
\text { Method }\end{array}$ & $\begin{array}{c}\text { Estimated } \\
\text { Detection } \\
\text { Limit } \\
(\mu \mathrm{g} / \mathrm{L})\end{array}$ & $\begin{array}{c}\text { Detection } \\
\text { Limit }^{1} \\
(\mu \mathrm{g} / \mathrm{kg})\end{array}$ \\
\hline \multicolumn{4}{|l|}{ Graphite Furnace } \\
\hline \multirow[t]{2}{*}{ Antimony } & 204.2 CLP-M & 3 & 300 \\
\hline & 206.2 CLP-M & 1 & 100 \\
\hline Cadmium & 223.2 CLP-M & 0.1 & 10 \\
\hline Chromium & 218.2 CLP-M & 1 & 100 \\
\hline Lead & 239.2 CLP-M & 1 & 100 \\
\hline \multirow[t]{2}{*}{ Selenium } & 270.2 CLP-M & 2 & 200 \\
\hline & 279.2 CLP-M & 1 & 100 \\
\hline \multicolumn{4}{|l|}{ Flame } \\
\hline Osmium $^{2}$ & 7550 & 300 & 30,000 \\
\hline \multicolumn{4}{|l|}{ Cold Vapor } \\
\hline Mercury & 245.5 CLP-M & 0.2 & 20 \\
\hline
\end{tabular}

'Soil detection limit calculated based on 1 gram sample adjusted to $100 \mathrm{~mL}$ volume.

2Preparation of Osmium and mercury is given in analysis method. 
Table 6.10. Analyte list for inductively coupled plasma metals

\begin{tabular}{|c|c|c|c|}
\hline Analyte & $\begin{array}{c}\text { EPA } \\
\text { Method }\end{array}$ & $\begin{array}{c}\text { Estimated } \\
\text { Detection } \\
\text { Limit } \\
(\mu \mathrm{g} / \mathrm{L})\end{array}$ & $\begin{array}{c}\text { Estimated } \\
\text { Detection } \\
\text { Limit }^{1} \\
(\mu \mathrm{g} / \mathrm{kg})\end{array}$ \\
\hline Aluminum & 200.7 CLP-M & 45 & 4500 \\
\hline Barium & 200.7 CLP-M & 2 & 200 \\
\hline Beryllium & 200.7 CLP.M & 0.3 & 30 \\
\hline Boron & 200.7 CLP-M & 5 & 500 \\
\hline Calcium & 200.7 CLP-M & 10 & 1000 \\
\hline Cobalt & 200.7 CLP-M & 7 & 700 \\
\hline Copper & 200.7 CLP-M & 6 & 600 \\
\hline Iron & 200.7 CLP-M & 7 & 700 \\
\hline Lithium & 200.7 CLP-M ${ }^{2}$ & 5 & 500 \\
\hline Magnesium & 200.7 CLP-M & 30 & 3000 . \\
\hline Manganese & 200.7 CLP-M & 2 & 200 \\
\hline Molybdenum & 200.7 CLP-M & 8 & 800 \\
\hline Nickel & 200.7 CLP-M & 15 & 1500 \\
\hline Potassium $^{3}$ & 200.7 CLP-M & & \\
\hline Silicon & 200.7 CLP-M & 58 & 5800 \\
\hline Silver & 200.7 CLP-M & 7 & 700 \\
\hline Strontium & 200.7 CLP-M $^{1}$ & 3 & 300 \\
\hline Vanadium & 200.7 CLP-M & 8 & 800 \\
\hline Zinc & 200.7 CLP-M & 2 & 200 \\
\hline
\end{tabular}

'Soil detection limit calculated based on 1 gram sample adjusted to $100 \mathrm{~mL}$ volume.

'This method has not been promulgated as of this writing.

${ }^{3}$ Dependent on operating conditions and plasma position. 
Table 6.11. Analyte list for inductively coupled plasma/mass spectrometry metals

\begin{tabular}{||l|c|c|c||}
\hline \multicolumn{1}{|c|}{ Analyte } & \multicolumn{1}{|c|}{$\begin{array}{c}\text { EPA } \\
\text { Method }\end{array}$} & $\begin{array}{c}\text { Estimated } \\
\text { Detection } \\
\text { Limit } \\
(\mu \mathrm{g} / \mathrm{L})\end{array}$ & $\begin{array}{c}\text { Estimated } \\
\text { Detection } \\
\text { Limit }^{1} \\
(\mu \mathrm{g} / \mathrm{kg})\end{array}$ \\
\hline Aluminum & 6020 CLP-M & 4500 \\
\hline Antimony & $6020 \mathrm{CLP}-\mathrm{M}$ & 0.1 & 3200 \\
\hline Arsenic & $6020 \mathrm{CLP}-\mathrm{M}$ & 0.4 & 5300 \\
\hline Barium & $6020 \mathrm{CLP}-\mathrm{M}$ & 0.02 & 200 \\
\hline Beryllium & $6020 \mathrm{CLP}-\mathrm{M}$ & 0.1 & 30 \\
\hline Cadmium & $6020 \mathrm{CLP}-\mathrm{M}$ & 0.07 & 400 \\
\hline Chromium & $6020 \mathrm{CLP}-\mathrm{M}$ & 0.02 & 700 \\
\hline Cobalt & $6020 \mathrm{CLP}-\mathrm{M}$ & 0.01 & 700 \\
\hline Copper & $6020 \mathrm{CLP}-\mathrm{M}$ & 0.03 & 600 \\
\hline Lead & $6020 \mathrm{CLP}-\mathrm{M}$ & 0.02 & 4200 \\
\hline Manganese & $6020 \mathrm{CLP}-\mathrm{M}$ & 0.04 & 200 \\
\hline Nickel & $6020 \mathrm{CLP}-\mathrm{M}$ & 0.3 & 1500 \\
\hline Silver & $6020 \mathrm{CLP}-\mathrm{M}$ & 0.04 & 700 \\
\hline Thallium & $6020 \mathrm{CLP}-\mathrm{M}$ & 0.05 & 4000 \\
\hline Zinc & $6020 \mathrm{CLP}-\mathrm{M}$ & 0.08 & 200 \\
\hline
\end{tabular}

'Soil detection limit calculated based on 1 gram sample adjusted to $100 \mathrm{~mL}$ volume.

${ }^{2}$ This method has not been released by the U.S. EPA for promulgation. We are requesting this method since it will be used on future anatytical activities; therefore, background information from this method will be important.

Table 6.12. Analyte list for inorganic parameters

\begin{tabular}{|l|c|}
\hline \multicolumn{1}{|c|}{ Analyte } & Analysis Method \\
\hline \hline Nitrate & 9200 \\
\hline Sulfate & 9038 \\
\hline Cyanide & 335.2 CLP-M \\
\hline
\end{tabular}


Table 6.13. Analyte list for radionuclides

\begin{tabular}{|c|c|c|c|}
\hline Analyte & $\begin{array}{l}\text { Analysis } \\
\text { Method }\end{array}$ & $\begin{array}{c}\text { Estimated } \\
\text { Detection } \\
\text { Limit }\end{array}$ & Reference \\
\hline Strontium-90 & 905.0 & $2 \mathrm{pCi} / \mathrm{g}$ & EPA $600 / 4-80-032$ \\
\hline Technetium-99 & & $2 \mathrm{pCi} / \mathrm{g}$ & $\begin{array}{l}\text { AEC (1972) } \\
\text { Manual }\end{array}$ \\
\hline Radium-226 & $904.0(903.1)$ & $20 \mathrm{pCi} / \mathrm{g}$ & EPA $600 / 4-80-032$ \\
\hline Tritium & 906.0 & $1 \mathrm{pCi} / \mathrm{g}$ & EPA $600 / 4-80-032$ \\
\hline Cesium-137 & 901.1 & $3 \mathrm{pCi} / \mathrm{g}$ & EPA $600 / 4-80-032$ \\
\hline Thorium-228, 230, 232, 234 & 901.1 & $0.1 \mathrm{pCi} / \mathrm{g}$ & EPA $600 / 4-80-032$ \\
\hline Cobalt-60 & 901.1 & $0.5 \mathrm{pCi} / \mathrm{g}$ & EPA $600 / 4-80-032$ \\
\hline Zinc-65 & 901.1 & $1 \mathrm{pCi} / \mathrm{g}$ & EPA $600 / 4-80-032$ \\
\hline Zirconium-95 & 901.1 & $1 \mathrm{pCi} / \mathrm{g}$ & EPA $600 / 4-80-032$ \\
\hline Niobium-95 & 901.1 & $1 \mathrm{pCi} / \mathrm{g}$ & EPA $600 / 4-80-032$ \\
\hline Barium-133 & 901.1 & $1 \mathrm{pCi} / \mathrm{g}$ & EPA $600 / 4-80-032$ \\
\hline Amercium-241 & 901.1 & $0.1 \mathrm{pCi} / \mathrm{g}$ & EPA $600 / 4-80-032$ \\
\hline Chromium-51 & 901.1 & $0.2 \mathrm{pCi} / \mathrm{g}$ & EPA $600 / 4-80-032$ \\
\hline Cobalt-57 & 901.1 & $0.2 \mathrm{pCi} / \mathrm{g}$ & EPA $600 / 4-80-032$ \\
\hline Potassium-40 & 901.1 & NA & EPA $600 / 4-80-032$ \\
\hline Ruthenium-103 & 901.1 & $1 \mathrm{pCi} / \mathrm{g}$ & EPA $600 / 4-80-032$ \\
\hline Europium-152, 154, 155 & 901.1 & $0.2 \mathrm{pCi} / \mathrm{g}$ & EPA 600/4-80-032 \\
\hline Hafnium-181 & 901.1 & $0.2 \mathrm{pCi} / \mathrm{g}$ & EPA 600/4-80-032 \\
\hline Iridium-192 & 901.1 & $0.2 \mathrm{pCi} / \mathrm{g}$ & EPA 600/4-80-032 \\
\hline $\begin{array}{l}\text { Uranium-233, 234, 235, 236, } \\
238\end{array}$ & 907.0 & $0.1 \mathrm{pCi} / \mathrm{g}$ & EPA $600 / 4-80-032$ \\
\hline Uranium (total) & & $1 \mathrm{pCi} / \mathrm{g}$ & \\
\hline Neptunium-237 & 907.0 & $0.1 \mathrm{pCi} / \mathrm{g}$ & EPA $600 / 4-80-032$ \\
\hline Plutonium-238, 239, 240 & 907.0 & $0.1 \mathrm{pCi} / \mathrm{g}$ & EPA $600 / 4-80-032$ \\
\hline Curium-243, 244, 245, 247 & 907.0 & $0.2 \mathrm{pCi} / \mathrm{g}$ & EPA $600 / 4-80-032$ \\
\hline
\end{tabular}

AEC 1972, Health and Safery Laboratory Procedures Manual, Health and Safety Laboratory, New Yort, NY.

EPA 1980b, Prescribed Procedures for Measurement of Radioactiving in Drinking Water, Environmental Monitoring and Support Laboratory, Cincinnati, $\mathrm{OH}$. 
6.6.3.2 Laboratory data reduction and reporting

The specific deliverables for this project are based on the data deliverables detailed in the CLP Statement of Work, March 1990 (EPA 1990a,b). For analytical parameters not under the CLP Statement of Work, the deliverables included in Table 6.14, plus the raw data for all samples, blanks, standards, and QC samples are required. Photocopied pages of laboratory notebooks, worksheets which refer to sample weights, dilutions, concentration, data reduction, sample cleanup, sample prep logs/worksheets, and instrument calibration logs. All Laboratory Control Sample (LCS) results and/or control charts must be supplied with the data package.

- All data shall be included in data packages regardless of CLP or other QA/QC noncompliances, such as missed holding times.

- Blank corrections (field blank, trip blank, method blank, etc.) are not allowed. Trip blanks will be used for transportation of samples for VOC analysis.

- A narrative shall be provided with each data package. This narrative will describe circumstances where the QC criteria were not met and any instrumental, technical, and administrative problems encountered during the analysis of the samples. In addition, the corrective actions and resolutions to these problems shall be provided.

- All entries and corrections must be made in indelible ink with a single line drawn through errors and changes initialed and dated by the individual making the changes.

- All data shall be qualified using the nomenclature and "flags" described in the USEPA CLP Statement of Work (3/90), (EPA 1990a). Other flags used by the laboratory must be described and provided in the data package.

- All chain-of-custody forms and pertinent shipping information shall be included in the data package.

- All results shall be expressed in the significant figures and units discussed in the EPA CLP Statement of Work (3/90), (EPA 1990b), for inorganics and organics.

- Percent moisture shall be reported for all soil samples.

\subsubsection{Data validation}

The data shall be shipped to the Analytical Project Office where the data will be screened against the project plan and statement of work (Contract Compliance Screen). Upon completion of the Contract Compliance Screen, the data will be delivered for validation.

Data validation is in the process of screening data and accepting, rejecting, or qualifying data on the basis of sound criteria. At a minimum, data generated from Level IV/D analyses shall be validated per the CLP criteria as outlined in the following documents:

- $\quad$ EPA 1991b, Hazardous Site Control Division, Laboratory Data Validation Functional Guidelines for Evaluating Organic Analyses, latest edition. 
- EPA 1991c, Hazardous Site Control Division, Laboratory Data Validation Functional Guidelines for Evaluating Inorganic Analyses, latest edition.

- Radionuclides will be validated against the guidelines provided in Table 6.14.

- The LCS validation guidelines for Level IV/D will follow Level C guidelines which are outlined below.

The prime contractor or the laboratory may submit a validation procedure for methods not encompassed by the CLP guidelines for approval by the Analytical Project Office.

Pesticide/Polychlorinated Biphenyl/Herbicide/Polynuclear Anomatic Hydrocarton Validation Guidelines

Holding Times-Ensure that holding times have been met and that samples have been properly preserved. Both samples and extracts must be preserved at $4^{\circ} \mathrm{C}$. Water samples must be extracted within 7 days of collection, and analyzed within $\mathbf{4 0}$ days of the extraction date. Soil samples must be extracted within 14 days of sample collection and analyzed within 40 days of the extraction date.

If holding time was exceeded or samples were not preserved:

- Document that samples were not properly preserved.

- Document that holding times were exceeded.

- $\quad$ Flag all positive results as estimated (J).

- Flag all associated sample quantitation limits as estimated (UJ).

If holding time is grossly exceeded:

- Use best professional judgment as to data reliability. Reviewer may flag all associated nondetect data as unusable (R).

Calibration-Ensure that an External Calibration Procedure is used for quantitation by the laboratory.

If Calibration Factors are used for sample quantitation:

- For initial calibration, all \% RSD must be less than or equal to $20 \%$.

- For continuing calibration, all \% D must be less than $15 \%$.

If Linear Regression is used for sample quantitation:

- Verification of the calibration curve is required, and the correlation coefficient must be greater than or equal to 0.995 . 
Table 6.14. Deliverables for the BSCP

\begin{tabular}{|c|c|c|}
\hline & Method Requirements & Deliverables \\
\hline \multicolumn{2}{|c|}{ Requirements for all methods: } & \multirow{4}{*}{$\begin{array}{l}\text { Signed chain of custody forms } \\
\text { Case narratives } \\
\text { Control Charts }\end{array}$} \\
\hline- & $\begin{array}{l}\text { Holding time information and } \\
\text { methods requested }\end{array}$ & \\
\hline- & $\begin{array}{l}\text { Discussion of laboratory problems, } \\
\text { including any laboratory problems }\end{array}$ & \\
\hline- & $\begin{array}{l}\text { LCS with results on control charts. } \\
\text { Rur with each batch of samples } \\
\text { processed }\end{array}$ & \\
\hline \multicolumn{2}{|c|}{ Onganics } & \multirow{3}{*}{$\begin{array}{l}\text { CLP Form } 1 \text { or equivalent } \\
\text { CLP Form } 2 \text { or equivalent }\end{array}$} \\
\hline & Sample results, including TICs & \\
\hline & $\begin{array}{l}\text { Surrogate recoveries. Surrogates to } \\
\text { be used in volatiles, semivolatiles, } \\
\text { pesticides/PCBs. For volatiles by } \\
\text { GC, surrogate names should } \\
\text { reflect the appropriate surrogate } \\
\text { used }\end{array}$ & \\
\hline- & $\begin{array}{l}\text { Matrix spike/spike duplicate. One } \\
\text { spike and spike duplicate per } 20 \\
\text { samples of similar matrix }\end{array}$ & CLP Form 3 or equivalent \\
\hline- & Method blank data & CLP Form 4 or equivalent \\
\hline- & $\begin{array}{l}\text { GC/MS tuning for } \\
\text { volatiles/semivolatiles }\end{array}$ & CLP Form 5 or equivalent \\
\hline- & $\begin{array}{l}\text { GC/MS initial calibration data for } \\
\text { volatiles/semi-volatiles }\end{array}$ & CLP Form 6 or equivalent \\
\hline- & Pesticide/PCB calibration data & CLP Form 9 or equivalent \\
\hline - & $\begin{array}{l}\text { For volatiles by } G C \text {, initial } \\
\text { calibration data } \\
\text { If calibration factors are used }\end{array}$ & $\begin{array}{l}\text { CLP Form } 8 D \text { or equivalent, listing each } \\
\text { analyte, the concentration of each stan- } \\
\text { dard, the relative calibration factor, the } \\
\text { mean calibration factor, and the \% RSK }\end{array}$ \\
\hline & If calibration curve is used & $\begin{array}{l}\text { A plot of the calibration curve is } \\
\text { required, and a linear determination with } \\
\text { flagged correlation coefficient, if it is less } \\
\text { than } 0.995 \text {. }\end{array}$ \\
\hline
\end{tabular}


Table 6.14. (continued)

\begin{tabular}{|c|c|c|}
\hline- & $\begin{array}{l}\text { For volatiles by GC; continuing } \\
\text { calibration data } \\
\text { If calibration factors are used, } \\
\text { calibration factors and their } \\
\text { percent differences from the initial } \\
\text { calibration must be reported. } \\
\text { Retention time (RT) windows and } \\
\text { analyte RTs for the analytes must } \\
\text { be included in this form. }\end{array}$ & CLP Form 9 or equivalent \\
\hline- & $\begin{array}{l}\text { GC/MS continuing calibration data } \\
\text { No chromatograms or mass spectra } \\
\text { are presented for calibration. } \\
\text { These data should be filed in the } \\
\text { laboratory and available if prob- } \\
\text { lems arise in reviewing/ validating } \\
\text { the data. The calibration informa- } \\
\text { tion should be available for } \\
\text { checking during on-site audits. }\end{array}$ & CLP Form 7 or equivalent \\
\hline- & GC/MS internal standard area data & CLP Form 8 or equivalent \\
\hline- & $\begin{array}{l}\text { Second column confirmation shall } \\
\text { be done for all GC work when } \\
\text { compounds are detected above re- } \\
\text { porting limits. Chromatograms of } \\
\text { confirmation must be provided. }\end{array}$ & $\begin{array}{l}\text { Chromatograms for all samples and CLP } \\
\text { Form } 10 \text { or equivalent for all positive hits }\end{array}$ \\
\hline \multicolumn{3}{|c|}{ Metals } \\
\hline- & Sample results & CLP Form 1 or equivalent \\
\hline - & Initial and continuing calibration & $\begin{array}{l}\text { CLP Form } 2 \text { or equivalent and dates of } \\
\text { analyses and calibration curve, and the } \\
\text { correlation coefficient factor }\end{array}$ \\
\hline- & $\begin{array}{l}\text { Method blank taken through } \\
\text { digestion (one per } 20 \text { samples of } \\
\text { same matrix) }\end{array}$ & $\begin{array}{l}\text { CLP Form } 3 \text { or equivalent and dates of } \\
\text { analyses }\end{array}$ \\
\hline - & ICP interference check sample & $\begin{array}{l}\text { CLP form } 4 \text { or equivalent and dates of } \\
\text { analyses }\end{array}$ \\
\hline- & $\begin{array}{l}\text { Spike sample recovery (one per } 20 \\
\text { samples of similar matrix) }\end{array}$ & CLP Form 5A or equivalent \\
\hline
\end{tabular}


Table 6.14. (continued)

\begin{tabular}{|c|c|c|}
\hline & $\begin{array}{l}\text { Postdigestion spike sample } \\
\text { recovery for ICP metals. Only } \\
\text { done if predigest spike recovery } \\
\text { exceeds CLP limits. }\end{array}$ & CLP Form 5B or equivalent \\
\hline- & Postdigestion spike for GFAA & Recovery will be noted on raw data \\
\hline- & $\begin{array}{l}\text { Duplicates (one per } 20 \text { samples) } \\
\text { will be split and digested as } \\
\text { separate samples) }\end{array}$ & CLP Form 6 or equivalent \\
\hline- & LCS & CLP Form 7 or equivalent \\
\hline- & $\begin{array}{l}\text { Standard addition. The decision } \\
\text { process outlined in CLP Page E-3 } \\
\text { will be used to determine when } \\
\text { standard additions are required. }\end{array}$ & $\begin{array}{l}\text { CLP Form } 8 \text { or equivalent and dates of } \\
\text { analyses }\end{array}$ \\
\hline- & Holding times & CLP Form 10 or equivalent \\
\hline \multicolumn{3}{|c|}{ Wet Chemistry/Radionuclides } \\
\hline- & LCS (one/batch) & Control Chart \\
\hline- & Method blank (one/batch) & Report result \\
\hline- & Sample results & Report result \\
\hline- & $\begin{array}{l}\text { Spike/spike duplicate or calibration } \\
\text { information }\end{array}$ & $\begin{array}{l}\text { Report result (\% recovery and \% RPD), } \\
\text { if applicable }\end{array}$ \\
\hline- & Initial calibration & $\begin{array}{l}\text { Calibration curve and correlation coeffi- } \\
\text { cient }\end{array}$ \\
\hline- & $\begin{array}{l}\text { Continuing calibration check; } \\
\text { report \% relative standard } \\
\text { deviation or \% difference from } \\
\text { calibration }\end{array}$ & Report percent or percent difference \\
\hline - & Run Log & Copy of run $\log$ \\
\hline
\end{tabular}


In the primary analysis, all standards are analyzed at the beginning of the 72-hour period, followed by the proper sample/standard sequence. Confirmation analysis requires a mid-level standard at the beginning of the 72-hour period. The midlevel standard must be repeated after every ten samples.

If the criteria for initial calibration are not met:

- Flag all associated quantitative results as estimated (J).

If the criteria for continuing calibration are not met:

- In the primary analysis, flag all associated quantitative results as estimated (J).

- In the confirmation analysis, use professional judgment as to data reliability.

If proper standards have not been analyzed:

- Use professional judgment as to data reliability.

Blanks-Ensure that all associated blanks were analyzed. taken.

If a compound is found in a blank but not found in the associated sample, no action is

If a compound is found in a blank and the associated sample, the following $5 x$ rule applies:

- When the concentration of that compound is greater than or equal to the CRQL but less than five times the highest concentration found in any blank, consider the result as a nondetect and flag it with a (U).

- When the concentration of that compound is less than the CRQL and less than five times the highest concentration fcund in any blank, report the result as the CRQL with a (U) qualifier.

- When the concentration of the compound is greater than or equal to five times the highest concentration found in any blank, consider the result as positive, and no flag is required.

- Sample analytes not detected or detected at levels less than CRQL are reported as the CRQL with a (U) flag added.

Laboratory Control Samples-Ensure that each sample is analyzed in a batch in which an LCS has been performed. Any LCS exceeding internal QC limits set by the laboratory for a given sample matrix shall require all data from the associated batch of samples to be closely inspected. 
If no analytical problems are found:

- Data analyzed with the out-of-control point shall be discussed.

If problems are found in the analytical data:

- Ensure that samples associated with the batch were reanalyzed and data from the reanalysis reported.

If holding times are exceeded in the reanalysis, both sets of data shall be presented.

If the LCS results are outside internal laboratory limits and if MS results are outside the CLP limits, the data shall be qualified as follows:

- Qualify nondetects for all samples associated with the LCS as unusable (R).

- Qualify positive results for all samples associated with the LCS as estimated (J).

Surrogates-Ensure that all samples are spiked with the surrogate compounds stated in the specific method. Control limits must be established by the laboratory for each surrogate.

If any surrogate recovery is out of specification but greater than $10 \%$ recovery:

- Flag positive results as estimated (J).

- Flag negative results with the CRQL as estimated (UJ).

If any surrogate shows less than $10 \%$ recovery:

- $\quad$ Flag positive results as estimated (J).

- $\quad$ Flag nondetects as unusable (R).

If any blank has surrogates out of specification:

- Flag results using professional judgement.

If zero recovery is reported:

- The reviewer should request the sample chromatograms and examine them to determine if the surrogate may be present but slightly outside its retention time window. If this is the case, in addition to assessing surrogate recovery for quantitative bias, the overriding consideration is to investigate qualitative validity of the analysis.

If the surrogate is not present:

- $\quad$ Flag positive results as estimated (J).

- $\quad$ Flag all nondetects as unusable (R). 
Matrix Spike/Matrix Spike Duplicate (MS/MSD)-Ensure that a MS/MSD has been associated with each sample. Control limits must be established by the laboratory for each spiking compound. These criteria cannot be used alone to evaluate precision and accuracy. Flagging is not required.

Compound Identification-Ensur: that retention times of reported compounds fall within the calculated window for two chromatographic columns. Second column confirmation is mandatory.

If the qualitative criteria for two-column confirmation were not met:

- Qualify all positive results as unusable (R).

If GC/MS confirmation was required but not performed:

- Document that samples were not confirmed by GC/MS.

Metals and Cyanide Validation Guidelines

Validation for metals and cyanide will essentially iollow the CLP Function Validation Guidelines.

Holding Times-Ensure that holding times have been met and that samples were properly preserved. Most metal samples must be analyzed within 6 months of sample collection. The exceptions follow:

- Mercury shall be analyzed within 28 days from date of sample collection.

- Cyanide shall be analyzed within 14 days from date of sample collection.

- Hexavalent chromium shall be analyzed within 24 hours from time of sample collection.

All holding times listed above apply to preserved samples.

If holding time was exceeded or samples were not preserved:

- Document that samples were not properly preserved.

- Document that holding times were exceeded.

- Qualify all associated positive results as estimated (J).

- Qualify all associated sample quantitation limits as estimated (UJ).

- Qualify all associated results that are less than the CRDL as unusable (R).

Initial Calibration Verification-Ensure that instruments were calibrated daily and each time they were set up. 
If the minimum number of standards were not used for initial calibration or if the instrument was not calibrated daily and each time the instrument was set up:

- Qualify data as unusable (R).

If the correlation coefficient was less than 0.995 :

- Qualify results greater than or equal to the IDL as estimated (J).

- Qualify results less than the IDL as estimated (UJ).

Continuing Calibration Verification-Ensure that analysis results fall within the control limits of 90 to $110 \%$ recovery $(\% \mathrm{R})$ of the true value for all analytes, except mercury and cyanide.

Analysis results for mercury must fall within control limits of 80 to $120 \%$ recovery.

Analysis results for cyanide must fall within control limits 85 to $115 \%$ recovery.

If the initial calibration verification (ICV) or continuing calibration verification (CCV) $\% \mathrm{R}$ falls outside criteria:

- Qualify results greater than or equal to the IDL as estimated (J).

- Qualify results less than the IDL as estimated (UJ).

Blanks-Ensure that all associated blanks were analyzed. Each blank shall contain less than the detection limit for all analytes.

If contaminant concentration in the associated blank is above the detection limit and if the lowest analyte concentration is < five times the blank sample reanalysis should have been performed.

If reanalysis was not performed:

- Qualify results as $\mathrm{U}$.

Laboratory Control Samples-Ensure that each sample is analyzed in a batch in which an LCS has been performed. Any LCS exceeding internal QC limits set by the laboratory for a given sample matrix shall require all data from the associated batch of samples to be closely inspected.

If no analytical problems are found:

- Data analyzed with the out-of-control point shall be discussed. 
If problems are found in the analytical data:

- Ensure that samples associated with the batch were reanalyzed and data from the reanalysis reported.

If holding times are exceeded in the reanalysis, both sets of data shall be presented.

If the LCS results are outside internal laboratory limits and if MS results are outside the CLP limits, the data shall be qualified as follows:

- Qualify nondetects for all samples associated with the LCS as unusable (R).

- Qualify positive results for all samples associated with the LCS as estimated (J).

Matrix Spike-Ensure that the spike recovery (\% R) is within the limits of 75 to $125 \%$.

If spike recovery is greater than $125 \%$ and reported sample results are less than the IDL:

- Data are acceptable.

If spike recovery is greater than $125 \%$ or less than $75 \%$ and sample results are greater than the IDL:

- Qualify data for these samples as estimated (J).

If spike recovery falls within the range of 30 to less than $75 \%$ and sample results are less than the IDL:

- Qualify data for these samples as estimated (UJ).

If spike recovery results fall less than $30 \%$ and sample results are less than the IDL:

- Qualify data for these samples as unusable (R).

Duplicate-Ensure that the Relative Percent Difference was within $\pm 20 \%$ (35\% for soil) for samples values greater than or equal to $5 \times$ the CRDL. Also, ensure that a control limit of \pm CRDL ( \pm two times CRDL for soil) was used for sample values less than five times CRDL.

If duplicate analysis results are outside the appropriate control limits:

- Qualify the results for that analyte in all associated samples as estimated (J).

Partdigestion Spike-Ensure that a postdigestion spike was analyzed for Furnace AA analysis. Also, ensure that a postdigestion spike was analyzed for ICP analysis when the MS did not meet criteria (except silver). These data are used to qualify sample results for Furnace AA analysis but not for ICP. 
If a postdigestion spike was not analyzed for ICP:

- Document that a post digestive spike was not analyzed.

If the postdigestion spike recovery for Furnace AA was less than $40 \%$ :

- Qualify results greater than or equal to the IDL as estimated (J).

If the post digestive spike recovery for Furnace $\mathrm{AA}$ is greater than or equal to $10 \%$ but less than $40 \%$ :

- Qualify results less than the IDL as estimated (UJ).

If the postdigestion recovery is less than $10 \%$ :

- Qualify results less than the IDL as unusable (R).

If sample absorbance is less than $50 \%$ of the postdigestion spike absorbance and the postdigestion spike recovery is not within $85-115 \%$ :

- Qualify results greater than or equal to the IDL as estimated (J).

- Qualify results less than the IDL as estimated (UJ).

Inductively Coupled Plasma Interference Check Sample-Ensure that an interference check sample (ICS) was run at the beginning and end of each sample analysis run (or a minimum of twice per 8 hour shift) and that the results were within $+/-20 \%$ of the true value.

The following applies to samples with concentrations of aluminum, calcium, iron, and magnesium which are comparable to or greater than their respective levels in the ICS.

If the ICS recovery for an element is greater than $120 \%$ and the sample results are less than the IDL:

- Data are acceptable for use.

If the ICS recovery for an element is greater than $120 \%$ or falls between 50 to $79 \%$ and the sample results are greater than or equal to the IDL:

- Qualify the results for that element in all associated samples as estimated (J).

If the ICS recovery for an element falls between $\mathbf{5 0}$ to $\mathbf{7 9 \%}$ and the sample results are less than the IDL:

- Qualify the results for that element in all associated samples as estimated (UJ).

If ICS recovery results for an element fall less than 50\%: 
- Qualify the results for that element in all associated samples as unusable (R).

If results greater than the IDL are observed for elements which are not present in the ICS:

- For samples with comparable or higher levels of interferants and with analyte concentrations that approximate those levels found in the ICS, qualify sample results greater than the IDL as estimated (J).

If negative results are observed for elements that are not present in the ICS, and their absolute value is greater than the IDL:

- For samples with comparable or higher levels of interferants and with analyte concentrations that approximate those levels found in the ICS, qualify sample results less than the IDL as estimated as estimate (UJ).

If aluminum, calcium, iron, and magnesium are present in the sample at greater than the level in the ICS, or other elements are present in the sample at greater than $10 \mathrm{mg} / \mathrm{I}$ investigate the possibility of other interference effects by using Table 6.15. This information should only be considered estimated values. If the estimate is greater than two times CRDL and also greater than $10 \%$ of the reported concentration of the effected element:

- Qualify results as estimated (J). 
Table 6.15. Analyte concentration equivaleat (milligrm per biter) ariving from interferants at 100 mel

\begin{tabular}{|c|c|c|c|c|c|c|c|c|c|c|c|}
\hline \multirow[b]{2}{*}{ Analyte } & \multirow{2}{*}{$\begin{array}{c}\text { Wavelength } \\
\text { nm }\end{array}$} & \multicolumn{10}{|c|}{ Interferant } \\
\hline & & Al & $\mathrm{Ca}$ & $\mathrm{Cr}$ & $\mathrm{Cu}$ & $\mathrm{Fe}$ & $\mathbf{M g}_{\mathbf{g}}$ & $\mathbf{M n}$ & $\mathbf{N i}$ & $\mathrm{Ti}$ & $\mathbf{v}$ \\
\hline Aluminum & 308.215 & -- & -- & - & -- & - & -- & 0.21 & -- & -- & 1.4 \\
\hline Antimony & 206.833 & 0.47 & - & 2.9 & -- & 0.08 & - & - & -- & 0.25 & 0.45 \\
\hline Arsenic & 193.696 & 1.3 & - & 0.44 & - & $\cdots$ & -- & -. & $\cdots$ & - & 1.1 \\
\hline Barium & 455.403 & -- & -- & - & - & -- & - & - & -- & - & $\ddot{-}$ \\
\hline Beryllium & 313.042 & - & - & - & - & - & -- & - & -- & 0.04 & 0.05 \\
\hline Boron & 249.773 & 0.04 & - & - & - & 0.32 & - & -- & -- & -- & - \\
\hline Cadmium & 226.502 & -- & - & - & - & 0.03 & - & -- & 0.02 & - & - \\
\hline Calcium & 317.933 & -- & - & 0.08 & - & 0.01 & 0.01 & 0.04 & - & 0.03 & 0.03 \\
\hline Chromium & 267.716 & -- & - & - & - & 0.003 & - & 0.04 & - & - & 0.04 \\
\hline Cobalt & 228.616 & - & -- & 0.03 & - & 0.005 & - & -- & 0.03 & 0.15 & - \\
\hline Copper & 324.754 & -- & -- & -- & - & 0.003 & - & -- & $\cdots$ & 0.05 & 0.02 \\
\hline Iron & 259.940 & -- & -- & -- & - & -- & - & 0.12 & 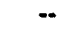 & -- & - \\
\hline Lead & 220.353 & 0.17 & - & - & - & 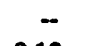 & - & $\ddot{-}$ & $\cdots$ & - & $\overline{-}$ \\
\hline Magnesium & 279.079 & -- & 0.02 & 0.11 & - & 0.13 & -- & 0.25 & $\cdots$ & 0.07 & 0.12 \\
\hline Manganese & 257.610 & 0.005 & - & 0.01 & - & 0.002 & 0.002 & - & -- & - & - \\
\hline Molybdenum & 202.030 & 0.05 & - & - & - & 0.03 & - & - & -- & - & - \\
\hline Nickel & 231.604 & $\ddot{-}$ & - & - & - & - & -- & -- & -- & -- & - \\
\hline Selenium & 196.026 & 0.23 & - & - & - & 0.09 & - & - & $\cdots$ & - & -- \\
\hline Silicon & 288.158 & - & - & 0.07 & - & - & - & - & -- & 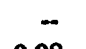 & 0.01 \\
\hline Sodium & 588.995 & - & - & - & - & - & - & - & - & 0.08 & - \\
\hline Thallium & 190.864 & 0.30 & - & -- & - & -- & - & - & -- & - & - \\
\hline Vanadium & 292.402 & - & - & 0.05 & - & 0.005 & - & -- & - & 0.02 & - \\
\hline Zinc & 213.856 & - & - & - & 0.14 & - & - & - & 0.29 & -- & - \\
\hline
\end{tabular}

Method of Standand Addition-Ensure that the Method of Standard Addition (MSA) has been performed when required.

If the MSA was required but not performed:

- Qualify results as estimated (J).

If any samples run by MSA were not spiked at the appropriate levels:

- Qualify results as estimated (J).

If the MSA correlation coefficient is less than 0.995:

- Qualify results as estimated (J).

Wet Chemistry Validation Guidelines

Holding Times-Ensure that holding times were met and samples were properly preserved. 
If the holding time was exceeded or samples were not preserved:

- Document that samples were not properly preserved.

- Document that holding times were exceeded.

- $\quad$ Flag all associated positive results as estimated (J).

- Flag all associated sample quantitation limits as estimated (UJ).

Initial Calibration-Ensure, at a minimum, that a three-point standard curve bracketing sample concentration is performed daily. The correlation coefficient must meet or exceed 0.995 before the analysis of samples.

If the minimum number of standards was not used for initial calibration:

- Qualify data as unusable (R).

If the instrument was not calibrated daily before sample analysis:

- Qualify data as unusable (R).

If the correlation coefficient is less than 0.995:

- Qualify sample results greater than or equal to the Instrument Detection Limit (IDL) as estimated (J).

- Qualify sample results less than the IDLs as unusable (R).

Continuing Calibration-Ensure that the continuing calibration falls within the $90-110 \%$ control limit.

If the criteria is not met:

- Qualify sample results greater than or equal to the IDL as estimated (J).

- Qualify sample results less than the IDL as unusable (R).

Blanks-Ensure that all associated blanks were analyzed.

If the concentration in the sample is less than or equal to the concentration found in the blank:

- The result is considered as a nondetect and flagged as such (U).

If the concentration in the sample is greater than five times the concentration found in the blank:

- The result is considered positive and no flag is required. 
Laboratory Control Samples-Ensure that each sample is analyzed in a batch in which an LCS has been performed. Any LCS exceeding internal QC limits set by the laboratory for a given sample matrix shall require all data from the associated batch of samples to be closely inspected.

If no analytical problems are found:

- Data analyzed with the out-of-control point shall be discussed.

If problems are found in the analytical data:

- Ensure that samples associated with the batch were reanalyzed and data from reanalysis reported.

If holding times are exceeded in the reanalysis, both sets of data shall be presented.

If the LCS results are outside internal laboratory limits and if the MS results are outside the laboratory limits, the data shall be qualified as follows:

- Qualify nondetects for all samples associated with the LCS as unusable (R).

- Qualify positive results for all samples associated with the LCS as estimated (J).

Matrix Spike/Duplicate-Ensure that a MS/MSD has been associated with each sample. Control limits must be estabished by the laboratory. These criteria cannot be used alone to evaluate precision and accuracy. Flagging is not required.

\section{Radiochemical Analysis}

Sample Preservation-Ensure that all samples were properly preserved. The ERD requires radiological samples to be analyzed within six months of collection. There is no technical qualification of data for missed holding times however. Specific QAPjPs should clearly identify the logistical time requirements for completion of radiological results.

If samples were not preserved:

- Document that samples were not properly preserved.

- Qualify all associated positive results as estimated (J).

- Quality all associated sample quantitation limits as estimated (J).

- Qualify all associated results that are less than the MDA as unusable (R).

Initial Calibration-Ensure that instruments were calibrated and the geometry properly identified. Calibration standards must be identified and distributed over the energy range of interest. 
If standards are not identified for the initial calibration, or if the instrument was not calibrated:

- Quality the data as unusable (R).

If standards were not distributed over the energy range of interest:

- Qualify results greater than or equal to the MDA as estimated (J).

- Qualify results less than the MDA as estimated (UJ).

Continuing Calibration-Ensure that instrument efficiency has remained consistent and is within the control limits ( $90-110 \%$ of initial calibration value).

If the continuing calibration falls outside criteria:

- Qualify results greater than or equal to the MDA as estimated (J).

- Quality results less than the MDA as estimated (UJ).

Blanks-Ensure that all associated blanks were analyzed and that background determinations have been performed. Ensure blank and background determinations contain less than the detection limit reported for all analytes.

If contaminant concentration in associated blanks is above the detection limit and, if the lowest analyte concentration is < five times the blank sample, reanalysis of the blank should have been performed.

If reanalysis was not performed:

- Qualify all sample results < five times the blank value as the reporting limit (U).

Laboratory Control Samples-Ensure that each sample is analyzed in a batch which contains an LCS analysis. Any LCS exceeding internal QC limits set by the laboratory for a given matrix and geometry shall require all data from the associated sample batch to be closely inspected.

If no analytical problems are found:

- Data analyzed with the out-of-control LCS shall be specifically referenced in the discussion of results.

If problems are found in the analytical data:

- Ensure samples associated with the batch were reanalyzed and data from the reanalysis is reported. 
If the LCS results are outside internal laboratory limits and, if MS results are outside laboratory limits, data shall be qualified as follows:

- Qualify nondetected analytes for all samples associated with the LCS as unusable (R).

- Qualify positive results for all samples associated with the LCS as estimated (J).

Self Absorption Factors--Ensure that self absorption factors have been determined for alpha and beta determination. These factors must be determined over the range of solids expected in the samples. It is recommended that the solids content not exceed $200 \mathrm{mg}$ total, $100 \mathrm{mg}$ total solids may be a more appropriate level.

If self absorption factors have not been determined:

- Qualify all associated sample data as unusable (R).

Matrix Spike-Ensure that the spike \% $\mathrm{R}$ is within limits of 75 to $125 \%$. MDA:

If spike recovery is greater than $125 \%$ and reported sample results are less than the

- Data are acceptable.

If spike recovery is greater than $125 \%$ or less than $75 \%$ and sample results are greater than the MDA:

- Qualify data for these samples as estimated (J). MDA:

If spike recovery falls within the range of $\mathbf{3 0}$ to $\mathbf{7 5 \%}$ and sample results are less than the

- Qualify data for these samples as estimated (UJ).

If spike recovery results fall less than $30 \%$ and sample results are less than the MDA:

- Qualify data for these samples as unusable (R).

Duplicate-Ensure the RPD was within $\pm 20 \%$ (35\% for soil) for sample values greater than or equal to five times the MDA. Also, ensure a control limit of \pm the $\mathrm{MDA}( \pm$ two times the MDA for soil) was used for duplicate sample comparison values less than 5 times the MDA.

If duplicate analysis results are outside the appropriate control limits:

- Qualify results for that analyte in all associated batch samples as estimated (J). 


\subsection{INTERNAL QUALITY CONTROL CHECKS}

\subsubsection{Field QAVC Samples}

The QA/QC protocols for this project requires the use of field QA/QC samples to verify the soundness of sample-handling techniques, equipment and container decontamination procedures, chain of custody, and chemical analysis results. The following types of samples will be prepared and sent to the analytical laboratory.

1. Duplicate samples will be collected at a rate of $10 \%$ of the total number of samples taken to determine the variability in sampling technique and method.

2. Distilled water blanks will be submitted for analyses from both laboratories (on-site and UT) that will serve as sources for equipment rinsate water. One blank will be submitted by each lab for Phase I and another submitted for Phase II.

3. Equipment rinsate blanks will be collected to determine the effectiveness of cleaning procedures and to ensure that samples are not being affected by the equipment used to collect them. One equipment blank will be collected from each piece of equipment used in the sampling process at a sampling site. One equipment blank will be collected prior to start of sampling at the sites to be sampled for a total of 12 blanks (i0\% of total number of locations).

Equipment rinsate blanks will consist of distilled water that has been poured over the cleaned sampling tools, then collected into an appropriate sample container, and preserved and handled as outlined in the soil sampling procedures. The Technical Coordinator or his designee will determine which equipment needs to be included in the rinse blank for each site.

4. Trip blanks will be carried to check for VOC contamination that might occur during the sample handling, transportation, and storage process. A standard pre-cleaned VOA sample bottle will be filled in the laboratory with distilled water and carried to and from the field each day along with the regular soil samples collected for VOC analyses. The trip blank will be analyzed only if a regular sample collected that day is first found to be contaminated with VOCs. The trip blank results will either confirm or eliminate one possible source of the sample contamination. If the site is determined to be contaminated, it will be rejected, and no additional analyses will be performed on samples collected at that site.

5. A well-homogenized reference soil sample will be submitted three times during the analytical laboratory analysis period to each contract laboratory for metals and radionuclide analysis. The data generated from analysis of these reference soil samples will be used to evaluate the overall performance of the contract laboratory.

\subsubsection{Laboratory QAMC Samples}

This section outlines the requirements for the quality assurance program. This project is a Level IV/D project which requires that the QA/QC be in accordance with the Contract 
Laboratory Program Statement of Work for Inorganics and Organics, March 1990 (EPA $1990 \mathrm{a}, \mathrm{b})$. There are methods in this project that do not currently have EPA CLP methods available. This project requires that these methods be run under "CLP-like" procedures with the minimum QC being that listed below.

\subsection{Organics}

\section{Herbicides (EPA Method 8150)}

1.0 Before processing any samples, it should be demonstrated that interferences from the analytical system, glassware, and reagents are under control by analyzing a reagent water blank. This should be done each time a set of samples is extracted or when there is a change in reagents. The blank should be carried through all stages of sample preparation and measurement.

2.0 For each analytical batch, a reagent blank, matrix spike and matrix spike duplicate must be analyzed (the frequency can be found in the particular QC for the method).

3.0 Recoveries of surr gates shall be calculated for the analysis of each GC column of each sample, blank, matrix spike, and matrix spike duplicate. The quality control limits will be those that have been generated by the laboratory and shall be reported with the results.

4.0 A daily calibration sample should be analyzed in order to determine whether the chromatographic system is operating properly.

\subsection{Instrument QC:}

- Calibration should be done in accordance with the procedure found in Sect. 7.4 of PA Method 8000 (in EPA (1991e)).

- When comparing calibration factors to determine if the five point calibration is linear, the \% RSD should vary by $<20 \%$.

- A limit of $\pm 15 \%$ difference is set when comparing daily analyte response versus the initial response. If limit is exceeded, a new standard curve must be prepared.

- Retention time windows need to be established against the requirements of Sect. 7.5 of EPA Method 8000.

- A limit of $\pm 15 \%$ difference is set when comparing the initial response of a given analyte versus any succeeding standard analyzed during an analysis sequence.

- All succeeding standards in analysis sequence must fall within the daily retention time window established by the first standard of the sequence.

6.0 A QC check sample is required containing each analyte of interest. For preparation and analysis of QC check samples, refer to Sect. 8.6 of EPA Method 8000 (in EPA (1991e)). 
7.0 At least one spike sample per analytical batch must be analyzed to assess accuracy. The concentration of the spiked samples and more detailed information regarding spiked sample analysis can be found in Sect. 8.7 of EPA Method 8000 .

8.0 If any analyte fails the acceptance criteria for recovery of the spiked sample, A TC check standard containing each analyte that failed must be analyzed. For preparation of the QC check standard and more detailed instructions on the requirements for the standard, see Sect. 8.8 of EPA Method 8000.

9.0 Method accuracy for each matrix studied must be assessed and records maintained.

10.0 The accuracy and precision limits for surrogate standards must be determined. The laboratory should follow the procedure outlined in Sect. 8.10 of EPA Method 8000 .

\section{Polynuclear Anomatic Hydrocarbons}

1.0 The HPLC system operation must be velidated according to the procedure found in EPA Method 8000, Sect. 8.6.

2.0 The quality control check sample must contain each analyte at the following concentrations in acetonitrile:

$\begin{array}{ll}\text { Naphthalene } & 100 \mu \mathrm{g} / \mathrm{mL} \\ \text { Acenaphthylene } & 100 \mu \mathrm{g} / \mathrm{mL} \\ \text { Acenaphthene } & 100 \mu \mathrm{g} / \mathrm{mL} \\ \text { Fluorene } & 100 \mu \mathrm{g} / \mathrm{mL} \\ \text { Phenanthrene } & 100 \mu \mathrm{g} / \mathrm{mL} \\ \text { Anthracene } & 100 \mu \mathrm{g} / \mathrm{mL} \\ \text { Benzo(k)fluoranthene } & 5 \mu \mathrm{g} / \mathrm{mL} \\ \text { any other PAH } & 10 \mu \mathrm{g} / \mathrm{mL}\end{array}$

3.0 Table 3 of EPA Method 8310 indicates the calibration and QC acceptance criteria that must be used for this project. Any deviation from this table must be approved before analysis.

4.0 Calculation of surrogate recoveries must be performed on all samples, blanks, and spikes. The recovery must be within the following limits:

Upper Control Limit: \% recovery +3 s

Lower Control Limit: \% recovery $-3 \mathrm{~s}$

5.0 If the recovery is not within the limits, the following is required:

1. Check to be sure there are no errors in calculations (surrogate solutions and internal standards). Also, check instrument performance.

2. Re-calculate the data and/or re-analyze the extract if any of the above checks reveal a problem. 
3. Re-extract and re-analyze the sample if none of the above are a problem, or flag the data as "estimated concentration."

\subsection{Inorganics}

\section{Inductively Coupled Plasma/Mass Spectrometry (ICP/MS)}

- Instrument detection limits (IDLs) in $\mathrm{mg} / \mathrm{L}$ will be estimated by multiplying by 3 the average of the standard deviations obtained on three nonconsecutive days from the analysis of a standard solution (each analyte in reagent water) at a concentration $3 \times 10$ $25 \times \mathrm{IDL}$, with seven consecutive measurements per day. Each measurement must be performed as though it were a separate analytical sample (i.e., each measurement must be followed by a rinse and/or any other procedure normally performed between the analysis of separate samples). IDLs must be determined at least every three months and kept with the instrument log book.

- The intensities of all internal standard must be monitored for every analysis. When the intensity of any internal standard fails to fall between 30 and $120 \%$ of the intensity of the internal standard in the initial calibration standard, follow the procedure discussed in Sect. 8.3 of EPA Method 6020.

- It is necessary to measure more than the analytes of interest in order to determine whether interference corrections are necessary. Follow the instructions outlined in Sect. 8.4 of EPA Method 6020 for interference corrections.

- One serial dilution must be analyzea for each 20 samples of each matrix in a batch.

- At least one spike sample analysis must be performed on each group of samples of a similar matrix type (i.e., water and soil) and concentration (i.e., low and medium). The spike recovery must be within 75 to $125 \%$ of the known value.

- One laboratory control sample (LCS) must be analyzed for each 20 samples and it should be analyzed for each analyte using the same sample preparations, analytical methods, and QAVQC procedures.

- The standardization of the instrument should be checked by analyzing the appropriate quality control samples discussed in Sect. 8.8 of EPA Method 6020.

- The magnitude of the elemental and molecular-ion isobaric interferences and the adequacy of any corrections must be verified at the beginning of an analytical run.

- One duplicate sample for every 20 samples of the same matrix must be analyzed. A control limit of $20 \%$ relative percent difference should not be excceded for analyte values greater than 100 times the instrumental detection limits. If this limit is exceeded, the reason for the out-of-control situation must be found and corrected, and any samples analyzed during the out-of-control condition must be re-analyzed. 
Nitrate

- Linear calibration curves must be composed of a minimum of a blank and five standards. A set of standards must be included with each batch of samples.

- Dilute samples if they are more concentrated than the highest standard or if they fall on the plateau of a calibration curve.

- Verify calibration with an independently prepared check standard every 15 samples.

- Run one spike duplicate sample for every 10 samples. A duplicate sample is a sample brought through the whole sample preparation and analytical process.

\section{Sulfate}

- Calibration curves must be composed of a minimum of a blank and three standards. A calibration curve must be made every hour of continuous sample analysis.

- Dilute samples if they are more concentrated than the highest standard or if they fall on the plateau of a calibration curve.

- Employ a minimum of one blank per sample batch to determine if contamination has occurred.

- Verify calibration with an independently prepared check standard every 15 samples.

- Run one spike duplicate sample for every 10 samples. A spike duplicate sample is a sample brought through the whole sample preparation and analytical process.

\subsubsection{Radiochemicals}

\section{Sample Preparation (excluding Gamma Spectrascopy)}

Sample Batch:

1. $5 \%$ of a sample batch should consist of a reagent blank.

2. $5 \%$ of a sample batch should consist of a control standard sample.

3. $5 \%$ of a sample batch should consist of a sample duplicate.

4. $5 \%$ of a sample batch should consist of a sample spike.

\section{Gas Proportional Counter}

Daily Check:

Count an instrument blank and check sources (NIST traceable) to monitor instrument performance. QC plots for instrument background, counting efficiency, and cross-talk should be recorded and plotted. 
Annually or if required:

1. Determination of operating voltage:

- When a P-10 gas cylinder is changed out. This will check the consistency of the counting gas.

- When an out-of-control situation arises due to instrument failure or due to the failure of a daily instrument performance check.

- When the yearly instrument calibration is due.

2. Determination of counting efficiencies and attenuation curves for various nuclides.

\section{Liquid Scintillation Counting}

Daily Check:

Count unquench instrument blank and check sources (NIST traceable) to monitor instrument performance and to normalize the quench factors. QC plots for instrument background, and counting efficiency should be recorded and plotted for the region of interest.

Annually or if required:

1. Develop quench curves for the isotopes, total volume, and spectrum region that are of interest. A NIST traceable source with varying amounts of chemical and color quenching agents. This should be executed yearly or if daily AC requires calibration.

2. Develop a background quench curve to be used as a blank subtraction.

\section{Alpha and Gamma Spectrascopy}

Daily Check:

Count an instrument check source (NIST) traceable to monitor instrument performance. Centroid (KeV/channel), FWHM, and efficiency should be plotted daily for a few peaks. The out-of-control limits should be based on software requirements for peak identification.

Weekly Check:

An instrument background should be checked and plotted.

Annually or if required:

An energy, efficiency (and FWHM) calibration should be done with a mixed source, or in the case of alpha spectroscopy single isotope sources for the region of interest. 


\subsection{PERFORMANCE AND SYSTEM AUDITS}

\subsubsection{Laboratory}

Internal and external performance and systems audits are means of monitoring the capability and performance of the laboratory measurement system. The laboratory must successfully pass an on-site systems inspection before the laboratory is authorized to perform project analyses. The inspection serves to define laboratory capabilities and its compliance with project requirements and its own QA program. The laboratory inspection covers sample receiving, handling, and storage; performance of analytical procedures and adherence to protocols; documentation such as records of instrument calibration, sample preparation and run logs, maintenance logs, and standards traceability; standard operating procedures; and other areas of technical or regulatory interest.

In addition to the above external auditing activities, the QA department needs to conduct similar activities in house, submitting blind samples of known composition for analysis and conducting internal systems audits. The laboratory quality assurance plan for the laboratory performing the work should describe the auditing practices followed.

\subsubsection{Field}

Prior to the onset of field sampling activities, a readiness review will be conducted only by BSCP project participants in light of the fact that this project will not involve dealing with any significant contaminants usually encountered in remedial actions projects, and that it has been determined that 29 CFR 1910.120 is not applicable in this project. In addition, an operational dry run will be made under full simulated conditions well in advance of actual field sampling operations with documented QA surveillance.

Internal field surveillances will consist of on site observation of soil sampling activities by the project field QA/QC coordinator. At least one internal surveillance of both on-site and off-site sampling activities will be made. One internal surveillance and one QAS surveillance will be made during Phase I, and the same during Phase II field operations of the project as indicated in Table 6.16. These surveillances will be done and documented in accordance with ER/C-P1600, Rev. 0 Performance of Environmental Restoration Division Surveillance Activities, but distribution of surveillance reports generated will be limited to the BSCP Manager and Technical Coordinator. The purpose of these surveillances will be to aid in refining the project sampling activities in preparation for formal surveillances by the ER or ESD QASs.

Typical surveillance activities would include

- performing a review of procedures, instructions, and associated documents applicable to the project and

- observing field sampling activities and associated QAVQC activities to verify that these work activities are being performed in accordance with project documents.

The results of field surveillances will be discussed with the persons observed. The results of the surveillance will be documented in accordance with ER/C-P1600, Rev. 0 and signed by the Field QAVQC Coordinator. The resulting surveillance reports will be distributed to the 
project manager, technical coordinator, the appropriate project files and the ER or ESD QASs.

The BSCP field and laboratory analytical QA coordinators will provide formal reports on the status of $\mathrm{QA} / \mathrm{QC}$ in the project on a bimonthly basis to the project manager and to the technical and analytical coordinators. Project management will inform the QA specialist bimonthly, or as appropriate, of the QA status of the project, especially any significant quality accomplishments. BSCP field and technical staff are required to inform the project manager and the QA coordinators of all nonconformances or quality failures. The project manager and QA coordinators will document and immediately report any nonconformances or quality issues/failures to the QA specialist. It is the responsibility of the QA specialist to report all quality related activities to the ER quality assurance manager and ERP line manager.

Formal surveillances and audits by the ER or ESD QASs will be performed and documented in accordance with ER/C-P1600, Rev. 0 and reported as appropriate in the ERP.

The proposed surveillance schedule for the BSCP is presented in Table 6.16. Specific dates in the surveillance schedule may be subject to adjustment due to possible operational and weather related impacts and are represented here as TBD (to be determined). Specific dates in Table 6.16 will be set up as soon as practical after the field work gets under way.

\subsection{PREVENTIVE MAINTENANCE}

\subsubsection{Laboratory}

A program of preventive maintenance reduces the likelihood of analytical problems and unexpected delays resulting from equipment failure. The following comprise the preventive maintenance system:

- Determination and listing of measurement system components that require preventive maintenance.

- For each measurement component, development of a schedule of routine tasks that must be carried out to minimize downtime.

- Notation of preventive maintenance activities in a maintenance log.

- Inventory of critical and frequently required spare parts. 
Table 6.16. Background soil characterization project-1992 schedule of surveillance activities

\begin{tabular}{|c|c|c|c|}
\hline Date & Lead & Surveillance Activity & Comments \\
\hline \multicolumn{4}{|c|}{ PHASE I SAMPLING } \\
\hline $6 / 8 / 92$ & J. Switek & Field Sampling Activities & Project Surveillance \\
\hline TBD & T. Hatmaker & $\begin{array}{l}\text { Verification of Lab Data } \\
\text { Validation, Phase I Data }\end{array}$ & Project Surveillance \\
\hline $7 / 30 / 92$ & T. Koepp & $\begin{array}{l}\text { Project/QA Records } \\
\text { Verification of Lab Data } \\
\text { Validation, Phase I Date }\end{array}$ & ER Surveillance \\
\hline \multicolumn{4}{|c|}{ PHASE I SAMPLING } \\
\hline $8 / 26 / 92$ & J. Switek & Field Sampling Activities & Project Surveillance \\
\hline $9 / 15 / 92$ & T. Koepp & Filed Sampling Activities & ER Surveillance \\
\hline $10 / 1 / 92$ & J. Switek & Project/QA Records & Project Surveillance \\
\hline TBD & T. Hatmaker & $\begin{array}{l}\text { Verification of Lab Data } \\
\text { Validation, Phase II Data }\end{array}$ & Project Surveillance \\
\hline $11 / 16 / 9$ & T. Koepp & $\begin{array}{l}\text { Project/QA Records } \\
\text { Verification of Lab Data } \\
\text { Validation, Phase II Date }\end{array}$ & ER Surveillance \\
\hline
\end{tabular}

Dates will be determined upon approval of the QAPP and Project Plan and after start of field work.

The responsibility for routine preventive maintenance is assigned to particular individuals. More specialized maintenance is provided by a trained instrument technician, either in-house or through a service contract.

\section{9 .2 Field}

The soil sampling equipment to be used by the BSCP has been procured and sufficient backup equipment will be on hand or readily available within the time frame of the project. The instrumentation to be used will require only minor on site calibration by project staff. Radiological or industrial hygiene instrumentation to be used will be obtained from health physics or industrial hygiene departments from one of the MMES plants (most likely ORNL) and will be covered by the department preventive maintenance programs. 


\subsection{PROCEDURES TO ASSESS DATA PRECISION, ACCURACY AND COMPLETENESS}

The contract laboratory will have its own laboratory QC program in place as part of their contract with MMES. The adequacy of the laboratory QC program will be overseen by the appropriate MMES quality organization. The QC program is outlined in Sect. 6.6 on DQOs.

\subsection{NONCONFORMANCES AND CORRECTIVE ACTIONS}

\subsubsection{Laboratory}

Procedures for handling nonconformances and corrective actions will be in accordance with ER/CR-SOP1200 or site-level procedure. Laboratory corrective actions monitoring will be the responsibility of the BSCP Analytical Coordinator.

\subsubsection{Field}

During project field surveillances corrective actions dealing with minor discrepancies from the approved procedures will be brought to the attention of the person(s) involved, and corrections will be accomplished at the time of disclosure under the supervision of the Technical Coordinator or field QA coordinator. This may lead to the generation of a field change if the discrepancy appears to improve sampling efficiency.

Discrepancies in health and safety protocols will also be corrected at the time of disclosure, and work will be suspended until corrective action is affected.

Major findings and nonconformances and corrective actions resulting from formal audits and surveillances by the ER and ESD QASs or external audits will be handled and corrected through to final resolution in accordanee with ER/CR-SOP1200 which is driven by ER/CP1300, Rev. 0 and with Energy Systems Praiedure ESS-OP-301, ESP-QA-16.1 and ESS.16.0, as appropriate.

\subsection{QUALTTY ASSURANCE REFORTS TO MANAGEMENT}

Reports shall be prepared as needed for the CER program management that provide evidence of the quality, cost, and schedule of the project. A list follows of possible reports and their content.

\subsubsection{Formal Written Reports}

- Audit and surveillance reports shall be prepared and submitted by the auditor or surveillant.

- Reports on significant quality problems, recommended solutions, and results of corrective actions shall be prepared by the project manager. 


\subsubsection{Project Reports}

Reports to the Project Manager shall be prepared by project personnel designated by the projut manager. The reports shall identify the status of the following:

- permit approvals;

- document preparation and approvals;

- scheduled versus actual completions of field sampling and laboratory analyses;

- accuracy and precision of laboratory analyses;

- amount, type, and location of field-generated wastes; and

- actual cost and schedule versus plan.

Regardless of whether reports are presented to management in writing or verbally, records of activities shall be maintained by the personnel responsible for presenting the report.

\subsection{RECORDS MANAGEMENT SYSTEM}

A records management system shall be implemented as described in Sect. 7.5 for identifying, maintaining, and accessing quality assurance and general project records.

\subsubsection{Records Administration}

Records that furnish documentation or evidence of quality shall be identified in QA procedures, project work plans, technical procedures, and procedural documents and shall be designated QA records.

Other records of value generated by the project required to provide a complete and accurate history of data collection and analysis, to document conduct of project business, and to support any future legal or administrative actions that may be taken are designated nonpermanent records.

The Records Management Plan (Sect. 7.5) and procedures will follow ER/CR-SOP1100 in which records of value and retention periods will be identified. The records management plan will establish an indexing system which will provide sufficient information to permit identification of record an the items or activities to which it applies.

\subsubsection{Records Receipt}

Individuals assigned to review records shall be responsible for reviewing the records to verify that they meet requirement for completeness, identification, legibility and documentation. Acceptable records shall be duplicated and entered into a dual records system. 


\subsubsection{Storage, Preservation, and Safekeeping}

Records shall be kept in a dual records system located in remote storage facilities. The facilities shall meet the NQA-1 requirements for dual facilities [NQA-1 Supplement 17S-1, Para. 4.4.3, Dual Facilities (ASME 1989)].

- Paper documents are to be protected from damage due to environmental conditions, natural disorders, and pests.

- Records indexed as described in ER/CR-SOP1100 are to be securely bound or placed in folders and stored in appropriate storage containers. Original records and those awaiting processing will be stored in a fireproof cabinet.

- Special arrangements will be made to store photographs, negatives, microfilm, and magnetic media to prevent damage from excessive light, stacking, electromagnetic fields, temperature, and humidity.

- Control of files and access to files shall be limited to authorized personnel.

\subsubsection{Retrieval and Final Disposition}

Records shall be available to project staff through a request system. The final disposition of project records will be governed by requirements of the ER Division records management system.

\subsection{DOCUMENT CONTROL}

Document control is the process of assuring that documents are reviewed for adequacy, approved for release by authorized personnel, and distributed to and used at the location where the prescribed activity is performed (see Sect. 7.4). Document control is essential to BSCP activities to ensure the completeness and integrity of the sampling activities, laboratory analyses, and resulting conclusions.

The Project Manager has the responsibility of identifying the documents to be controlled and their specific distributions.

To meet these objectives BSCP plans and reports will be prepared according to ER/CP1103, "Preparation, Clearance, and Approval of Environmental Restoration Division Documents," and distributed according to the draft ER procedure "Distritiution of Controlled Documents within ER." BSCP procedures will be prepared following implementation of ER/CR-SOP1000, "Initiation, Review, Revision, Approval, and Issuance of Clinch River Environmental Restoration Program Standard Operating Procedures and Instructions." 


\subsection{PROCUREMENT DOCUMENT CONTROL}

This criterion (NQA-1 Criterion 4) ensures that purchasing documents such as bid specifications are properly prepared. Purchasing for the BSCP will be through normal ORNL channels, which implement NQA-1 procurement document control requirements.

As required by the ERD Quality Assurance Program Plan (ES/ER/TM-4/R1) the BSCP staff will generate a statement of work (SOW) requiring compliance with ES/ER/TM-4/R1 and with the relevant analytical QAVQC requirements in Sect. 6 of this plan. A SOW will be prepared for MMES laboratories doing screening analyses, as well as each contract iaboratory selected from the preapproved CLP pool as these laboratories are identified. The SOW will specify the analyses and activities to be performed, the methods to be used, and the EPA DQ level to which the analyses or activities will be performed.

\subsection{PURCHASED ITEMS AND SERVICES CONTROL}

This criterion (NQA-1 Criterion 7) ensures that quality is maintained in purchasing items or services. Purchasing for the BSCP will be accomplished through normal ORNL procedures. These procedures implement NQA-1 procurement control requirements.

The deliverables for work done by contract laboratories for the BSCP are defined in Table 6.14. Section 6.6.3 outlines the validation of data generated for the project. 


\section{DATA MANAGEMENT PLAN}

\subsection{INTRODUCTION}

The background soils investigation will generate data sets from sources including field measurements, laboratory analyses of environmental samples, and output from statistical analyses and risk assessment models. A data set is a structured collection of data items that are stored in and retrieved from a computer file by computer software (such as spreadsheet or data base software).

Records of collection, analysis, and disposition of the samples and data will be generated. Data records are electronic or hard copy documents with entries describing data items and their attributes.

Computer software programs and procedures will be developed to manipulate and store data, summarize and reduce data, and perform simulations and risk assessment calculations. Data from the BSCP data base will be transferred to OREIS data base. OREIS will make available BSCP data to other groups.

\section{O'BJECTIVES}

The objectives of the data management plan are to provide organiration, integrity, security, traceability, and consistency of the data sets and data records generated during the background soils investigation. Organization will insure that data and documents are adequate to describe the procedures and results of the investigation. The data and documents must be able to support any future legal or administrative actions. Data sets, programs, and data records will be maintained to minimize introduction of error resulting from faulty entry, transcription, storage, or management. Thus accurate data will be available for statistical analysis, reporting, and modeling. Data sets, programs, and data records will be protected from unauthorized access, deletion, and modification.

Information will be recorded in enough detail to allow traceability of the data as it evolves from one form to another. For instance, identification values will associate original hard copy sources to values in data sets and to reported summary tables.

Data values will be consistent. For instance, different data values should not have the same meaning, and like values should not have different meanings. 


\subsection{DATA MANAGEMENT}

Data management for this project will develop the BSCP data base plan for management and rtorage of field, analytical, and risk assessment data. Data sets will be manipulated primarily with SAS software and stored as SAS data sets on the ORNL IBM 3090 mainframe computer. SAS and other compatible software (Lotus 1-2-3 and dBASE) will be utilized with individual personal computers. The principal steps for processing data for the BSCP data base are identified in Fig. 7.1.

\subsubsection{Data Collection}

\subsubsection{Field data measurements and observations}

Field logbooks will be maintained to record samples collected, measurements taken, and observations of events and conditions that could affect data quality. Logbooks are intended to provide sufficient data and observations to enable participants to reconstruct events that occurred during the data collection process, to help qualify data, and to refresh the memory of field personnel.

Field measurements will be recorded according to prescribed format in the field data logbooks. A sequential form control number will be entered on the data form and in the logbook. This form control number will be entered into the computer data set to provide a reference to the associated field records.

Field data forms will be sent to K-25 ADP service center data entry. The data will be double entered and verified. The electronic data files will be copied using error-checking protocols to ORNL computers. A BSCP sample identification number will be entered into the field data sets.

Field logbooks and field data forms are Quality Assurance records.

\subsubsection{Laboratory analytical data}

Analytical laboratories will provide data forms of analytical results and quality control results (such as blanks, spikes, duplicates) as specified in Table 6.14. The analytical lab will maintain BSCP sample identification numbers and lab identification numbers in the data forms.

Analytical data forms will be sent to K-25 data entry. The data will be double entered and verified. The electronic data files will be copied using error-checking protocols to ORNL computers.

Original electronic laboratory data and hard copy data are Quality Assurance records. 


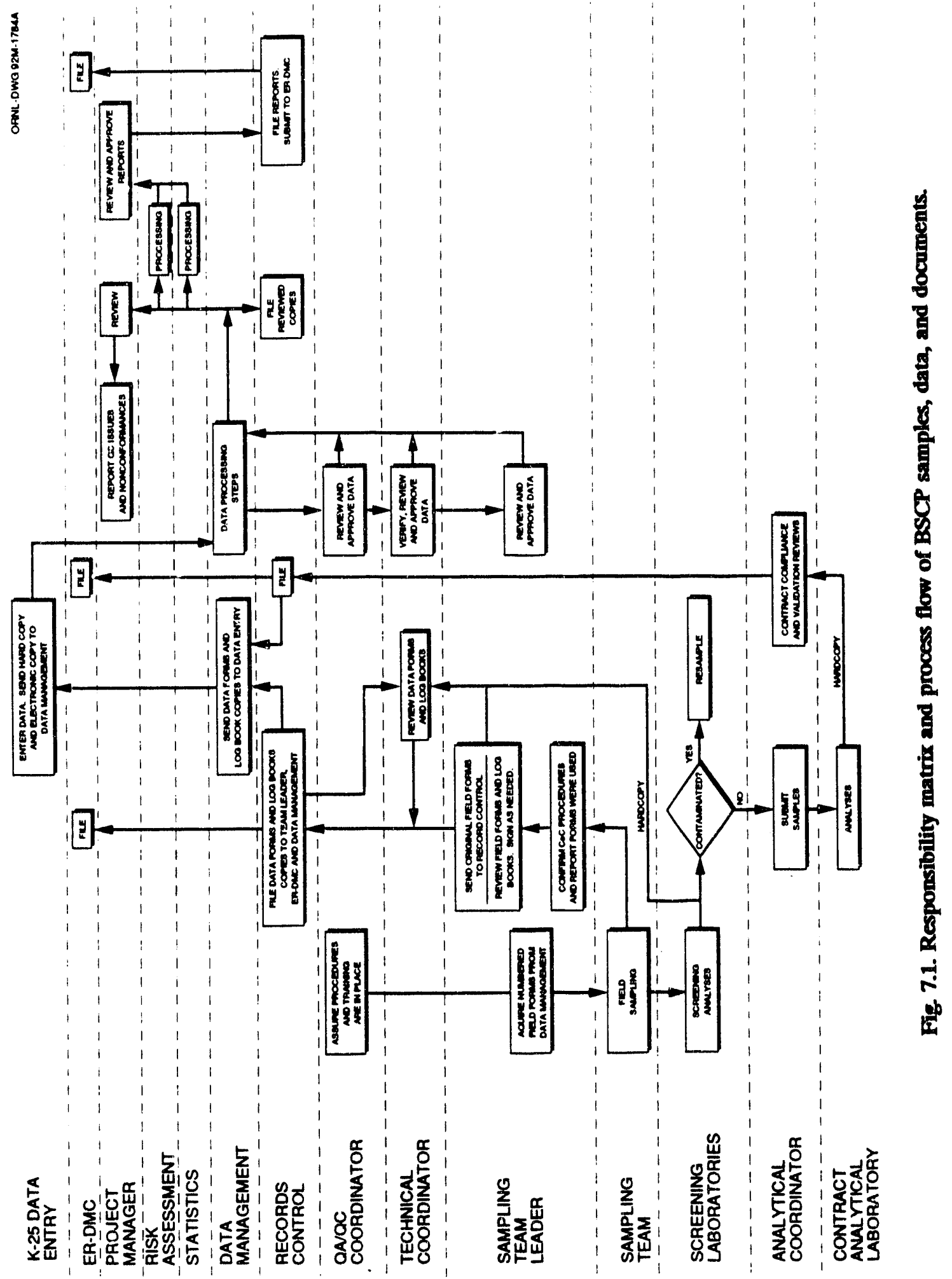




\subsubsection{Risk assessment}

Background soil concentrations will be used to quantify baseline risk to human health for comparison with the risks associated with contaminated sites. All input data sets, output data sets, and data files for risk assessment will be retained. All program files and data sets containing equations, factors, and assumptions in the risk assessment will be retained.

\subsubsection{Statistical analyses, data summaries, and reductions}

All input data sets and program files will be retained. All final output files for statistical analyses, data summaries, and data reductions will be retained.

\subsubsection{Data Entry}

Data Entry Department at K-25 will receive data forms for double entry and verification. The hard copy records will be returned to the data manager. Electronic data files will be copied to the ORNL IBM 3090 using error-checking protocols.

\subsubsection{Data Encoding}

Standardized identification codes will be used to facilitate match-merging of data of the BSCP data base and other data bases, such as OREIS. Variables such as analysis name will have stándard values. A sufficient number of variables will be provided in order to define the result and its conditions and assumptions. Values of variables will be consistent. Sample measurements that are accidentally lost or that are not made will be denoted as missing values. Censored values (nondetectable laboratory results) will be consistently flagged in separate qualifying fields. A remarks field will be available for field and analytical data.

\subsubsection{Data Traceability}

Information will be recorded in the amount of detail to allow it to be traced to the project and location that the data was obtained. The date and time of data acquisition will be recorded. The instrument will be referenced by serial number and type. The laboratory method will be recorded. The names of the members of the sampling team will be recorded. When data are entered into the BSCP data base, the field form control number and document control number will be recorded to provide a link to the original hard copy record. 


\subsubsection{Quality Assurance/Quality Control}

The QA/QC coordinator will assure that field sampling procedires and trained field staff are in place. The field data forms will be reviewed by the Technical Coordinator for completeness. The QA/QC coordinator will review the field data sets. The laboratory data will be measured and recorded with known precision and will be technically defensible. The Analytical Coordinator will review the laboratory result forms. The field and laboratory data sets will be merged by their common index. Data sets will be reviewed by the technical coordinator for compatibility with physical and chemical principles.

\subsubsection{Facilities}

The BSCP data base will be stored on tape cartridges in the ORNL automated data library (ADL) in Building $4500 \mathrm{~N}$. Daily and weekly backups will be performed by computer operations staff. Computer software programs will be stored on the ADL and will be executed from TSO on the ORNL IBM 3090 mainframe computer.

\subsubsection{Data Security and Availability}

Read, write, delete, and execute access to computer data files and program files on the ADL will be controlled by the data management staff through ACF2 security system on the IBM 3090. Project users may be given read access privileges to files on the ADL as needed.

Validated field and analytical data will be transferred to OREIS with the approval of the project manager. Other ER Division projects needing backgrour ' soil concentration data may get copies of the data from OREIS.

\subsection{DOCUMENT CONTROL}

Document control is the process of assuring that documents are reviewed for adequacy, approved for release by authorized personnel, and distributed to and used at the location where the prescribed activity is performed. Document control is essential to BSCP activities to ensure the precision and integrity of the sampling activities, laboratory analyses, and resulting conclusions.

The Project Manager has the responsibility of identifying the documents to be controlled (consistent with the QAPP) and their specific distributions. 
To meet these objectives BSCP plans and reports will be prepared according to ER/CP1103, "Preparation, Clearance, and Approval of Environmental Restoration Division Documents," and distributed according to the draft ER procedure "Distribution of Controlled Documents within ER," when appropriate. BSCP procedures will be prepared following implementation of ER/CR-SOP1000, "Initiation, Review, Revision, Approval, and Issuance of Clinch River Environmental Restoration Program Standard Operating Procedures and Instructions."

These procedures clearly define the process to be followed from initiation through distribution for their respective document types. Distributions will be handled by either the ER-DMC, or the BSCP-DMC. Experienced staff will follow procedures that ensure that once a reproducible copy of the document has been received, the document will be reproduced in sufficient quantity, distributed with return receipts for numbered copies, updated when necessary with instruction and return receipts, and that copies are returned to the DMC when no longer needed.

\subsection{RECORDS MANAGEMENT SYSTEM}

All information that is required to provide a complete and accurate history of the project organization, sample collection, and analysis activities will be controlled in a records management system. A hard copy repository (the BSCP Document Management Center (DMC)) and associated index database provide for organization, protection, retrievability, and accountability of project records. All requests for access to BSCP information require the approval of the BSCP Project Manager.

Protocols for communication of necessary documents and data between the BSCP DMC and the DOE administrative record will be implemented as part of the BSCP data management activities.

\subsubsection{Records Control Process}

Records to be controlled as well as responsible personnel and organizations are shown in Table 7.1. All BSCP staff have the responsibility to identify record items and forward appropriate information to the DMC.

\subsection{Document Archive and Index}

The operation of the dual facility DMC is described in ER/CR-SOP1100 (CR-ERP 1992). This procedure will be implemented for the BSCP. The record copy will be maintained at the DMC located within the Environmental Sciences Division and the duplicate copy forwarded to the ER Division DMC. The index database associated with the DMC serves as 
a computerized index for retrieval of record documents generated by the project. Backup files of the document index will be created throughout each day during which new records were created or existing records edited. All documents submitted will be indexed to meet project needs and document retention schedules prepared.

\subsubsection{Document Accessibility}

BSCP documents are under the control of the project DMC staff as specified in the DMC operating procedure. BSCP staff may request copies of documents at any time. Access to BSCP records by others requires the approval of the Project Manager.

\subsection{ADMINISTRATIVE RECORD}

When BSCP data and documents become part of other project administrative records, DOE will maintain and preserve the complete administrative record, including supporting BSCP documents, for a minimum of 30 years following the termination and satisfaction of the project. DOE shall notify EPA and TDEC at least ninety days before the destruction of any such records or documents. DOE will upon request by EPA or TDEC make such documents (or copies) available.

Copies of the current index to the administrative record and selected documents shall be available to the public during normal working hours at the Information Resource Center established by DOE in Oak Ridge. 
Table 7.1. Records to be included in the BSCP DMC and the originating office. Items of record (duplicate or original) are to be transmitted to the BSCP Project Manager for inclusion in the DMC.

\begin{tabular}{|c|c|c|}
\hline $\begin{array}{l}\text { Record } \\
\text { Origination }\end{array}$ & Items of Record & Comment \\
\hline \multicolumn{3}{|c|}{ Records prepared by or for the BSCP and under direct project control. } \\
\hline $\begin{array}{l}\text { BSCP Project } \\
\text { Manager }\end{array}$ & $\begin{array}{l}\text { Project Plans and } \\
\text { correspondence }\end{array}$ & $\begin{array}{l}\text { Plans to be prepared, } \\
\text { reviewed, and approved }\end{array}$ \\
\hline $\begin{array}{l}\text { BSCP Technical } \\
\text { Coordinator }\end{array}$ & $\begin{array}{l}\text { Field and Laboratory notebooks } \\
\text { Personnel training } \\
\text { Reports } \\
\text { Analysis procedures } \\
\text { Sampling procedures }\end{array}$ & $\begin{array}{l}\text { Duplicates kept by } \\
\text { Tech. Coordinator, } \\
\text { originals transmitted }\end{array}$ \\
\hline $\begin{array}{l}\text { BSCP field and } \\
\text { laboratory technical } \\
\text { support staff }\end{array}$ & Field and laboratory notebooks & $\begin{array}{l}\text { Duplicates are kept by } \\
\text { staff, originals are } \\
\text { transmitted to the DMC }\end{array}$ \\
\hline $\begin{array}{l}\text { BSCP Analytical } \\
\text { Coordinator }\end{array}$ & $\begin{array}{l}\text { Chain-of-custody forms } \\
\text { Request for analysis forms } \\
\text { Analytical results } \\
\text { QA/QC results }\end{array}$ & $\begin{array}{l}\text { Originals are transmitted } \\
\text { to the DMC }\end{array}$ \\
\hline $\begin{array}{l}\text { Quality } \\
\text { Assurance }\end{array}$ & $\begin{array}{l}\text { Audits } \\
\text { Readiness review } \\
\text { Surveillance reports }\end{array}$ & $\begin{array}{l}\text { Originals transmitted to } \\
\text { the project manager and } \\
\text { transferred to the DMC }\end{array}$ \\
\hline \multicolumn{3}{|c|}{$\begin{array}{l}\text { Records which may be maintained by others in support of the BSCP and may be requested by the Project } \\
\text { Manager. }\end{array}$} \\
\hline ORNL Medical & Employee physician statements & $\begin{array}{l}\text { Duplicates transmitted at the } \\
\text { project manager's request } \\
\text { through S\&H Coordinator }\end{array}$ \\
\hline $\begin{array}{l}\text { ORNL Industrial } \\
\text { Safety }\end{array}$ & $\begin{array}{l}\text { Inspections } \\
\text { Reports }\end{array}$ & $\begin{array}{l}\text { Duplicates transmitted at } \\
\text { project manager's request } \\
\text { through S\&H Coordinator }\end{array}$ \\
\hline
\end{tabular}


Table 7.1. (continued)

Record

Origination

Items of Record

Comment

Resords which may be maintained by others in support of the BSCP and may be requested by the Project Manager.

ORNL Technical

Resources and

Training

ORNL Industrial

Hygiene

Division

ORNL Radiation

Protection

Department

(Health

Physics)

Environmental

Monitoring and

Compliance

Division (EMC)
Training/qualification records

OSHA training

RCRA training

Employee training

Category III training

Personnel monitoring

Equipment monitoring

Logbooks

Routine surveillance reports

Respirator fit testing and training

Personnel monitoring

Equipment monitoring

Decontamination records

Unusual occurrence reports

Routine Surveillance reports

Logbooks

ALARA memoranda

Engineering permits

Environmental documents

(ADM, EAM)
Duplicates transmitted

at the Project manager's

request through $\mathbf{S} \& \mathrm{H}$

Coordinator

Duplicates transmitted at the Project manager's request through $S \& H$

Coordinator

Duplicates transmitted through S\&H Coordinator, at project manager's request

Duplicates transmitted at project manager's request through the S\&H Coordinator 


\section{HEALTH AND SAFETY PLAN}

\subsection{INTRODUCTION}

\subsubsection{Purpose}

The purpose of this section is to address health and safety issues associated with the Background Soil Characterization Project (BSCP). Health and safety requirements and procedures outlined within this plan are intended to address in-field sampling activities. The goal of this plan is to: minimize avoidable accidents and injuries, eliminate worker exposure to chemicals greater than natural background concentrations in the performance of sampling activities, and to provide contingencies that may arise during soil sampling.

\subsubsection{Applicability}

The provisions of this health and safety section are mandatory for all on-site personnel and visitors engaged in field activities. All on-site personnel shall be provided copies of the work plan (which includes this health and safety section). A copy of the work plan shall be on site with each field team. All work shall be completed in accordance with this plan. A review of this plan by all sampling staff is required prior to conducting field activities. The Site Health and Safety Officer will resolve any questions regarding health and safety before sampling commences. All potential on-site personnel will sign and date the field logbook to verify that they been provided a copy of the plan and that they will conduct work in accordance with the plan.

\subsection{SITE INFORMATION}

\section{General}

Sites chosen for soil sampling will be screened by project personnel, as discussed in Sect. 5.3.2, to ensure that contaminants are not present. Any indication of contamination or disturbance will dictate that the site be removed from the list of sampling site candidates. Sampling sites will be chosen in accordance with Sect. 5.2 of this plan. ORR site locations were coordinated with ORNL Engineering Department to preclude contact with buried utility lines. All potential sampling sites within the confines of the Oak Ridge Reservation (ORR) shall be approved by the ORNL Industrial Hygiene HAZWOPER. (Hazardous Waste Operations and Emergency Response, 29 CFR 1910.120) prior to the commencement of sampling activities within the ORR. The ORNL Industrial Hygiene HAZWOPER may require the assistance of the K-25 or Y-12 HAZWOPER if the proposed sampling locations fall in closer vicinity to these respective sites. Sites sampled in Roane and Anderson Counties will be in a rural setting away from structures and facilities.

- All on-site personnel will have read the plan and discussed the health and safety issues with the Site Health and Safety Officer. In addition, all personnel shall be briefed as to on-site conditions and any potential safety hazards before being permitted access to the site by the SHSO. 
- Hard hats, safety glasses, gloves and safety shoes shall be required when sampling is being conducted using power equipment. Otherwise, only work gloves and appropriate field work clothes are required.

- Sampling crews will have an operable field radio with them when sampling within the ORR. Use of a mobile telephone is optional within the ORR. A mobile telephone, or a telephone in close proximity to the sampling sites at the extremes of Anderson County and Roane County should be available. A listing of appropriate radio numbers and/or phone numbers will be kept in the field logbook and are listed in section 8.5 of this plan.

- The BSCP Technical Coordinator or his appointee will be informud as to the sampling crew(s) intended sampling sites for each given day. The crew will endeavor to inform the BSCP Technical Coordinator or his appointee as to progress and changes in field plans as necessary.

\subsubsection{Physical Hazards}

Physical hazards expected to be encountered during sampling include: machinery related hazards when rotating equipment such as power augers or drill rigs are used, site related hazards such as uneven surfaces, trees and other obstacles, mud and slippery conditions and transportation related hazards.

Before starting sampling, the Technical Coordinator or his designee will verify that a penetration/excavation permit has been acquired. A copy of this permit shall be provided to the Site Health and Safety Officer. This permit, once reviewed and signed by the appropriate disciplines/personnel at Energy Systems, serves to inform that sampling sites have been selected in areas where underground utilities/obstructions should not be encountered.

The SHSO will ensure that sampling is carried out safely and in accordance with this workplan. Personnel involved in operating the equipment, collecting the sample, and the SHSO will be allowed to approach the sampling operation when power equipment is operating. The SHSO will limit the number of personnel that may be in close proximity to the sampling equipment in a manner that is consistent with the safe operation of the equipment.

Sampling shall not be attempted during periods of precipitation, subfreezing temperatures, or when illumination of the sampling site is less than 5 foot-candles. Sampling operations in progress may continue after onset of such ambient conditions if only a short time is required to complete the task and if work can proceed safely, i.e., light is available, and all monitoring equipment is functional.

\subsection{SITE TASK HAZARD ANALYSIS}

The purpose of the site task hazard analysis is to identity potential health and safety concerns that may be encountered by sampling personnel and the personal protective equipment required for the task. The site task hazard analyses described are minimum requirements. 


\subsubsection{Site Requirements}

Sites selected for sampling will be rural in setting either wooded or fields and for the most part sampling will be done using hand tools. A power auger and rarely, if needed, a small drill rig may be used for sampling the deeper soil horizons. Pre-entry health and safety briefings in the form of team "Tailgate" meetings will be held at each site to asses each site for potential hazards and site specific set up/layout of equipment and operations to minimize hazards and optimize efficiency of sampling.

Level D is required only for sampling with power equipment. Splash shields and rubber gloves will be worn by personnel handling fuel for the power aliger and or drill rig when these are used. In addition, hard hats, hearing protection, safety glasses, gloves and steel toed boots will be required for those working around the drill rig or power auger, refer to Table 8.1.

Table 8.1. Protective equipment for on-site activities

\begin{tabular}{lll}
\hline Activity & Level & Protective equipment \\
\hline Sampling using power & $D$ & Hard hat \\
augers and drill rigs. & & Safety glasses \\
& & Hard-toed boots \\
& & Field work clothes \\
& & Hearing protection \\
& Work gloves \\
\hline Equipment precleaning & D & Rubber gloves \\
Cleaning (laboratory) & D- & Safety glasses \\
& & Work clothes \\
& & Face shield \\
& & Splash apron \\
\hline Normal sampling & D- & Work clothes \\
& & Work gloves \\
& Work shoes \\
\hline
\end{tabular}

Rubber gloves, aprons and splash shields will be required during precleaning or clean up of equipment and sample containers where washing/rinsing operations are involved. This operation will be conducted at the laboratory.

Inadequate health and safety precautions on the part of any on-site personnel or the belief that personnel are or may be exposed to an immediate health hazard shall be sufficient cause for the Site Health and Safety Officer to suspend site work and require personnel to evacuate a potentially hazardous area.

Soil sampling for the BSCP will occur through the spring and summer of 1992 . The actual dates for sampling individual sites are dependent upon weather and logistical factors. The Technical Coordinator has determined that the time set aside for sampling is adequate to accommodate any anticipated delays. 


\subsubsection{Suspected Contaminants}

Sites sampled for the BSCP are selected and screened to ensure that no contaminants are present. In addition, periodic monitoring will be employed to demonstrate the absence of detectable contaminants, refer to Sect. 8.7.

\subsubsection{Hazard Evaluation}

\begin{tabular}{|l|l|l|l|}
\hline Waste types: & Liquid/Free No & Solid No & Sludge No \\
\hline Characteristics: & Corrosive No & Ignitable No & Radioactive No \\
\hline & Volatile No & Toxic No & Reactive No \\
\hline & Unknown No & & \\
\hline Hazards: & Chemical No & Physical Yes & Radiological No \\
\hline
\end{tabular}

\subsubsection{Sampling}

Level $\mathrm{D}$ protective clothing will be required only when sampling is being conducted using power equipment. In other cases the sampling crew will be responsible for wearing clothing sufficient to protect them from ambient conditions and poison ivy during site preparation. Because the sites will be selected on the basis of no contamination, there is no need for requiring extensive PPE measures above level $D$.

In addition to level $D$ protection, ear protection will be required by all sampling personnel within a distance of 20 radial feet from where power equipment is being used. Rubber gloves, splash goggles and splash aprons will be worn when fueling the equipment. All personnel not required for equipment operation and sampling will be kept away at a minimum of 20 radial feet, or the height of the mast of the drill rig, whichever is greater, from the sampling area during power equipment operation and mobilization/demobilization. The drill rig operator and the sampling crew leader will verify that the drill rig will not be located so that any part of the rig is within 10 feet of any electrical transmission lines. The voltage of a transmission line in close proximity to sampling site should be determined. Table 8.2 should then be consulted in order to determine the distance required for safe operation of the drill rig when in proximity to transmission lines.

\subsubsection{Equipment Cleaning}

Equipment cleaning will be done to prevent cross contamination of samples between sites even though contaminants in hazardous concentrations, or above regulatory limits, are not believed to be present at the sampling sites. Equipment will be returned to the laboratory and cleaning will be affected by soap and water wash and rinse and acid wash and water rinse. Level D-PPE requiring rubber gloves, splash goggles and splash aprons or other water resistant gear will be worn by personnel cleaning the sampling equipment in the laboratory. The drilling rig, when used, will be washed with a pressure washer or hose and potable water on-site. PPE will be as above but with a hard hat, work boots and face shield instead of just splash goggles. 
Table 8.2. Safe working distances

from electrical transmission lines for drill rigs

\begin{tabular}{cc}
\hline $\begin{array}{c}\text { Normal voltage } \\
(\text { phase-to-phase })\end{array}$ & $\begin{array}{c}\text { Minimum clearance } \\
\text { required } \\
(\mathrm{kV})\end{array}$ \\
\hline
\end{tabular}

When operating near high voltage power lines

$\begin{array}{rl}0 \text { to } 50 & 10 \\ 50 \text { to } 200 & 17 \\ 200 \text { to } 350 & 22 \\ 350 \text { to } 500 & 27 \\ 50 \text { to } 750 & 35 \\ 750 \text { to } 1000 & 44\end{array}$

While in transit with mast lowered

All voltages 10

Sounce: Crawler locomotive and truck cranes [29 CFR 1910.180j(1)].

\subsection{SPECTAL HAZARDS}

All site investigation personnel may potentially be exposed to the hazards outlined below.

\subsubsection{Heat Stress}

Sampling activities may be physically demanding during the warmer months. Physical demands may be compounded through the use of protective clothing/equipment, moderate to heavy workloads, ambient air temperatures, relative humidity, and exposure to nonionizing radiation (sunlight).

Two important factors will help personnel function in hot environments, acclimatization and consumption of fluids. Acclimatization of workers most likely will not be a problem as the sampling will span the transition from cool to hot weather. During this period especially, workers should concentrate on maintaining a balanced diet, consuming plenty of fluids throughout the day, and remaining aware of telltale signs of heat-related stress. Headaches, dizziness, high body temperature, and increased heart rate are all early warning signals of heat stress. It is imperative that the SHSO be informed of this condition if a worker experiences these signs.

All sampling will be done by a crew of at least two persons at the investigative site, which will incorporate a "buddy" system, and as samplir $y$ continues, all personnel should be apprised of their buddy's condition with respect to heat. A work regimen will be instituted, if necessary, to help in combatting heat-related disorders during the worst of the hot weather. The SHSO may develop work/rest regimens in accordance with his/her best professional judgment and 
the guidelines published by the American Conference of Governmental Industrial Hygienists (ACGIH) and may consult ORNL IH for assistance in determining WBGT readings.

\subsubsection{Biological Stress}

Field conditions may present a variety of biological stresses. It is the responsibility of investigative personnel to inform the SHSO of pre-existing health conditions they have that may be affected by on-site biological stresses. Examples of these stresses may be, but are not limited to, bee stings, ticks, poison ivy, asthmatic conditions that may be affected by exposure to certain pollens and grasses, snakes, etc.

\subsubsection{Illumination}

Normal operating conditions for the BSCP will involve conducting field activities during daylight hours. A minimum of $5 \mathrm{ft}-\mathrm{c}$ will be required to conduct field activities; however, actual field measurements of illumination will not be collected. A conservative guideline may be that field work will commence $15 \mathrm{~min}$ after sunrise and conclude $15 \mathrm{~min}$ prior to sunset. Adherence to the minimum $5 \mathrm{ft}-\mathrm{c}$ requirement will depend on the SHSO's best professional judgment.

\subsubsection{Dust}

Based upon previous experience associated with sampling activities, it is likely that dust generation will be minimal. A generic rule of thumb is that a visible cloud of dust will constitute an action limit. An engineering control may be employed to control dust, such as wetting the auguring area with deionized water that is sprayed as a fine mist from a garden sprayer. In the unlikely event that engineering controls are unsuccessful, the appropriate Industrial Hygiene organization will be summoned to assess the situation and to provide guidance.

\subsubsection{Ergonomics}

Potential hazards related to the interaction of personnel with their working environment may be present for sampling. The primary ergonomic hazards that may exist may be lifting heavy loads, equipment vibrations, body positioning, and physical obstacles associated with traversing ditches and brush. Personnel should always position themselves properly and lift from the legs when attempting to lift equipment. Personnel should rely on their "buddy" to assist in lifting loads that are too heavy for one person to properly lift and carry. Back strain, the most common ergonomic hazard in the field, may be easily avoided, provided the on-site workers always ask for assistance when they need it.

A certain degree of vibration may be encountered by sampling personnel when operating the power auger or drill rig. If any tingling of digits is encountered, appropriate work/rest regimens will be employed by the SHSO within his/her best professional judgment. If any ergonomic symptoms are encountered in the field, the SHSO should be notified immediately. 


\subsubsection{Physical Sampling Location Hazards}

These hazards may include, but are not limited to, movement of equipment around the site, mechanical equipment malfunctions, unestablished roads, and pitential noise hazards. Personal hazards, such as tripping or falling, can also have an adverse effect on the health and safety of personnel.

Overhead electrical transmission lines may cross some sampling locations. Prior to placing drilling rig at an auger hole location,if a drill rig is to be used, sampling crew leader or his designee shall verify that the rig will not be operated when any part of the drill rig mast enters within a minimal radial distance of $10 \mathrm{ft}$ from electrical transmission lines or as specified in Table 8.2. All personnel should stay out from under overhead work and temporarily suspended or moving equipment whenever possible. The sampling locations will be certified clear of all known underground hazards by authorized personnel (Energy Systems Civil Engineering) prior to sampling.

\subsection{PROJECT ORGANIZATION AND RESPONSIBIIITIES}

This project is being conducted under the direction of the ORNL Environmental Sciences Division for the Environmental Restoration Program at the K-25 Plant site. Table 8.3 shows the responsible BSCP personnel. The small scale of this project places most of the responsibility for on site health and safety on the Project Technical Coordinator and sampling crew. The Project Technical Coordinator may designate an alternate individual experienced in functioning as the SHSO.

Table 8.3. Key BSCP personnel

\begin{tabular}{|c|c|c|}
\hline Responsibility & Name & Telephone \\
\hline Project Manager & D. R. Watkins & $576-9931$ \\
\hline Technical Coordinator & S. Y. Lee & $574-6316$ \\
\hline Project QA Coordinator (field) & J. Switek & $574-7415$ \\
\hline Project QA Coordinator (laboratory) & C. W. Kimbrough & $574-3715$ \\
\hline $\begin{array}{l}\text { Environmental Restoration Division } \\
\text { Technical Oversight Manager }\end{array}$ & D. T. Bell & 574-3208 \\
\hline Site Health and Safety Officer (SHSO) & $\begin{array}{l}\text { Sampling Team Leader } \\
\text { or S. Y. Lee or J. Switek }\end{array}$ & $574-6316$ \\
\hline $\begin{array}{c}\text { X-10 Industrial Hygiene } \\
\text { HAZWOPER }\end{array}$ & A. W. Saulsbury & $\begin{array}{l}576-5064 \\
564-5805)\end{array}$ \\
\hline X-10 Health Physics & C. S. Sims & $574-6692$ \\
\hline X-10 Safety & J. D. Miller & $574-6680$ \\
\hline
\end{tabular}




\subsubsection{Technical Integration Manager}

The Technical Integration Manager is responsible for overall management of the BSCP and for providing budget and programmatic information to the MMES Central ER Division and BSCP personnel.

\subsection{Project Manager}

The BSCP Project Manager is responsible for managing and coordinating field, statistical and analytical activities associated with the BSCP. Activities include

- coordinating the support organizations required for field, analytical and assessment activities;

- ensuring that required plans, permits and documentation are approved, implemented or obtained;

- ensuring that all personnel are qualified for their assigned tasks;

- providing oversight for field sampling activities and laboratory analyses;

- ensuring adherence to the workplan throughout the field activities;

\subsubsection{Technical Coordinator}

The Technical Coordinator is responsible for managing and coordinating field, analytical and data handling activities associated with the BSCP. He/she will be responsible for site accessibility, safety, and quality assurance (QA) and will delegate further responsibilities to members of the sampling team. Specific responsibilities of the Technical Coordinator are listed below:

- coordinating the sampling personnel and field activities;

- notifying the appropriate Shift Superintendent or support personnel of plans and scheduled field activities;

- defining sampling and analysis parameters for investigation;

- obtaining required permits and documentation;

- ensuring that all sampling staff have adequate health and safety training;

- overseeing field sampling activities and laboratory analyses;

- ensuring adherence to the workpis.n throughout the field investigation;

- determining the intended use of data;

- coordinating on-site operations, including logistics; 
- interfacing with plant and project personnel;

- $\quad$ acting as Site Health Safety Officer or designating a qualified individual to that role;

- participating in on-site characterization activities;

- determining in-field procedural variances necessary to respond to site-specific conditions; and

- documenting and reporting unforeseen site-specific changes and corrective actions.

\subsubsection{Site Health Safety Officer/Project Personnel}

The role of Site Health Safety Officer (SHSO) will be filled by an experienced individual, usually the sampling team leader. For most of the project the field crew will consist of two persons. The duties of the SHSO will only be shared by qualified crew members designated by the Technical Coordinator. The role of SHSO can be assumed by the Technical Coordinator or the field QA Coordinator.

Duties of the SHSO include the following.

- Approving all field operations plans.

- Ensuring that personnel review this plan and are aware of its provisions, are instructed in safe work practices, and are familiar with potential hazards and planned emergency procedures prior to initiation of site activities.

- Requesting that an individual volunteer any medical information that would necessitate special consideration (e.g., allergies, diabetes, pregnancy); medical information that is provided to the SHSO shall be kept confidential.

- Ensuring that all prospective site personnel sign and date the field logbook to verify that the previous two items have been fulfilled.

- Implementing the workplan, reporting to the Technical Coordinator any deviations from anticipated conditions, and authorizing the cessation of work if necessary. In the event that an unsafe condition or hazard becomes evident during the investigation, ordering operations to cease, safeguarding personnel, and contacting Industrial Hygiene/Health Physics to determine if sampling may continue at the site.

- Establishing and making available at the site an emergency action plan, with telephone numbers and appropriate radio communication information.

- Identifying key plant personnel (and alternates) who are responsible for specific safety-related areas, such as health, plant safety, health physics, industrial hygiene and the Shift Superintendent's organization to facilitate emergency response.

- Ensuring that penetration/excavation permits have been generated and that a signed copy is available on-site, prior to commencing the field work. 
- Ensuring that all project personnel who report an injury go to the Health Center for evaluation and treatment.

- Ensuring that personnel stay out from under overhead work and temporarily suspended equipment.

- Assisting personnel with the completion of report form(s) if needed. Ensuring that all completed forms, either originals or copies, are returned to the Technical Coordinator.

Duties of the Project Personnel include:

- Taking all reasonable precautions to prevent injury to themselves and their fellow employees; being alert to potentially harmful situations.

- Conducting radiation monitoring according to accepted procedures (BSCP-SOP01, Rev. 1).

* Performing only those tasks that they believe they can do safely and immediately reporting any accidents and/or unsafe conditions to the SHSO and the Technical Coordinator.

- Notifying the SHSO of any medical conditions (e.g., allergies, diabetes, pregnancy) that require special consideration. A medical department approval and/or a physician's recommendation may be required before an individual with a medical condition can be assigned a specific field task.

- Preventing spillage to the extent possible. In the event that a spillage occurs, containing liquid, if possible, and notifying the SHSO.

- Using their senses (all senses) to alert them to potentially harmful situations.

- Practicing good housekeeping by maintaining order, thereby reducing the likelihood of potentially harmful situations.

- Being familiar with the physical characteristics of sampling and the site.

- Reporting all injuries to the SHSO, no matter how minor.

It is not anticipated that any hazardous wastes or environmental contaminants will be generated as a result of operations in this project. All refuse and conventional wastes will be disposed according to approved ORNL practices.

\subsection{ORNL Industrial Hygiene (HAZWOPER)}

The ORNL IH Section shall be responsible for the oversight and approval of field investigative efforts related to industrial hygiene. In addition, the IH representative shall have stop-work authority and may be consulted regarding personal protective equipment as well as industrial hygiene monitoring and sampling. The IH representative also may be consulted to authorize a return to work after any site hazard has been resolved. 
Operating within the IH Section and located at ORNL, the HAZWOPER Program Coordinator shall approve all plans prior to mobilization and the commencement of field activities. All potential sampling sites within the confines of the Oak Ridge Reservation (ORR) shall be approved by the ORNL Industrial Hygiene HAZWOPER prior to the commencement of sampling activities within the ORR. The ORNL Industrial Hygiene HAZWOPER may require the assistance of the K-25 or Y-12 HAZWOPER if the proposed sampling locations fall in closer vicinity to these respective sites.

\subsubsection{ORNL Health Physics}

ORNL HP shall be responsible for the oversight of field investigative efforts related to health physics. ORNL HP shall approve all plans prior to mobilization and the commencement of field activities. In addition, HP shall have stop-work authority and may be consulted regarding personal protective equipment and health physics monitoring and sampling. HP also may be consulted to authorize a return to work after any hazardous situation on site has been resolved.

\subsubsection{ORNL Safety}

The ORNL Industrial Safety (IS) Section will be responsible for oversight of field investigative efforts relating to safety. The SHSO shall approve all plans prior to the mobilization and commencement of field activities. IS will review and provide necessary input to the plan(s). IS shall have stop-work and continuation authority and may be consulted regarding safety-related issues relevant to personnel and equipment.

\subsection{EMERGENCY PROCEDURES}

The Plant Protection and Shift Operations Divisions of all three of the ORR plants provide 24 hour emergency response coverage, which is the responsibility of the plant shift superintendents (PSS), Shift Operations Office/Department. The Stift Superintendents on duty are assisted by well-trained plant emergency squads and are the overall coordinators responsible for directing the response to emergencies such as fires, accidents, injuries, natural disasters, sabotage, etc. As most of the sampling activities will occur away from ORR plant facilities, the sampling crew will carry field radios (at least one) tuned to the ORNL KIN 294/295 network for communications in case of emergency. The ORNL security department is in communication with emergency response organizations for all three ORR plants and can notify the appropriate personnel. The shift superintendents on duty are the designated Plant Emergency Directors who are responsible for coordinating and responding to all ORR emergency situations. Any member of the sampling crew can notify or assign someone to notify the Shift Superintendent of an emergency situation as soon as possible. In the event that an off-site emergency occurs, 911 should be dialed on the mobile phone or should be called from the nearest available phone. The PSS should be notified after obtaining assistance from 911 for an off-site emergency. 


\subsubsection{Shift Superintendent}

EMERGENCIES: Plant Phone: 911 (all ORR Plants)

$\begin{array}{cl}\text { Off-Reservation Occurrences: } & \text { Phone: } 911 \\ \text { K-25 } & 574-3282 \\ \text { X-10 } & 574-6606 \\ \text { Y-12 } & 574-7172\end{array}$

ORNL Radio Network: KIN-294/295

Contact the Shift Superintendent first. The Superintendent is the trained emergency response director.

Listed below are emergency groups and their telephone numbers. A cellular phone will be present in the field and available for use when workers are not in close proximity to a plant phone.

\section{K-25 Emergency Numbers}

Environmental Management

574-8222

Guard Department

574-8315

Health Physics

574-0332

Industrial Hygiene

574-8622

Medical

574-8562

Public Relations

576-0437

Safety

574-8568

Security

\section{X-10 Emergency Numbers}

Environmental Management

Security Patrol

Health Physics

Industrial Hygiene

Medical

Public Relations

Industrial Safety

Security

574-8222

574-6646

574-6700

574-6165

574-7431

$574-4160$

574-6679

574-7196

\section{Y-12 Emergency Numbers}

$\begin{array}{ll}\text { Environmental Management } & 576-7113 \\ \text { Guard Department } & 574-7272 \\ \text { Health Physics } & 574-3547 \\ \text { Industrial Hygiene } & 574-1590 \\ \text { Medical } & 574-1577 \\ \text { Public Relations } & 576-1640\end{array}$


Safety

Security
574-1568

$574-3287$

\subsubsection{Reporting an Emergency}

\section{Telephone}

- If a plant telephone is accessible, dial 911. With an off-site (cellular) phone, dial 574-3282. With a plant radio, call KIN 294 or 295. When operating off the ORR dial the local 911 to obtain emergency assistance prior to contacting the PSS.

- Describe the type of emergency.

- Identify the location of the emergency.

- Identify who is calling.

- In case of an injury, tell whether an ambulance is needed.

- Listen to and follow any instructions that are given.

Fire Alarm Pull Boxes

Pulling a fire alarm box automatically transmits the location of the emergency to the Fire Department and the Emergency Control Center. The person pulling the alarm should remain at the alarm box and supply any needed information to the responding emergency squad.

\section{Radio}

By calling KIN 294 or 295, the Plant Shift Superintendent will be alerted of the emergency.

- Tell of the emergency.

- Tell the type of emergency.

- Tell the location of the emergency.

- Identify who is calling.

- Listen for any instructions

\section{IMPORTANT REMINDERS}

- Know the telephone/radio number(s) of the appropriate Plant Shift Superintendent, 911, or KIN 294/295. 
- Dial the local 911 in the event that an emergency occurs off of the ORR. Following notifying the local 911 and obtaining assistance, the PSS should be notified.

- Know how to summon an ambulance (in plant, someone has gone to a phone): Dial 911 and give the location. Wait at the location specified by the Plant Shift Superintendent to meet the arrival of the first-aid personnel.

- To summon the plant emergency squad at a fire alarm box: Pull the fire alarm and wait for the arrival of the Emergency Response Team at the box.

\section{SITE MONITORING}

This periodic monitoring program is designed to protect all site investigative personnel from the unlikely potential of encountering volatile organic and radiological contaminants, within the best of our knowledge and the limits of our resources. The sampling sites selected are based on historical information which suggests that the background samples will be collected from locations devoid of chemical and radiological contamination that may pose an on-site health and safety risk to project personnel.

\subsubsection{Monitoring Frequency}

Representative monitoring of volatile organics will be done by ORNL IH or a designated representative for $25-30 \%$ of the selected sampling sites. A beta/gamma walkover survey of each sampling site will be conducted prior to sampling by the sampling crew, trained by ESD Health Physics, and the results recorded/documented in the field logbook. Monitoring will be continuous during excavation for sampling. Radiological and volatile organic monitoring equipment shall be required for only that phase of the investigation that is conducted within the boundaries of the ORR due to the historical background and incomplete knowledge of the characteristics of the ORR.

\subsubsection{Instrument Calibration/Response Checks}

All applicable instruments shall be calibrated within the proper time frame in accordance with the manufacturer's recommendations and specifications described in the manufacturer's SOPs and in accordance with X-10 Industrial Hygiene and Health Physics requirements. Calibration readings and the number of each radiological source will be recorded in the field logbook and flagged in the margin. Background concentrations/levels shall also be recorded in the field logbook for each individual sampling site.

All radiation monitoring instruments will be loaned from the Environmental Sciences Division. A Health Physics representative will be available and will be enrolled in the ORNL calibration and maintenance program for qualification in the use of such instrumentation.

\subsubsection{Monitoring Equipment Action Limits}

Evaluation of site data does not warrant the anticipation of chemical or radiological contamination. Although chemical and radiological contaminants are not expected at the project site, precautions shall be taken to minimize the possibility of exposures to site 
workers. Industrial Hygiene shall be contacted to monitor $25-30 \%$ of the selected sampling sites, and at other times as requested by the SHSO or deemed necessary by Industrial Hygiene. If VOCs are detected in the breathing zone at $5 \mathrm{ppm}$ for $5 \mathrm{~min}$, work shall halt, and the IH will determine actions necessary to coordinate appropriate response actions. It may become necessary to abandon the location and proceed to the next sampling location.

\subsection{SITE CONTROL MEASURES-SAMPLING AREA}

Site zonation will not be used during BSCP sampling activities. Efforts will be made to restrict access to the sampling operation for the purpose of protecting the integrity of the sample and when power equipment is being used. The only area marked off will be the sampling area itself. This area will be controlled by the sampling team leader.

The corners of the sampling area will be marked with flags and access will be controlled to protect the integrity of the area. Protective clothing will normally consist of work clothing and gloves necessitated by ambient conditions and site factors, such as briars, poison ivy and insects. When power equipment is to be used, the sampling personnel involved will wear Level D protective clothing, as specified in Table 8.1.

Prohibited personnel, items, and conduct in the Sampling Area include the following:

- eating, drinking, smoking, or chewing anything;

- failure to inform the sampling team leader or SHSO of any illness that could affect safety or cause health-related complications;

- any individual not involved in the sampling effort;

- any conduct or item thought to be potentially dangerous to the well-being of the sampling team or the integrity of the samples; and

- application of insect spray or cosmetics, since interaction of these substances may affect the screening samples obtained for VOCs. After the VOC screening samples have been collected, insect repellents may be applied, as warranted.

\subsection{HEALTH AND SAFETY TRAINING REQUIREMENTS}

All personnel who participate in field sampling for the BSCP are subject to the following training requirements.

- All personnel working on the site must have attended the pre-entry health and safety briefing, and documentation of the training must be entered in the field logbook before site access will be granted. All on-site sampling personnel will also be on the Energy Systems radiological dosimetry program, and those badges will be required during this project. 
- Documentation of project specific health and safety training for BSCP sampling personnel will be in accordance with MMES Training Program requirements.

- All site personnel shall be trained in the hazards associated with this project prior to commencement of work activities. MSDSs for any fuels, solvents, and decontamination fluids shall be kept on site and available to all workers at all times. The SHSO shall be responsible for upkeep of MSDSs. 


\section{REFERENCES}

AEC (U.S. Atomic Energy Commission). 1972. Health and Safety Laboratory Procedures Manual. HASL-300. New York, New York.

ASME (American Society of Mechanical Engineers). 1989. Quality Assurance Program Requirements for Nuclear Facilities. ASME/NQA-1. New York, New York.

Baumgardner, D. R. and W. W. Chance. 1984. Resource Management Plan for the U.S. Department of Energy Oak Kidge Reservation, Appendix K: Site Development. ORNL-6026/V11. Martin Marietta Energy Systems, Inc., Oak Ridge, Tennessee.

DOE (U.S. Department of Energy). 1989. General Environmental Protection Program. DOE Order 5400.1. U.S. Department of Energy, Washington, D.C.

EPA (U.S. Environmental Protection Agency). 1980a. Interim Guidelines and Specifications for Preparing Quality Assurance Project Plans. EPA QAMS-005/80. Quality Assurance Management Staff. Washington, D.C.

EPA (U.S. Environmental Protection Agency). 1980b. Prescribed Procedures for Measurement of Radioactivity in Drinking Water. EPA-600/4-80-032. Cincinnati, Ohio.

EPA (U.S. Environmental Protection Agency). 1980c. Samplers and Sampling Procedures for Hazardous Waste Streams. EPA/600/2-80/018. Washington, D. C.

EPA (U.S. Environmental Protection Agency). 1983. Preparation of Soil Sampling Protocol, Techniques and Strategies. PB83-206979. University of Nevada. Las Vegas, Nevada.

EPA (U.S. Environmental Protection Agency). 1987a. RCRA Facility Investigation Guidance. EPA/SW-87-001. Office of Solid Waste and Emergency Response, U.S. Environmental Protection Agency. Washington, D.C.

EPA (U.S. Environmental Protection Agency). 1987b. A Compendium of Superfund Field Operations Methods. EPA/540/P-87/001. Washington, D.C.

EPA (U.S. Environmental Protection Agency). 1987c. Data Quality Objectives for Remedial Response Activities. EPA/540/G-87/003. Washington, D.C.

EPA (U.S. Environmental Protection Agency). 1989. Risk Assessment Guidance for Superfund, Volume 1, Human Health Evaluation Manuah Part A. Office of Emergency and Remedial Response. EPA/540/1-89-002. Washington, D.C.

EPA (U.S. Environmental Protection Agency). 1990a. Contract Laboratory Program Statement of Work for Organics. Las Vegas, Nevada.

EPA (U.S. Environmental Protection Agency). 1990b. Contract Laboratory Program Statement of Work for Inonganics. Las Vegas, Nevada. 
EPA (U.S. Environmental Protection Agency). 1991a. Human Health Evaluation Manual, Supplement Guidance: "Standard Default Exposure Factors." OSWER Directive 9285.6-03. Office of Solid Waste and Emergency Response. Washington, D.C.

EPA (U.S. Environmental Protection Agency). 1991b. Laboratory Data Validation Functional Guidelines for Evaluating Organic Analyses. Hazardous Site Control Division. Latest Edition. Alexandria, Virginia.

EPA (U.S. Environmental Protection Agency). 1991c. Laboratory Data Validation Functional Guidelines for Evaluating Inorganic Analyses. Hazardous Site Control Division. Latest Edition. Alexandria, Virginia.

EPA (U.S. Environmental Protection Agency). 1991d. Engineering Support Branch Standard Operating Procedures and Quality Assurance Manual. Region IV. Athens, Georgia.

EPA (U.S. Environmental Protection Agency). 1991e. Test Methods for Evaluating Solid Waste. SW-846, 3rd Edition. Washington, D.C.

Hardeman, W. D. 1966. Geologic Map of Tennessee, East-Central Sheet: Tennessee Division of Geology and U.S. Geological Survey, scale 1:250,000.

Kimbrough, C. W., L. W. Long, and L. W. McMahon (eds.). 1988. Environmental Surveillance Procedures Quality Control Program. ESH/Sub/87-21706/1. Martin Marietta Energy Systems, Inc., Oak Ridge, Tennessee.

Lemiszki, P. J. 1992. Macroscopic and Mesoscopic Structural and Stratigraphic Analysis of the Oak Ridge Reservation and Mechanical Modeling of Lithologic Controls on Fracture and Fold Development. (Ph.D. Dissertation). University of Tennessee, Knoxville.

Lietzke, D. A., S. Y. Lee, and R. E. Lambert. 1988. Soils, Surficial Geology, and Geomorphology of the Bear Creek Valley Low-Level Waste Disposal Development and Demonstration Program Site. ORNL/TM-10573. Oak Ridge National Laboratory, Oak Ridge, Tennessee.

McMaster, W. M. 1967. Hydrologic Data for the Oak Ridge Area, Tennessee. U.S. Geological Survey Water-Supply Paper 1839-N.

MMES (Martin Marietta Energy Systems, Inc.). 1986. Environmental Surveillance of the Oak Ridge Reservation and Surrounding Environs During 1986. ORNL-6271. Martin Marietta Energy Systems, Inc., Oak Ridge, Tennessee.

MMES (Martin Marietta Energy Systems, Inc.). 1989a. Oak Ridge Reservation Site Development and Facilities Utilization Plan. DOE/OR-885. Martin Marietta Energy Systems, Inc., Oak Ridge, Tennessee.

MMES (Martin Marietta Energy Systems, Inc.). 1989b. Clinch River RCRA Facility Investigation Plan 1990. ES/ER-1\&D1. Environmental Restoration Division, Oak Ridge National Laboratory, Oak Ridge, Tennessee. 
MMES (Martin Marietta Energy Systems, Inc.). 1990. Remedial Investigation Plan for Waste Area Grouping 2 at the Oak Ridge National l.aboratory, Oak Ridge, Tennessee. ES/ER-14\&D1. Environmental Restoration Division, Oak Ridge National Laboratory, Oak Ridge, Tennessee.

MMES (Martin Marietta Energy Systems, Inc.). 1991. Environmental Restoration Division Quality Assurance Program Plan. ES/ER/TM-4/R1. Martin Marietta Energy Systems, Inc., Oak Ridge, Tennessee.

Petrich, C. H., et al. 1984. Resource Management Plan for the U.S. Department of Energy, Oak Ridge Reservation, Appendix G: Geography, Demography Topography and Soils. ORNL 6026/V7. Martin Marietta Energy Systems, Inc., Oak Ridge, Tennessee.

U.S.D.A. (U.S. Department of Agriculture). 1975. Soil Taxonomy, A Basic System of Soil Classification for Making and Interpreting Soil Surveys. Agriculture Handbook No. 436, Soil Conservation Service. U.S.D.A. Washington, D.C. 
APPENDIX A

REFERENCE SOIL PROFILE DESCRIPTIONS 
Soil Series No: $205 \quad$ Dismal Gap Formation

Location: ORR, Bear Creek Area. E 32260, N 30315, Y-12 Grid.

Classification: Ruptic Ultic Dystrochrepts; clayey Bt and loamy-skeletal cambic and ruptic.

Geomorphic Position: Upper shoulder off ridgetop.

Slope and Aspect: $6 \%$ SE.

Parent Materials: Shale and siltstone saprolite and lime beds from Dismal Gap Formation.

Vegetation: Old-field re-growth of hardwoods.

Described by: Lietzke.

Date: 2-11-92.

\section{ARGILLIC PART}

Oi $\quad 5$ to $0 \mathrm{~cm}$, leaf litter.

A 0 to $4 \mathrm{~cm}$; dark brown (10YR 3/3) silt loam; moderate fine granular structure; very friable; abrupt wavy boundary.

Ap 4 to $15 \mathrm{~cm}$; dark yellowish brown (10YR 4/4) heavy silt loam; moderate fine granular structure; very friable; abrupt wavy boundary.

Bt 15 to $30 \mathrm{~cm}$; red (2.5YR 4/6) silty clay-clay; moderate medium subangular blocky structure; friable to firm; yellowish red (5YR 4/6) clay films on ped faces; clear irregular boundary.

BC 30 to $45 \mathrm{~cm}$; red (2.5YR 4/6) ped interiors and yellowish brown (10YR 5/6) fragment interiors; crushes to clay or shaly clay; rock controlled structure but peds in areas between fragments; peds and saprolite fragments coated with yellowish red (5YR 4/6) clay; finer cracks in saprolite fragments are coated with black manganese oxides and red (10YR 4/6) iron oxides; near vertical dip on saprolite; clear irregular bounda:y.

CB 45 to $76 \mathrm{~cm}$; yellowish brown (10YR 5/6) soft saprolite that crushes to shaly silty clay; rock controlled structure with nearly vertical dip; red (10R 4/6) iron oxides, black manganese oxides and yellowish red (5YR 4/6) clay plugged zones; very firm; very irregular broken boundary. 
Cr 76 to $80 \mathrm{~cm}$; light olive brown (2.5Y 5/6) harder shale and siltstone saprolite; tragments coated with black manganese oxides and red (10R 4/6) iron oxides.

\section{CAMBIC PART}

A $\quad 0$ to $5 \mathrm{~cm}$; dark brown (10YR 3/3) shaly loam; moderate fine and medium granular structure; friable; many fine roots and pores throughout; $\mathrm{pH} 4.7$; clear smooth boundary.

Bw 5 to $16 \mathrm{~cm}$; dark yellowish brown (10YR 4/4) very shaly loam; weak fine and medium subangular blocky structure; firm; common fine and medium roots and pores throughout; $\mathrm{pH} 4.7$; gradual inclined boundary.

Cr $\quad 16 \mathrm{~cm}$

Soil Series No: $301 \quad$ Nolichucky Shale Formation

Location: Bear Creek LLWDDD Site. \# 30230, N 29250, Y-12 grid.

Classification: Ruptic Ultic Dystrochrepts; loamy-skeletal, mixed, thermic.

Pedon Classification: Ruptic Aquultic Dystrochrepts; loamy-skeletal, mixed, thermic.

Geomorphic Position: Upper slightly convex sideslope of low hillside.

Slope: $4 \%$ with southeast aspect.

Parent material: Saprolite from claystone, siltstone and argillaceous limestone along with thin strata of very fine sandy loam.

Described by: Lambert, Lietzke and Jenkins. March 13, 1987.

Because of the ruptic nature of the soil, it was necessary to described three profiles in order to encompass the "cyclic" variability of one pedon. 


\section{ARGILLIC PART}

O 2 to $0 \mathrm{~cm}$; leaf litter.

Ap 0 to $18 \mathrm{~cm}$; dark yellowish brown (10YR 4/4) shaly silt loam; moderate fine granular structure; very friable; many fine and medium roots between peds; many fine pores; pH 4.7; abrupt wavy boundary.

Bt 18 to $33 \mathrm{~cm}$; mottled yellowish red (5YR 5/8), yellowish brown (10YR 5/6) and strong brown (7.5YR 5/6) silty clay; moderate medium subangular blocky structure; firm; common fine prominent brownish gray (10YR 6/2) mottles in ped interiors; many continuous and distinct brown (7.5YR 5/4) clay films on ped faces; few fine and medium roots between peds; common fine pores; $\mathrm{pH} 4.8$; clear irregular boundary. (Argillic Horizon part of pedon)

BC 33 to $64 \mathrm{~cm}$; strong brown (7.5YR 5/6) shaly silty clay loam; weak medium subangular blocky structure; firm; common medium prominent light brownish gray (2.5YR 6/2) mottles in ped interiors; many continuous distinct brown (7.5YR 5/4) clay films on ped faces and coating rock fragments; common discontinuous prominent red (2.5YR 4/6) iron stains on some ped faces; common fine and medium roots; few to common pores; pH 4.8; abrupt inclined boundary. (Thin sandstone strata are 10YR 6/8)

C 64 to $71 \mathrm{~cm}$; strong brown (7.5YR 5/6) very shaly silty clay loam; massive rock controlled structure; firm; common discontinuous faint brown (7.5YR 5/4) clay films on rock fragments; few fine roots in cracks; common fine pores; about $50 \%$ shale and siltstone fragments; pH 4.8; abrupt inclined boundary.

2CB 71 to $81 \mathrm{~cm}$; yellowish red (5YR 5/6) silty clay; massive; firm; many discontinuous distinct brown (7.5YR 5/4) clay films on fracture and joint faces; few fine roots; few fine pores; pH 4.8; abrupt irregular inclined boundary. (Argillaceous limestone saprolite stratum sandwiched between shale and siltstone saprolite) 
$3 \mathrm{Cr} 81$ to $92 \mathrm{~cm}$; oxidized and leached saprolite from siltstone and shale; fragment interiors are brown (7.5YR 5/6); common discontinuous prominent red (2.5YR 4/6) iron-clay films on fragment faces; water flow zones are light brownish gray (2.5YR 6/2).

$4 \mathrm{Cr} 292$ to $100 \mathrm{~cm}$; oxidized and leached saprolite from siltstone and claystone; fragment interiors are 10YR 5/6 and 7.5YR 5/6; very tirm; many discontinuous prominent red (10YR 4/8) stains on fragment faces; few discontinuous distinct strong brown 7.5YR 4/6) clay coatings on fragment faces in flow zones; very few fine roots in flow zones; pH 4.8.

\section{CAMBIC PART}

O 2 to $0 \mathrm{~cm}$; leaf litter, abrupt smooth boundary.

Ap 0 to $20 \mathrm{~cm}$; dark yellowish brown (10YR 4/4) silt loam; moderate fine granular structure; very friable; many fine roots throughout; many fine and medium tubular pores; pH 4.7; abrupt wavy boundary.

Bw 20 to $40 \mathrm{~cm}$; brown (7.5YR 5/4) extremely shaly silty clay loam; weak medium subangular blocky structure; firm; many continuous faint brown (7.5YR 5/4) clay films on some ped faces and on most shale fragments; few fine roots; many pores; $\mathrm{pH} \mathrm{4.8;}$ clear irregular inclined boundary. (Cambic part of soil profile)

Cr 40 to $70 \mathrm{~cm}$; oxidized and leached saprolite from claystone and siltstone; fragment interiors have (10R 4/8) iron coatings on some fragment faces; common discontinuous prominent black manganese coatings on other fragment faces; many discontinuous brown (7.5YR 5/4) clay films on other rock fragments in more permeable zones; water flow zones have gray (10YR 5/1) streaks; root mats continue down through gray areas; pH 4.8. 


\section{RUPTIC PART}

Ap 0 to $18 \mathrm{~cm}$; dark yellowish brown (10YR 4/4) shaly silt loam; weak fine granular structure; very friable; many fine and medium roots between peds; many fine pores; $\mathrm{Ph} 4.7$; abrupt wavy boundary.

Cr 18 to $30 \mathrm{~cm}$; oxidized and leached saprolite from siltstone and claystone; fragment interiors are (10YR 5/6 or 7.5YR 5/6); rock controlled structure; very firm; fragments are coated with either brown (7./5YR 5/4) clay or black manganese coatings; few fine roots in cracks; $\mathrm{pH} 4.8$; abrupt inclined boundary.

2Bt 30 to $66 \mathrm{~cm}$; yellowish brown (10YR 5/6) silty clay loam; moderate coarse subangular blocky structure; firm; common fine prominent gray (10YR 6/1) mottles in ped interiors; ped exteriors are coated with continuous strong brown (7.5YR 5/4) clay; common fine and medium roots between peds; common fine and medium pores; $\mathrm{pH}$ 4.8; abrupt inclined boundary. (This horizon formed in saprolite from argillaceous limestone. This section was described just above the massive $\mathrm{C}$ horizon zone which perched water into this $\mathrm{Bt}$ zone)

$3 \mathrm{Cr} 66$ to $117 \mathrm{~cm}$; oxidized and leached saprolite from siltstone and claystone; rock controlled structure; very firm; many discontinuous prominent red (2.5YR 4/6) iron stains on some fragment faces; other fragments are partially coated by black manganese oxides; no clay films were noted on fragments. Water seems to flow in the unsaturated mode in this material. pH 4.9.

\section{Soil Series 400 $\quad$ Copper Ridge Dolomite Formation}

Location: East Chestnut Ridge, Doline A sideslope trench in upper northeast corner of site. E60950, N27650.

Classification: Typic Paledults; (Hapludults); clayey, kaolinitic, thermic.

Geomorphic Position: Doline Sideslope.

Slope and Aspect: 25 to $30 \%$ SW.

Parent Material(s): Copper Ridge residuum.

Vegetation: Pines, hardwoods and cedars of old field succession.

Described by: Lietzke. 
Date: $5-30-89$.

\section{SOIL DESCRIPTION}

O $\quad 3$ to $0 \mathrm{~cm}$; leaf litter and twigs.

A $\quad 0$ to $7 \mathrm{~cm}$; dark brown (10YR 3/3) extremely cherty silt loam; strong fine granular structure; very friable; many fine and common medium roots; 50 to $60 \%$ chert fragments; clear wavy boundary.

Ap 7 to $25 \mathrm{~cm}$; dark yellowish brown (10YR 4/4) extremely cherty silt loam; moderate fine granular structure; very friable; common fine and medium roots; 50 to $60 \%$ chert fragments; gradual wavy boundary. (Base of surficial creep materials)

E/B 25 to $40 \mathrm{~cm}$; yellowish brown (10YR 5/4) E part and strong brown (7.5YR 5/6) B part; extremely cherty silt loam; weak fine subangular blocky structure; very variable; few fine and medium roots; 60 to $70 \%$ fragments; gradual irregular boundary.

B/E 40 to $64 \mathrm{~cm}$; yellowish red (5YR 5/6) B part and strong brown (7.5YR 5/6) E part; extremely cherty silty clay loam; weak medium subangular blocky structure; very friable; few fine roots; 50 to $60 \%$ fragments; gradual irregular boundary.

Bt1 64 to $86 \mathrm{~cm}$; red (2.5YR 4/8) cherty clay; moderate medium subangular blocky structure; firm; yellowish red (5YR 5/6) clay on ped surfaces; yellowish and reddish saprolite colors within ped interiors in lower part; few fine roots; 15 to $25 \%$ fragments; gradual wavy boundary.

Bt2 86 to $130 \mathrm{~cm}$; highly mottled red (2.5YR 4/8), yellowish red (5YR 5/6) brownish yellow (10YR 6/8) cherty clay; weak medium subangular blocky structure; firm; yellowish red (5YR 5/6) clay on ped surfaces; few fine roots; 20 to $30 \%$ fragments; gradual wavy boundary.

BC 130 to $150 \mathrm{~cm}$; yellowish red (5YR 5/6) and brownish yellow (10YR 6/8) saprolitic material that easily crushes to cherty clay; weak coarse subangular blocky structure, but 
ped interiors are saprolite; very firm; thick red (2.5YR 4/6) clay on surfaces; few fine roots; 15 to $20 \%$ chert fragments.

NOTE: The Copper Ridge residual soils in this trench, about $30 \mathrm{~m}$ long, and on slopes of 25 to $30 \%$ are borderline Hapludults-Paleudults based on soil morphology.

Soil Series No. $402 \quad$ Chepultepec Dolomite Formation

Location: ORR. Telephone ROW transect across Chestnut Ridge. 2nd pit north of gasoline road and telephone line intersection. E29900, N26300.

Classification: Typic Hapludults; clayey, mixed, thermic.

Physiography: Upland.

Geomorphic Position: Mid sideslope.

Slope and Aspect: 25 to $45 \%$ WNW.

Parent Material(s): Chepultepec residuum.

Vegetation: Chestnut oak, red oak and white oak.

Described by Lietzke.

Samples by: Lietzke, Ammons and Timpson.

Date: March 23, 1988.

\section{SOIL DESCRIPTION}

Oi 5 to $0 \mathrm{~cm}$; leaf litter and root mat.

E1 0 to $17 \mathrm{~cm}$; pale olive (5Y $6 / 3)$ cherty loam; weak fine granular structure; very friable; many fine and medium roots; many pores; 15 to $25 \%$ chert fragments; gradual wavy boundary.

E/B 17 to $40 \mathrm{~cm}$; olive yellow (2.5Y 6/6) E part and yellowish brown (10YR 5/6) B part; cherty loam; weak fine granular structure; very friable; many fine and medium roots; many pores; 15 to $25 \%$ chert fragments; gradual wavy boundary. (Lower boundary contains $\mathrm{B} / \mathrm{E}$ horizon). 
Bt1 40 to $69 \mathrm{~cm}$; yellowish red (5YR 5/8) clay or clay loam; moderate fine subangular blocky structure; friable; common medium and fine roots; many pores; 5 to $10 \%$ chert fragments; gradual wavy boundary.

Bt2 69 to $99 \mathrm{~cm}$; yellowish red (5YR 5/8) with red 2.5YR 4/8) and yellowish brown (10YR $5 / 6$ ) saprolite colors; clay or clay loam; moderate fine subangular blocky structure; firm; yellowish red (5YR 5/8) clay films on all ped faces; common medium and fine roots; many pores; 5 to $10 \%$ chert fragments; gradual wavy boundary.

BC 99 to $139 \mathrm{~cm}$; brownish yellow (10YR 6/6) and red (2.5YR 4/8) saprolite colors; clay or clay loam; weak coarse subangular and angular blocky structure; very firm; red (2.5YR 4/8) clay films on many ped faces and coating large pores; few fine roots; many pores; 5 to $10 \%$ chert fragments; gradual wavy boundary.

CB 139 to $187 \mathrm{~cm}$; yellowish brown (10YR 5/8) saprolite that easily crushed to silty clay loam; angular blocks from fractured saprolite; very firm; strong brown (7.5YR 5/6) clay flows on most faces; water flow zones with light gray (10YR 7/1) interiors and olive yellow (2.5Y 6/8) exteriors; few fine roots; many pores; clear wavy boundary.

C1 187 to $231 \mathrm{~cm}$; strong brown (7.5YR 5/6) and brownish yellow (10YR 6/8) saprolite that easily crushed to silty clay loam; angular blocks from fractured saprolite; very firm; yellowish red (5YR 5/8) clay flows on some faces; red (2.5YR 4/8) iron plasma in pores and coating some faces; few fine roots; many pores; less that $5 \%$ chert fragments; clear wavy boundary. (Manganese concentrate zone marks base of horizon)

C2 231 to $276 \mathrm{~cm}$; yellowish red (5YR 5/6) and brownish yellow (10YR 6/8) multi-colored saprolite with thin strata of disoriented highly weathered grayish and reddish very fine grained sandstone that crushes to silty clay loam; very firm; water flow zones have light gray (10YR 7/2) interiors and yellowish iron depleted exteriors; few fine roots; common to many manganese concentrate bodies; less than 5\% chert fragments. 
Soil Series No. 506 Witten Limestone Formation

Location: ORR. 410 feet east of Contractors Landfill Road off Route 95 and then $\mathbf{1 3 5}$ feet south near old home site. Pit located about 10 feet away from cistern.

Classification: Typic Hapludalfs; fine, mixed, thermic.

Geomorphic Position: Low upland, but with some alluvium influence.

Slope and Aspect: 2 to $6 \%$ SE.

Parent material(s): Unit E of Chickamauga.

Vegetation: Cedars, few hardwoods, and Japanese grass.

Described by: Lietzke.

Date: $2-19-92$

\section{SOIL DESCRIPTION}

O less than $1 \mathrm{~cm}$ thick consisting of dead grass and cedar needles.

Ap 0 to $5 \mathrm{~cm}$; dark brown (10YR 3/3) silt loam; moderate medium granular structure; very friable; abrupt wavy boundary.

Bt1 5 to $33 \mathrm{~cm}$; yellowish brown (10YR 5/8) clay; strong coarse prismatic parting to strong medium and fine prismatic parting to strong medium angular blocky structure; firm; coarse prisms coated with brown (10YR 5/3) clay-organic materials; fine prisms coated with yellowish brown (10YR 5/4) clay; angular peds uncoated; clear wavy boundary.

Bt2 33 to $50 \mathrm{~cm}$; yellowish red (10YR 5/6) 70\% and strong brown (7.5YR 5/6) 25\% clay; moderate medium and fine prismatic parting to strong medium angular blocky structure; peds coated with yellowish brown (10YR 5/6) clay; prisms end at base of horizon; few light brownish gray wetness zones about 1-2 mm wide in root channels; clear wavy boundary.

BC 50 to $70 \mathrm{~cm}$; yellowish brown (10YR 5/6) clay; massive; few to common pressure faces; common fine black concentrations throughout; common fine roots; very few light brownish gray (10YR 6/2) wetness zones in root channels; gradual wavy boundary. 
CB 70 to $104 \mathrm{~cm}$; light olive brown (2.5Y 5/6) clay; massive; few pressure faces; common fine to coarse black concentrations; few fine roots; abrupt irregular boundary.

R $104 \mathrm{~cm}$; rock. Depth to rock in pit varied from about $90 \mathrm{~cm}$ to $130 \mathrm{~cm}$.

Soil Series No. 603 Benbolt Limestone Formation

Location: ORR. About 200 feet east of intersection of Old County Road and East Fork Ridge Road.

Classification: Typic Paleudults; clayey, mixed, thermic. Collegedale Series.

Geomorphic Position: Mid Sideslope.

Slope and Aspect: $8-10 \%$ NW.

Parent Material(s): Deeply weathered Chickamauga residuum. Probably highly fractured or brecciated because of its nearness to the Whiteoak Mountain Fault.

Vegetation: Old field regrowth of white pine, white oak, small red maples, holly, and white pine seedlings.

Described by: Lietzke

Date: 2-19-92

\section{SOIL DESCRIPTION}

Oi $\quad 4$ to $0 \mathrm{~cm}$; leaf litter of oak and red maple along with pine needles.

Oa $\quad 0$ to $1 \mathrm{~cm}$; humic and sapric materials and many fine roots.

A 1 to $8 \mathrm{~cm}$; brown (10YR 4/3) silt loam; moderate medium granular structure; very friable; clear wavy boundary.

EB 8 to $17 \mathrm{~cm}$; strong brown (7.5YR 4/6) silt loam with a few peds of yellowish red (5YR 5/6) silty clay loam in the lower part; weak medium granular structure; very friable; abrupt wavy boundary.

BT1 17 to $43 \mathrm{~cm}$; red (2.5YR 4/6) clay; strong fine and medium angular blocky and subangular blocky structure; friable; yello: ish red (5YR 4/6) ped coatings; gradual wavy boundary. 
Bt2 43 to $68 \mathrm{~cm}$; mottled red (2.5YR 4/6)-80\% and strong brown (7.5YR 5/8) clay; strong fine angular blocky structure; firm; all peds coated with yellowish red (5YR 4/6) clay; some pressure faces in the lower part; gradual wavy boundary.

Bt3 68 to $95 \mathrm{~cm}$; highly mottled red (2.5YR 4/6) 50\% and yellowish brown (10YR 5/8) and strong brown (7.5YR 5/8) clay; strong fine angular blocky structure; firm; fine weathered chert fragments throughout; all peds coated with yellowish red (5YR 4/6) clay; common uncoated pressure faces; gradual wavy boundary.

BC 95 to $133 \mathrm{~cm}$; yellowish brown (10YR 5/6 and 5/8) 70\% and yellowish red (5YR 4/6)$25 \%$, clay; moderate medium and coarse angular blocky structure; very firm; about $5 \%$ red (2.5YR 4/6) mottles and about $1 \%$ very pale brown (10YR $7 / 3)$ streaks. Base of dug pit.

CBI 133 to $170 \mathrm{~cm}$; highly contrasting mottled red (10R 4/8), red (3.5YR 4/6) and yellowish brown (10YR 5/8), brownish yellow (10YR 6/8) clay; massive, very firm many fine pressure spots; few 3 and 2 chroma streaks associates with fine roots; gradual wavy boundary.

CB2 170 to $190 \mathrm{~cm}$; yellowish brown (10YR 5/6) and light yellowish brown (10YR 6/4) clay; massive; many fine red (2.5 YR 4/8) mottles throughout; about 10\% 2 and 3 chroma streaks and blotches; extremely firm. The section between 133 and $190 \mathrm{~cm}$ described from a $1 \mathrm{~cm}$ dia. core. 


\section{APPENDIX B}

SAMPLING AND ANALYSIS PLAN SUPPLEMENT 


\section{Sampling and Analysis Plan Supplement-Phase I}

\section{Distribution of Samples Obtained}

Phase I

Number of Formations

(Soil Series)

Number of Sampling Sites

Number of Noncomposited Samples (A Horizon)

Number of Composited Samples

Soil Horizon A

Soil Horizon B

Soil Horizon C

II Types of Samples Obtained

Composited Soil Samples

QA/QC Composites and Water Samples

Trip Blanks

Noncomposited Soil Samples

QAVQC Noncomposites and Water Samples

Trip Blanks
Location

\begin{tabular}{ccc}
$\begin{array}{c}\text { Roane } \\
\text { County }\end{array}$ & ORR & $\begin{array}{c}\text { Anderson } \\
\text { County }\end{array}$ \\
\cline { 2 - 3 } 1 & 2 & 1 \\
12 & 24 & 12 \\
12 & 24 & 12 \\
12 & 24 & 12 \\
4 & 8 & 4 \\
4 & 8 & 4 \\
4 & 8 & 4
\end{tabular}

Phase I

48

16

$\mathbf{0}$

64

48

12

18

78

142

Total Composited and Discrete Soil and QAVC Water Samples-Phase I

Note: VOA analyses are done on all A Horizon noncomposited samples only and are not included in the total of 142 for Phase I 


$$
B
$$




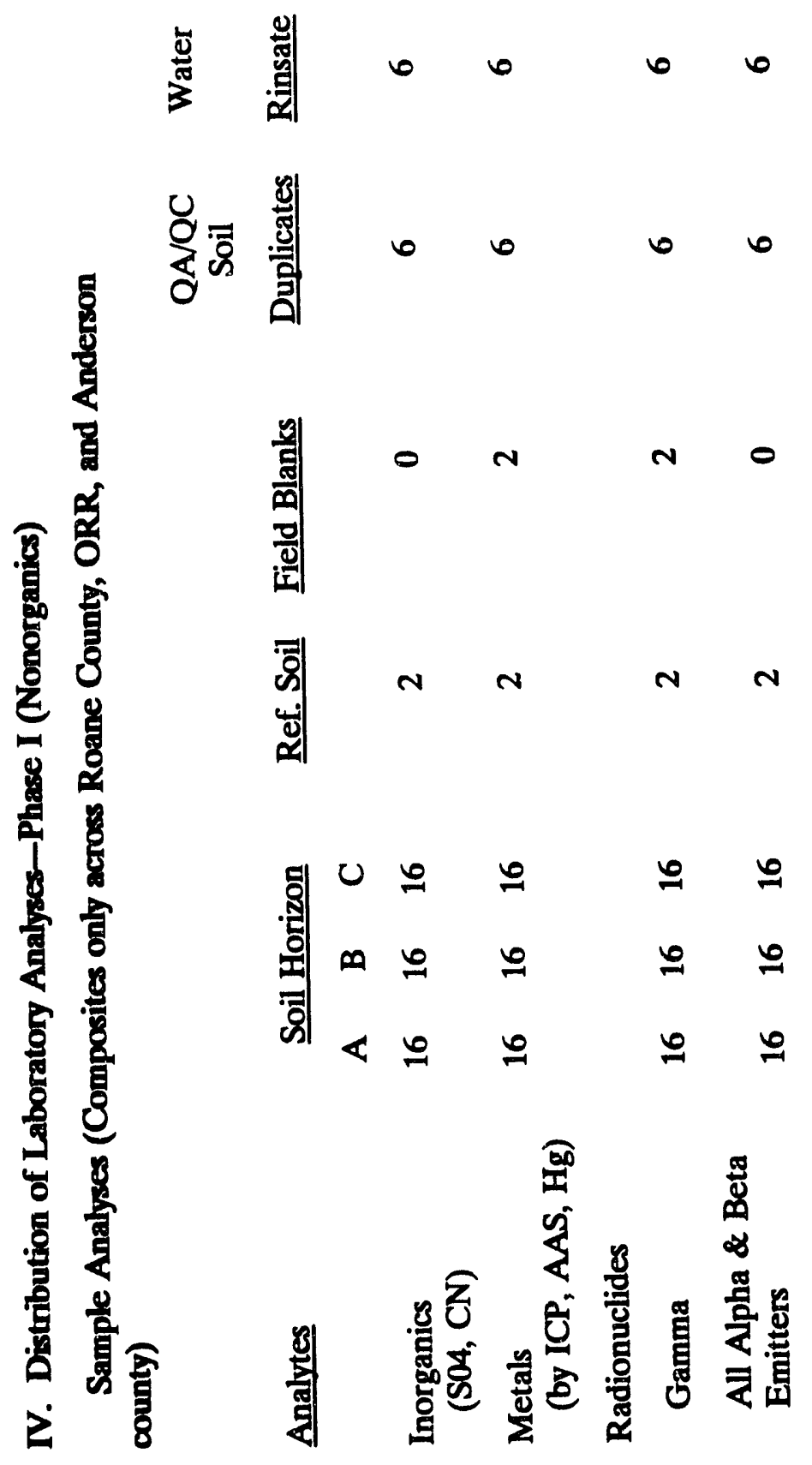




\section{Sampling and Analysis Plan Supplement-Phase II}

\section{Distribution of Samples Obtained}

Phase II

Number of Formations

(Soil Series)

Number of Sampling Sites

Number of Noncomposited Samples (A Horizon)

Number of Composited Samples

Soil Horizon A

Soil Horizon B

Soil Horizon C

\begin{tabular}{cccc}
\multicolumn{3}{c}{ Location } \\
$\begin{array}{ccc}\text { Roane } \\
\text { County }\end{array}$ & ORR & $\begin{array}{c}\text { Anderson } \\
\text { County }\end{array}$ \\
\cline { 2 - 3 } 1 & & \\
12 & 4 & 1 \\
12 & 48 & 12 \\
12 & 48 & 12 \\
4 & 48 & 12 \\
4 & 16 & 4 \\
4 & 16 & 4
\end{tabular}

VI. Types of Samples Obtained

Phase II

Composited Soil Samples

QA/QC Composites and Water Samples

Trip Blanks

Noncomposited Soil Samples

QA/QC Noncomposites and Water Samples

Trip Blanks

Total Composited and Discrete Soil and QAVQC Water Samples-Phase II

Note: VOA analyses are done on all A Horizon noncomposited samples only and are not included in the total of 213 for Phase II. 


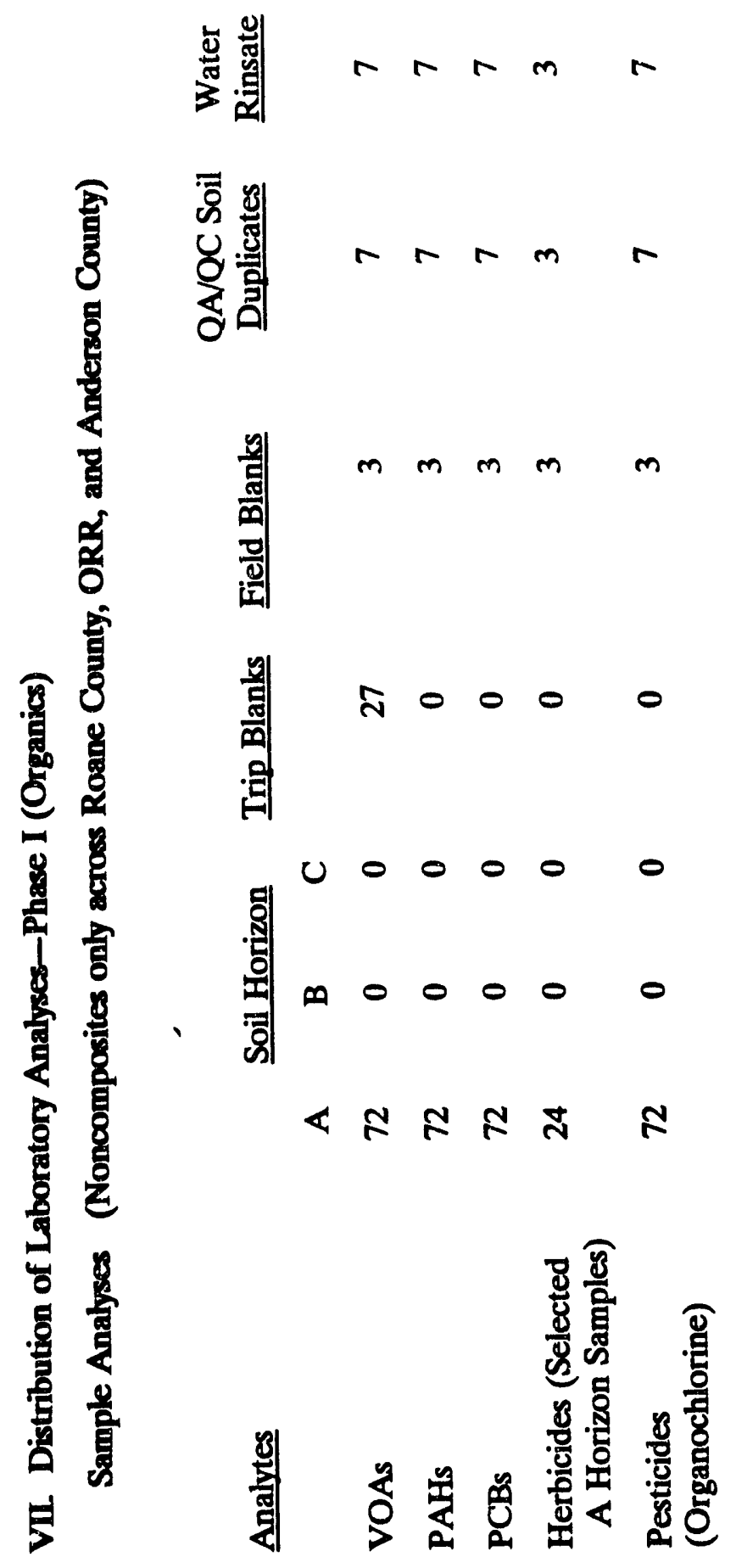




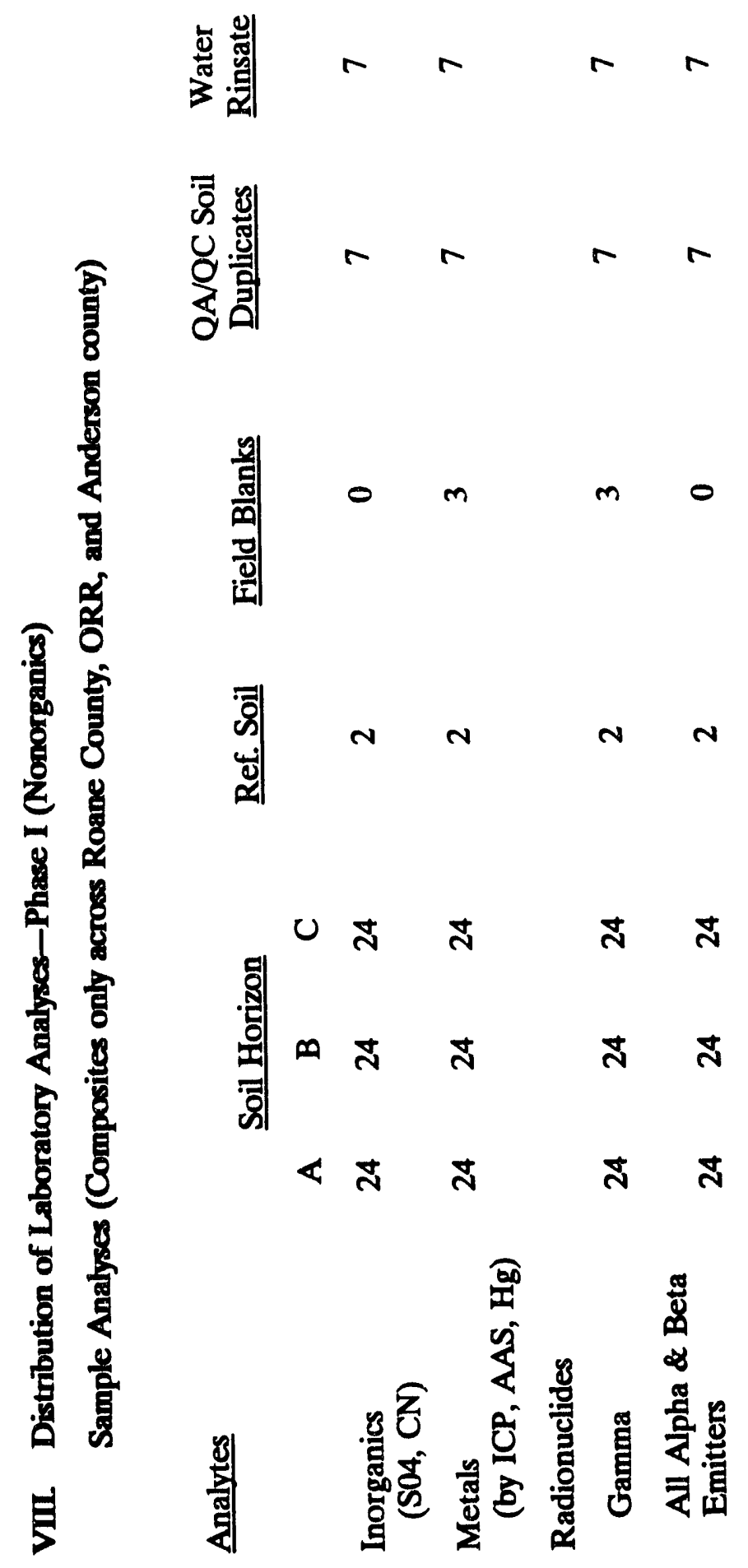


APPENDIX C

CHAIN-OF-CUSTODY FORMS FOR SOIL SAMPLES 


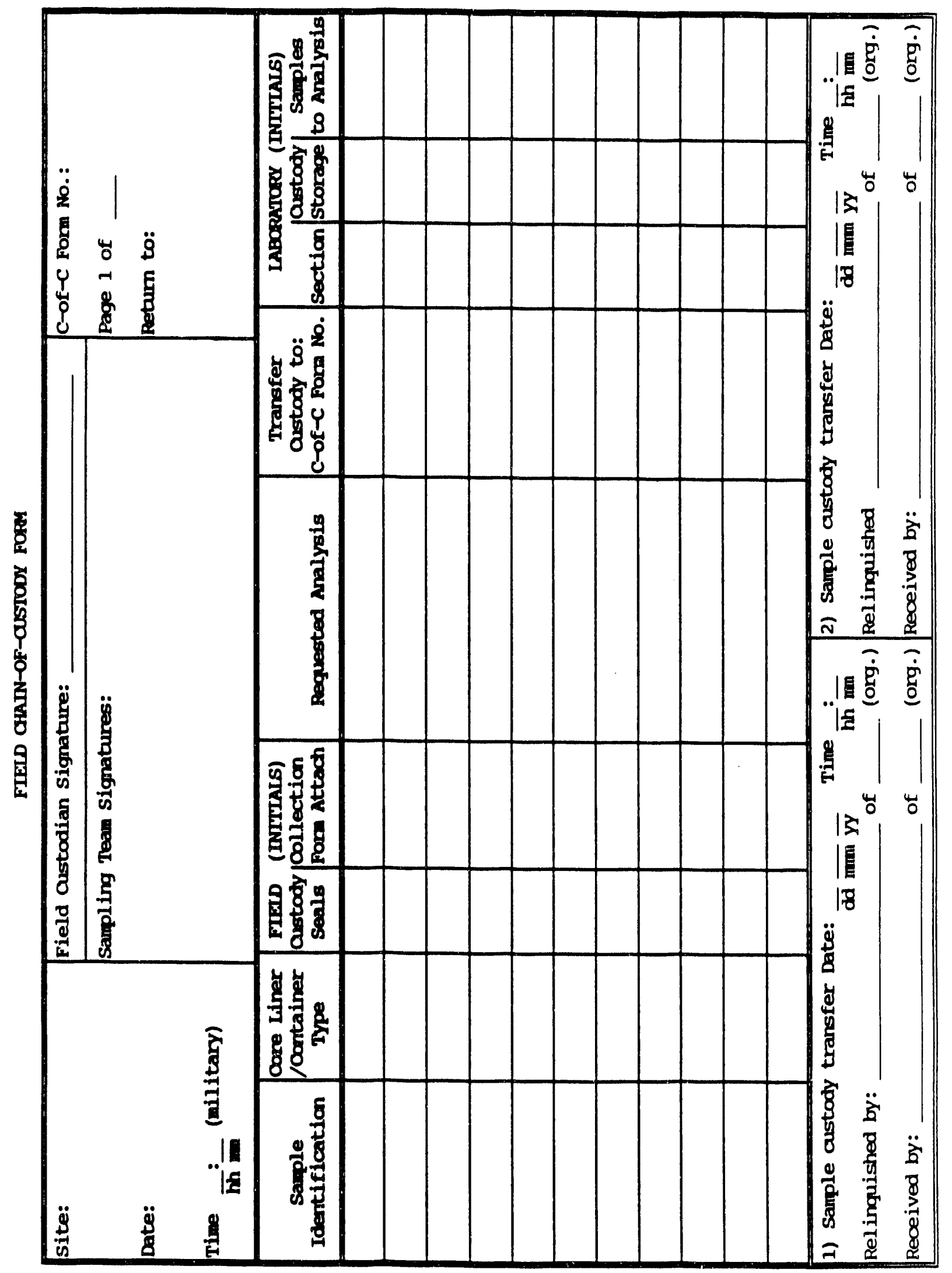




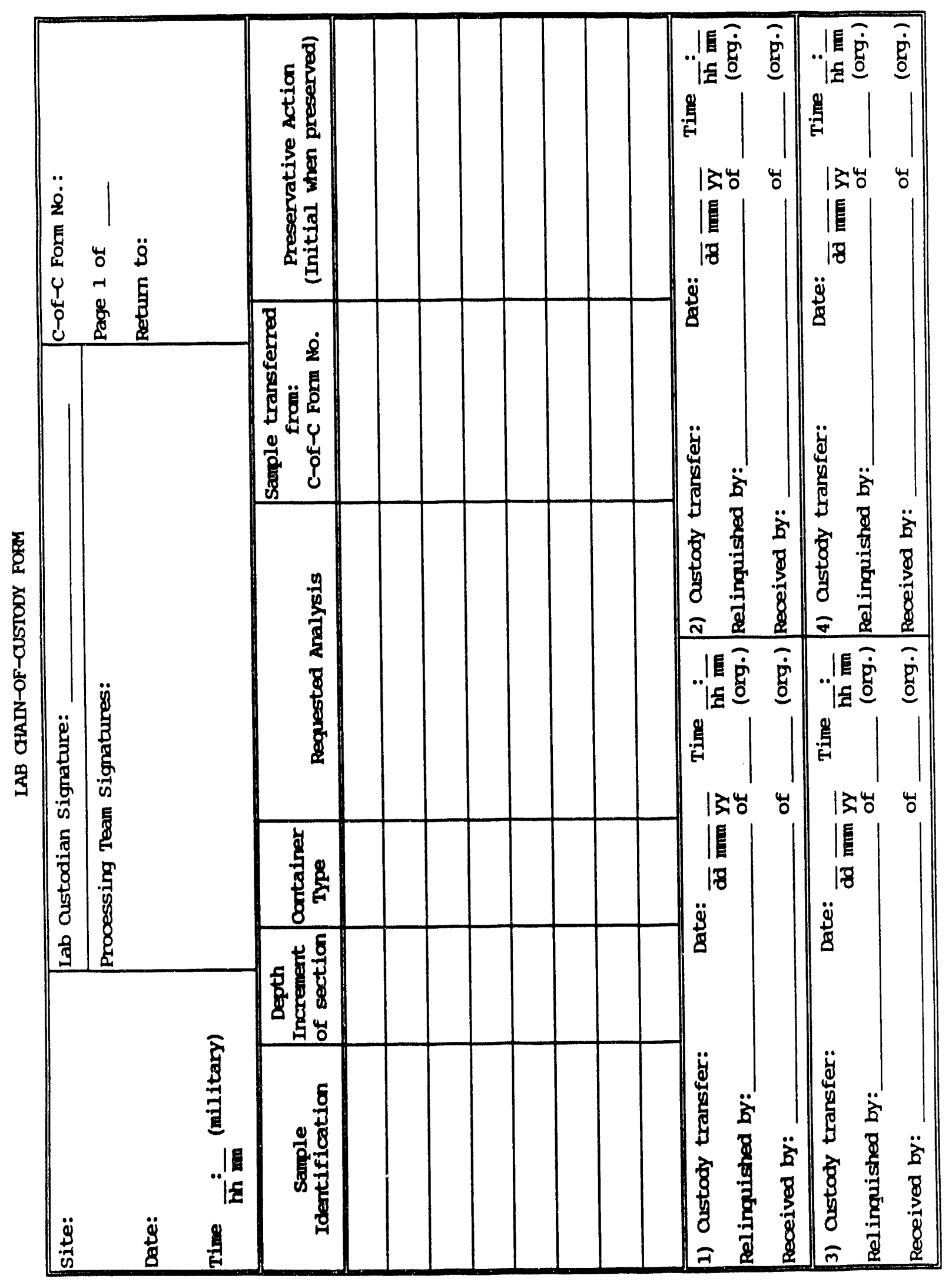


APPENDIX D

STATISTICAL ASPECTS OF DQOs 


\section{Statistical Aspects of DQOs}

The Problem: The data will be used to provide background reference values for contamination assessments. More specifically, the data will be used to compute upper and lower tolerance bounds as well as means and standard errors for background constituents. (A tolerance bound is a confidence bound for a distribution percentile, for example, a $95 \%$ lower confidence bound for the $90^{\text {th }}$ percentile of the distribution.) The very nature of soil background characterization makes it difficult, because it requires detecting constituents present only in very small amounts. Statistically, there is only a slight signal in the presence of much greater noise.

There is little preliminary data about $O R$ reservation background constituent levels. Summary data for some soil constituents are available for some distant geographic regions and geologic formations, but not with raw or summary data on errors, which would be needed for statistical design. There is some upgradient contaminated site data, for example, from (K1070A) bore holes at the K-25 Site. Although this is not true background data, it can be used for statistical design purposes.

Preliminary information about the relative costs and errors of field sampling and laboratory analysis indicates that soil samples should be composited to reduce the variability of survey estimates. Although a formal analysis suggests an even greater level of compositing, the level was conservatively taken to be three (composited) field samples per laboratory sample.

When there is plenty of data (e.g., 20 or more separately analyzed soil samples per horizon and soil type), sample percentiles can be used to compute nonparametric tolerance bounds that are valid under very general conditions. Unfortunately, the expense of the collection and, especially the analysis of the samples, precludes this approach. Therefore, as a compromise, our tolerance bounds will be premised on the underlying constituent distribution having a particular parametric form (such as normal or lognormal distribution), the choice of which will be based on the data itself.

Data Requirements: An analysis was made of the K1070A data (documented in letter of 8/2/91 from R. L. Schmoyer to P. L. Goddard). Attention was focused on lead, potassium, zinc and uranium, which were considered to be most important (along with cesium which is not included in the K1070A data). Uranium, all of whose values were non-detects, was considered separately. Results were consistent with previous reckoning about the relative magnitude of laboratory and spatial errors.

Under the assumption that a distribution is normal, its percentiles have the form $\mu+a \sigma$, where $\mu$ is the mean, and $\sigma^{2}$ is the variance. For an uncensored sample (i.e., no nondetects) 
from the distribution, normal tolerance bounds are of the form $\bar{x}+k s$, where $\bar{x}$ is the sample mean, and $S^{2}$ is the sample variance. They satisfy a probability statement like

$$
P(\bar{x}+k s \leq \mu+a r)=1-\alpha .
$$

The constant $k$, which does not depend on $\mu$ or $\sigma$, can be determined for any sample size $n$, any $a$, and any specified $\alpha$.

Two probabilities were considered as criteria for assessing data requirements:

$P\left(\bar{x}+k s<\mu+a^{\prime} \sigma\right)$, where $a^{\prime}<a$, and $P[\bar{x}+k s<\gamma(\mu+a \sigma)]$ where $\gamma<1$.

These probabilities were estimated using the K1070A data. It was concluded that six or seven composited samples would be needed to sample each soil class and horizon with reasonable certainty. Fewer could be used but would place the study more in the realm of a pilot experiment than a definitive study.

For a particular soil constituent, let $\sigma_{l}^{2}$ denote the variance of laboratory measurements, and let $\sigma_{S}^{2}$ denote the field (spatial) error. Given prior information about $\sigma_{L}^{2}$, or an estimate of it, for example from laboratory duplicates, $\sigma_{2}^{2}$ and $\sigma_{3}^{2}$ can be resolved. Stipulations about laboratory duplicates, splits, etc. are in section 6.7.1. If, for a particular constituent, results for several horizons are about the same, these essential replicates can be used to refine the variance component estimates.

The issue of prior information about or estimates of $\sigma_{l}^{2}$ is important, because overall variances of constituent measurements depend on the level of compositing, and separately, on both $\sigma_{L}^{2}$ and $\sigma_{s}^{2}$. Often $\sigma_{L}^{2}$ is a minor component of the overall variance, and for some applications, it can be ignored. But, especially with background data, $\sigma_{L}^{2}$ can be much more important.

For uncensored composites-of-three from a normal distribution, normal tolerance bounds are also of the form $\bar{x}+k s$. Tolerance bounds of the same form can be computed from any (statistically) independent estimates of the distribution's mean and variance, and thus for other than composites-of-three (e.g., uncomposited samples). This is important because BSCP results will be used in the future as references for samples composited at levels other than three.

Unless all or nearly all of the observations for a particular constituent are censored, the mean, variance, and other parameters of its distribution can be estimated from censored data, with basically the same approach as for uncensored data. (The method of maximum likelihood generalized to accommodate the censoring). The SAS LIFEREG procedure 
handles censored data for various parametric distributions including the normal and log-normal, and can be used to compute percentile estimates and standard errors, from which confidence bounds for percentiles can be constructed. If necessary, the same approach can be used to make variance components analysis accommodate censoring. However, software would have to be written to implement it.

Other approaches to dealing with censoring include setting censored values to zero, setting them to their detection limits, and "imputing" them by interpolation with a distribution fitted using the uncensored data. All these approaches will be considered, pending examination of the data.

By the nature of background, the possibility of all or nearly all nondetects for a particular constituent is an important issue. If all or nearly all of the data are nondetects, there will be few options for the statistical analysis. If there are numerous different detection limits, a parametric (e.g., normal or lognormal) model approach will still work, but, because there will be only four (composited) samples for any particular target area, numerous detection limits are not likely.

If all or nearly all of the data are nondetects, one can still compute upper confidence bounds for the probability that an observation exceeds the largest detection limit. These confidence bounds, which are based only on the binomial distribution, do not require the assumption of an underlying parametric form for the distribution.

Unfortunately, for small sample sizes the binomial upper confidence bounds will never be small. In fact, it can be shown that if all of the background data are censored, then $U$ is $1-(1-\gamma)^{1 / n}$, where $\gamma$ is the confidence level and $n$ is the sample size. For $\gamma=.90$ and $n=4, U$ is .44. Even without compositing, that is, if $n=12, U$ would still be .17 . Thus, for this approach to be useful, data from several horizons or areas will have to be combined. The most likely, realistic conclusion of the all-or-nearly-all censored outcome is that a future study with more data or better laboratory procedures will be needed to more adequately assess the distribution.

Certain inequalities can be used to address compositing when there are mostly non-detects. For example, for very low background levels, laboratory error may be the dominant component of error. Then, the probability of exceeding the detection limit does not vary with the degree of compositing. Thus, the probability that a single uncomposited sample exceeds $d$ would be the same as the probability that a composite-of-three does. Another inequality, for independent values

$$
X_{1}, X_{2} \text {, and } X_{3}, \text { is } P\left(X_{1}>d\right) \leq P\left[\left(X_{1}+X_{2}+X_{3}\right) / 3>d\right]^{1 / 3}
$$

Thus, if laboratory error is ignored, an upper confidence bound for composites-of-three is a conservative upper confidence bound for uncomposited samples. These approaches will also be considered in the statistical analysis.

Sampling Plan Design: On the basis of the K1070A data analysis, and a consideration of the relative size of the various geologic formations and their representation in current ER areas, 
the number of formations for study was reduced to six, and the number of composite-of-three samples per formation was taken to be four. Ten areas were selected: one for each of six formations on the reservation; and for each of two of the six formations, two areas, one in Roane and one in Arderson County. The actual sampling plan is described in section 5.5.3. 


\section{DISTRIBUTION}

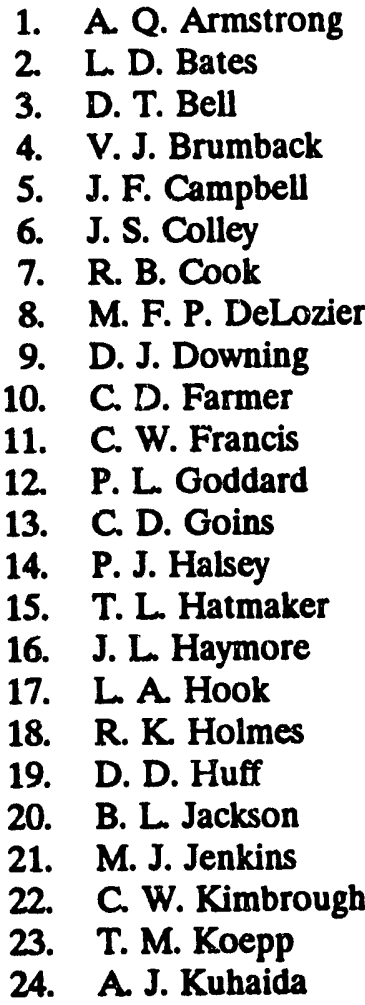

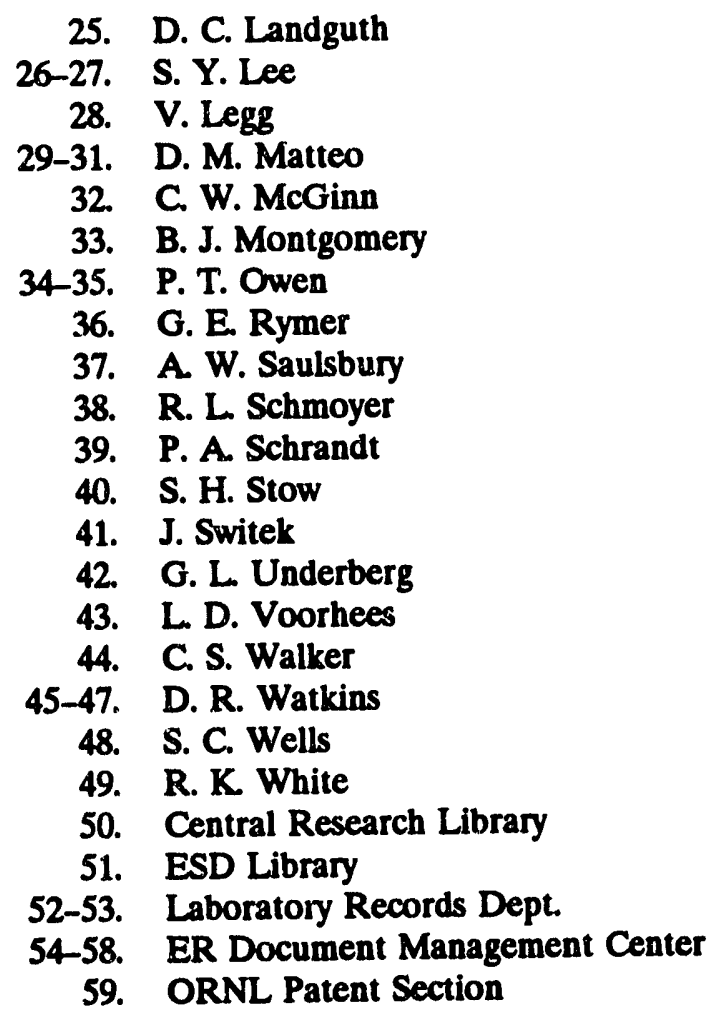

60. Office of Assistant Manager for Energy Research and Development, DOE Oak Ridge Field Office, P.O. Box 2001, Oak Ridge, TN 37831-8600

61. J. T. Ammons, Plant and Soil Science Department, Univ. of Tenn., Knoxville, TN 37916

62. D. A. Lietzke, Lietzke Soil Services, Route No. 3, Box 607, Rutledge, TN 37861

63. D. M. Carden, DOE Oak Ridge Field Office, P.O. Box 2001, Oak Ridge, TN 37831-8541

64. P. H. Edmonds, Radian Corporation, 120 S. Jefferson Circle, Oak Ridge, TN 37830

65. M. S. Ferre, DOE Oak Ridge Field Office, P.O. Box 2001, Oak Ridge, TN 37831-8541

66. C. S. Gist, DOE Oak Ridge Field Office, P.O. Box 2001, Oak Ridge, TN 37831-8541

67-68. R. L. Nace, Branch Chief, Nonenrichment Facilities, Oak Ridge Program Division, Office of Eastern Area Programs, Office of Environmental Restoration, EM-423, Trevion 2, U.S. Department of Energy, Washington, DC 20585

69. S. P. Riddle, DOE Oak Ridge Field Office, P.O. Box 2001, Oak Ridge, TN 37831-8541

70-71. R. C. Sleeman, DOE Oak Ridge Field Office, P.O. Box 2001, Oak Ridge, TN 37831-8541

72-73. J. T. Sweeney, DOE Oak Ridge Field Office, P.O. Box 2001, Oak Ridge, TN 37831-8541

74-75. H. M. Thron, Chief, Enrichment Facilities, Oak Ridge Program Division, Office of Eastern Area Programs, Office of Environmental Restoration, EM-423, Trevion 2, U. S. Department of Energy, Washington, DC 20585.

76-77. Office of Scientific and Technical Information, P.O. Box 62, Oak Ridge, TN 37831 

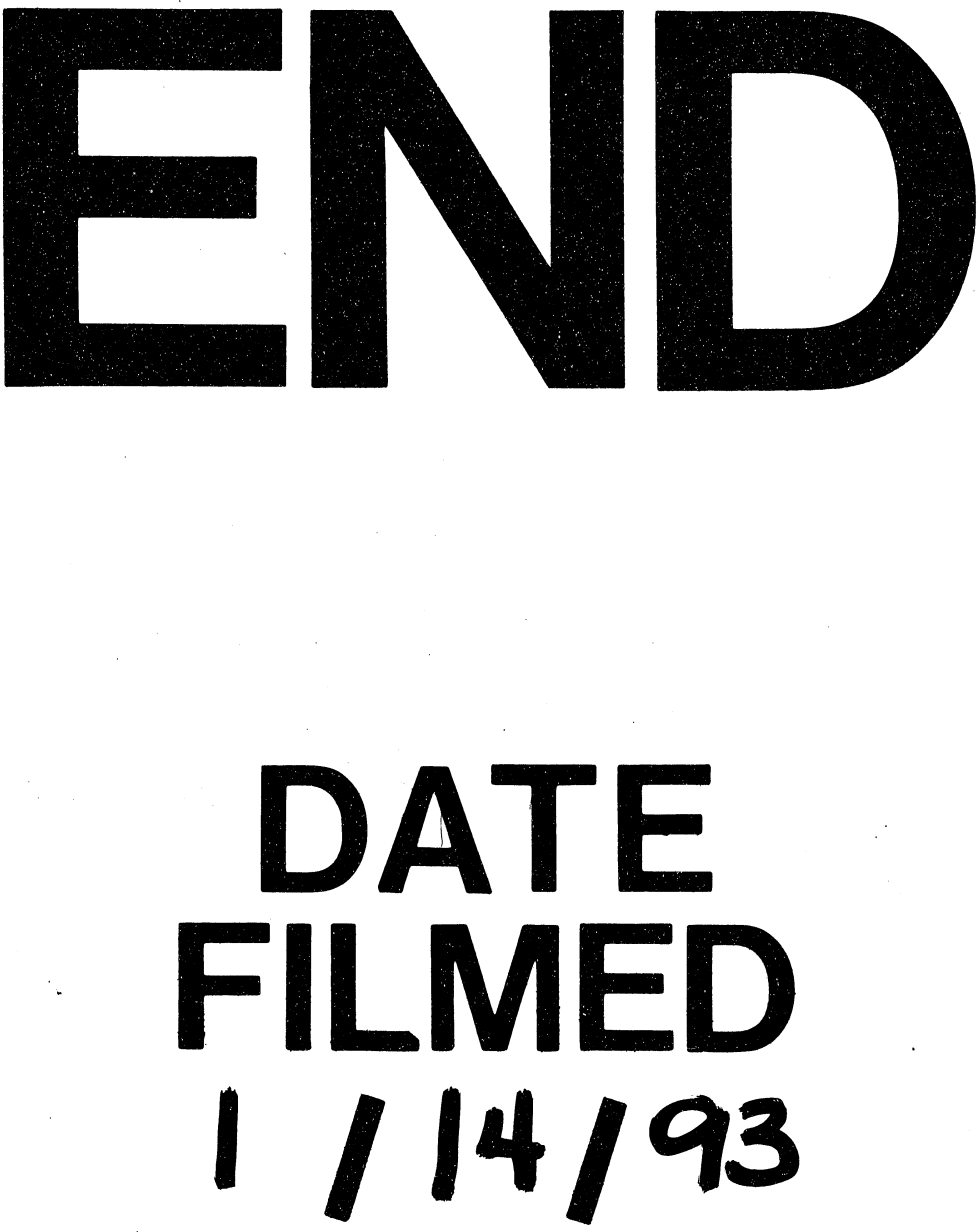
